\title{
Enhanced Catalytic Activity of Nickel Complexes of an Adaptive Diphosphine-Benzophenone Ligand in Alkyne Cyclotrimerization
}

\author{
Alessio F. Orsino, ${ }^{\dagger}$ Manuel Gutiérrez del Campo, ${ }^{\dagger}$ Martin Lutz, $^{\dagger}$ and Marc-Etienne Moret* ${ }^{\dagger}{ }^{\dagger}$ \\ ${ }^{\dagger}$ Utrecht University, Organic Chemistry and Catalysis, Debye Institute for Nanomaterials Science, Faculty of Science, \\ Universiteitsweg 99, 3584 CG Utrecht, The Netherlands \\ ${ }^{\ddagger}$ Utrecht University, Crystal and Structural Chemistry, Bijvoet Center for Biomolecular Research, Faculty of Science, Padualaan 8, \\ $3584 \mathrm{CH}$ Utrecht, The Netherlands
}

\section{Supporting Information}

ABSTRACT: Adaptive ligands, which can adapt their coordination mode to the electronic structure of various catalytic intermediates, offer the potential to develop improved homogeneous catalysts in terms of activity and selectivity. 2,2'-Diphosphinobenzophenones have previously been shown to act as adaptive ligands, the central ketone moiety preferentially coordinating reduced metal centers. Herein, the utility of this scaffold in nickel-catalyzed alkyne cyclotrimerization is investigated. The complex $\left[\left({ }^{p \text {-tol }} \mathbf{L 1}\right) \mathrm{Ni}\right.$ (BPI) $]\left({ }^{p \text {-tol }} \mathbf{L 1}=2,2^{\prime}\right.$-bis $($ di $($ para-tolyl $)$ phosphino $)$-benzophenone; BPI = benzophenone imine) is an active catalyst in the $[2+2+2]$ cyclotrimerization of terminal alkynes, selectively affording 1,2,4-substituted benzenes from terminal alkynes. In particular, this catalyst outperforms closely related bi- and tridentate phosphine-based Ni catalysts. This suggests a reaction pathway involving a hemilabile interaction of the $\mathrm{C}=\mathrm{O}$ unit with the nickel center. This is further borne out by a comparative study of the observed resting states and DFT calculations.

KEYWORDS: alkyne cyclotrimerization, nickel complexes, adaptive ligand, $\pi$-acceptor ligand, hemilabile ligand

\section{INTRODUCTION}

The search for improved activity and selectivity in transitionmetal based homogeneous catalysts strongly relies on the development of steering ligands to tune the steric and electronic properties of the metal center to the requirements of particular transformations. Recent years have seen the development of more sophisticated adaptive or cooperative ligands that can adjust their binding modes or engage in chemical transformations along a catalytic cycle. ${ }^{1-4}$ The use of such ligands also plays an important role in the development of catalysts based on inexpensive and nontoxic first-row transition metals that can compete with, or even surpass, their counterparts based on precious metals, contributing to a more sustainable chemistry. ${ }^{5}$ Perhaps one of the simplest implementations of the concept of adaptive ligands are hemilabile ligands, which are polydentate ligands featuring a weakly binding moiety that can reversibly (de)coordinate the metal center. ${ }^{6}$ Since their introduction in synthetic chemistry by Jeffrey and Rauchfuss, ${ }^{7}$ hemilabile ligands have played a significant role in the current transition from noble to base metals in homogeneous catalysis. The hemilabile interaction is important not only for opening up a masked coordination site but also to stabilize catalytic intermediates, by allowing the supporting ligand to adapt its binding mode throughout the reaction coordinate. Most commonly, weak donor groups, such as ether $\left(\mathrm{OR}_{2}\right){ }^{7,8}$ amine $\left(\mathrm{NR}_{3}\right),{ }^{9}$ or imine derivatives $\left(\mathrm{R}_{2} \mathrm{C}=\right.$ $\mathrm{NR}),{ }^{8 \mathrm{~b}, 10}$ are employed as the labile unit, often resulting in enhanced catalytic activity for different kinds of reactions. Examples include olefin oligomerizations and polymerizations, ${ }^{8,11}$ (cyclo)trimerization, ${ }^{9 c, 11}$ carbonylation of methanol and methyl acetate, ${ }^{12}$ (transfer) hydrogenation of ketones or dehydrogenation of alcohols, ${ }^{9 b, 13,14}$ hydroacylation of alkenes and alkynes, ${ }^{8 \mathrm{~d}, 15}$ and coupling reactions. ${ }^{9 \mathrm{c}, 11-19}$

In addition to weak $\sigma$-donor moieties, $\sigma$-acceptor groups ${ }^{20}$ (e.g., triarylborane) $)^{21}$ or $\pi$-ligands ${ }^{2}$ (e.g., $\mathrm{C}=\mathrm{C}$ double bond $)^{22}$ can also act as hemilabile fragments. Our group recently reported the hemilabile character of the ligand 2,2'bis(diphenylphosphino)benzophenone ${ }^{23} \quad\left({ }^{\mathrm{Ph}} \mathbf{L 1}\right)$ bound to nickel $^{24}$ and other first-row transition metals. ${ }^{25}{ }^{\mathrm{Ph}} \mathbf{L 1}$ was shown to function as a hemilabile $\pi$-acceptor ligand, with the central $\mathrm{C}=\mathrm{O}$ bond coordinating to the metal center in its more reduced forms (Figure 1). $\mathrm{Ru}^{23,26} \mathrm{Rh}^{27-29} \mathrm{Os},{ }^{30}$ and $\mathrm{Ir}^{31}$ complexes of ${ }^{\mathrm{Ph}} \mathbf{L} \mathbf{1}$ were also studied, more specifically in the catalytic hydrogenation of ketones, ${ }^{23,26,28,30}$ in which the formation of a hydroxyalkyl species was accessible via the hydrogenation of the ketone moiety of the ligand. ${ }^{28}$

Received: December 17, 2018

Revised: January 29, 2019

Published: January 31, 2019 


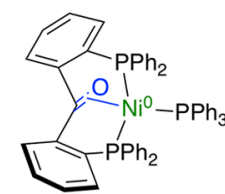

$\mathrm{Ni}(0)$
$\eta^{2}(\mathrm{C}, \mathrm{O})$ coordination

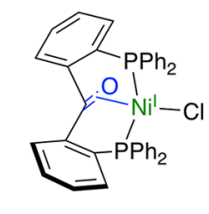

$\mathrm{Ni}(\mathrm{l})$

$\eta^{2}(\mathrm{C}, \mathrm{O})$ coordination

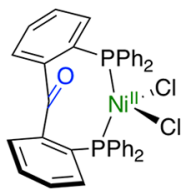

$\mathrm{Ni}(\mathrm{II})$
Figure 1. Previous work. ${ }^{24}$ Coordination of a diphosphine benzophenone ligand, ${ }^{\mathrm{Ph}} \mathbf{L}$, to nickel(0), nickel(I), and nickel(II).

In this context, we set out to assess the potential utility of an $\eta^{2}$-bound hemilabile $\pi$-acceptor moiety incorporated in a pincer type architecture for catalysis, using the cyclotrimerization of alkynes as a benchmark reaction. Since its discovery by Reppe et al. ${ }^{32}$ using a $\left[\mathrm{Ni}(\mathrm{CO})_{2}\left(\mathrm{PCl}_{3}\right)_{2}\right]$ catalyst, intermolecular $[2+2+2]$ cyclotrimerization of alkynes has been widely studied. ${ }^{33}$ Metal catalyzed cyclotrimerization is an elegant method for the formation of cyclic frameworks, particularly convenient when the desired product is not accessible via traditional aromatic substitution reactions. Many transition metal systems have been developed (e.g., $\left.\mathrm{Ti}^{34}{ }^{34},{ }^{35} \mathrm{Co},{ }^{36} \mathrm{Ni}^{37} \mathrm{Mo},{ }^{38} \mathrm{Ru}^{39} \mathrm{Rh}^{40}{ }^{40} \mathrm{Pd}^{41} \mathrm{Ir}^{42}\right)$. Literature precedents for the nickel-catalyzed conversion of alkynes to substituted benzene regio-isomers are known, both from an intramolecular ${ }^{36 c, 37 g-1, n, p, r, s}$ and intermolecular approach. $^{9 c, 32,36 \mathrm{a}, 37 \mathrm{a}-\mathrm{f}, \mathrm{m}, \mathrm{o}, \mathrm{q}, \mathrm{t}-\mathrm{z}}$ For the $[2+2+2]$ intermolecular alkyne cyclotrimerization, it starts from the early example by Reppe et al. ${ }^{32}$ to the combination of divalent nickel halide salts and reductants ${ }^{36,37 f}$ or even activated Ni-particles. ${ }^{37 b}$ Phosphine, ${ }^{9 \mathrm{c}, 36 \mathrm{a}, 37 \mathrm{j}, \mathrm{m}, \mathrm{t}, \mathrm{v}}$ NHC, ${ }^{37 \mathrm{v}, \mathrm{x}}$ mixed phosphine/imino $(\mathrm{P}, \mathrm{N}),{ }^{9 \mathrm{c}}$ or 1,4 -diazadiene ${ }^{37 \mathrm{c}, \mathrm{e}, \mathrm{u}, \mathrm{w}, \mathrm{y}, \mathrm{z}}$ ligands, have been introduced to $\mathrm{Ni}$ systems in order to improve selectivity and catalytic activity. Phosphine complexes generally favor the formation of benzene derivatives while 1,4-diazadiene complexes yield cyclooctatetraenes.

Besides their synthetic utility, alkyne condensations are also useful probes for ligand effects in catalysis. ${ }^{43}$ The possible formation of different products and isomers, such as cyclotrimers, cyclotetramers, linear oligomers, polymers, and other compounds, provides useful information about the reactivity of a particular catalyst. For example, Uyeda ${ }^{37 w, 44}$ and Ess ${ }^{44}$ recently applied this approach to the evaluation of the effect of catalyst nuclearity, and Jones ${ }^{9 c}$ applied it to assessing differences in catalytic performance between bidentate PP and PN ligands (Figure 2). In this study, we assess the effect of using hemilabile $\pi$-acceptor tridentate ligand $\left({ }^{p \text {-tol }} \mathbf{L} \mathbf{1}\right.$; Figure 3) in alkyne cyclotrimerization through comparison with diverse nickel systems. $\mathrm{Ni}(0)$ adopting a strong tridentate architecture

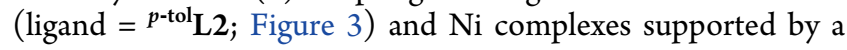

bidentate ligand $\left({ }^{\mathrm{Ph}} \mathbf{L}\right.$ 3; Figure 3) were selected for comparison

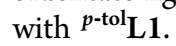

Here we report the synthesis of nickel(0) complexes of ${ }^{p \text {-tol }} \mathbf{L} 1,{ }^{p \text {-tol }} \mathbf{L}$ 2, and ${ }^{\mathrm{Ph}} \mathrm{L} 3$ featuring benzophenone imine (BPI) as a labile protecting ligand. Their stoichiometric reactivity with terminal alkynes is investigated, and the resulting $\mathrm{Ni}-$ alkyne complexes are thoroughly characterized. Then, a comparative study of these bi- and tridentate $\mathrm{Ni}(0)$-catalysts in the cyclotrimerization of terminal alkynes is described, aiming to study the effect of a hemilabile $\pi$-acceptor system. For all tested alkyne substrates, ${ }^{p \text {-tol } \mathbf{L} 1 \text { outperforms }}{ }^{p \text {-tol }} \mathbf{L} \mathbf{2}$ and ${ }^{\mathrm{Ph}} \mathrm{L} 3$, as well as the structurally more different diphosphine racBINAP ( $\left.{ }^{\mathrm{Ph}} \mathbf{L} 4\right)$, in terms of selectivity and activity. Reactivity studies combined with DFT calculations provide insight into the increased catalytic activity, suggesting that ${ }^{p \text {-tol }} \mathbf{L} \mathbf{l}$ can adapt its binding mode throughout the reaction pathway, by the labile (de)coordination of its ketone unit.

\section{RESULTS AND DISCUSSION}

Ni(0)-Benzophenone Imine Complexes. The diphosphine-benzophenone pincer-type ligand ${ }^{23} 2,2^{\prime}$-bis(di(paratolyl)phosphino)-benzophenone ${ }^{25}\left({ }^{p \text {-tol }} \mathbf{L} \mathbf{1}\right.$; Figure 3$)$ and the triphosphine pincer-type ligand ${ }^{45}$ bis(2-(di-(para-tolyl)-

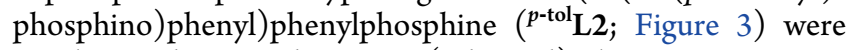
synthesized according to (adapted) literature procedures, ${ }^{24,25,46}$ by lithiation of $o$-bromo(diarylphosphino)benzene ${ }^{47}$ with $n$-BuLi followed by reaction with the appropriate electrophile (Scheme 1). para-Tolyl substituents on the phosphine were introduced both to improve the solubility of the complexes and to provide a convenient ${ }^{1} \mathrm{H}$ NMR handle for characterization. The ${ }^{31} \mathrm{P}$ NMR spectrum of ${ }^{p \text {-tol }} \mathbf{L} 2$ indicates the presence of an $\mathrm{AB}_{2}$ system $\left(\Delta \nu \approx J_{\mathrm{A}, \mathrm{B}}\right)^{48}$ with a coupling constant of ${ }^{3} J_{\mathrm{A}, \mathrm{B}}=155 \mathrm{~Hz}$, as previously observed for its phenyl-substituted analogue. ${ }^{46}$ The diphosphine ether ligand ${ }^{{ }^{P h}} \mathbf{L 3}^{49}$ was obtained from commercial sources and used as received.

Coordination of the chelating phosphine ligands to a nickel $(0)$ center was achieved by reaction with $\mathrm{Ni}(\operatorname{cod})_{2}$ ( $\operatorname{cod}=$ cyclooctatetraene $)$ in the presence of benzophenone imine (BPI), in a stoichiometric ratio, affording respectively complexes (i) $\left[\left({ }^{p \text {-tol }} \mathbf{L 1}\right) \mathrm{Ni}(\mathrm{BPI})\right] \quad\left({ }^{p \text {-tol }} \mathbf{1} ;\right.$ Scheme 2$)$, (ii) $\left[\left({ }^{p \text {-tol }} \mathbf{L 2}\right) \mathrm{Ni}(\mathrm{BPI})\right]\left({ }^{p \text {-tol }} \mathbf{2}\right.$; Scheme 2$)$, and (iii) $\left[\left({ }^{\mathrm{Ph}} \mathbf{L} \mathbf{3}\right) \mathrm{Ni}\right.$ -

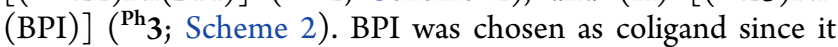
binds strongly enough to $\mathrm{Ni}(0)$ to prevent the formation of dimeric species ${ }^{24}$ but weakly enough to be exchanged with different types of potential substrates such as alkenes, nitriles, and alkynes (see below; Scheme 4).

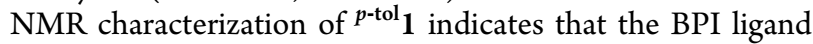
is bound in an $\eta^{1}$ fashion. The ${ }^{13} \mathrm{C}$ NMR signal corresponding to the imine appears as a triplet $\left(169.8 \mathrm{ppm},{ }^{3} J_{\mathrm{C}, \mathrm{P}}=6.1 \mathrm{~Hz}\right)$

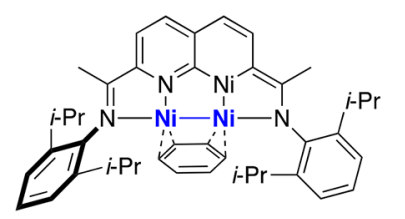

Uyeda et al. effect of catalyst nuclearity

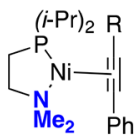

Jones et al. effect of labile bidentate ligand

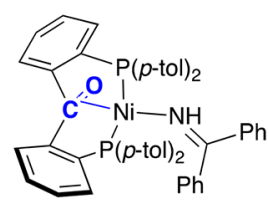

This study

effect of hemilable $\pi$-acceptor tridentate ligand

Figure 2. Examples of $\mathrm{Ni}(0)$ complexes used to evaluate the catalytic properties of a ligand-metal system by their reactivity with alkynes. ${ }^{9 c, 37 \mathrm{w}}$ Blue bold font $=$ property studied. $\mathrm{R}=\mathrm{Ph}, \mathrm{CF}_{3}$, tert-butyl. 


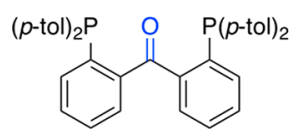

p-tolL1

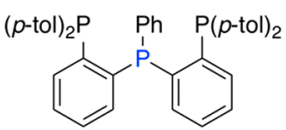

p-tolL2

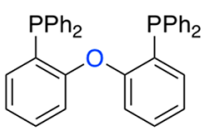

PhL3

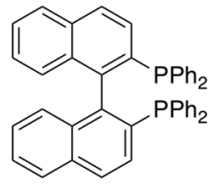

${ }^{\mathrm{Ph}} \mathrm{L4}$

Figure 3. Tridentate and bidentate ligands of comparison in this study.

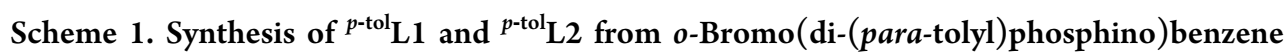

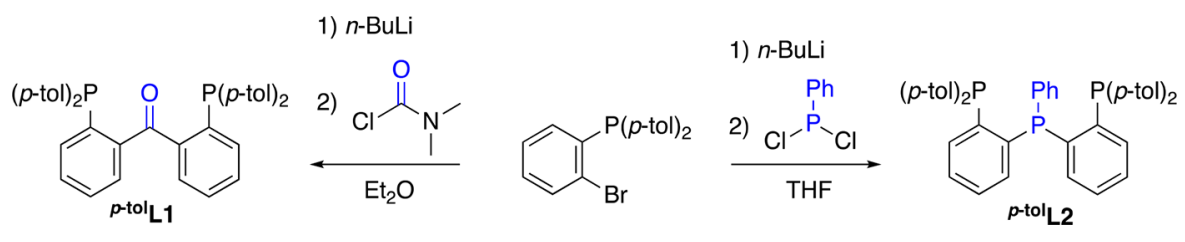

Scheme 2. $\mathrm{Ni}^{0}$-Benzophenone Imine Complexes ${ }^{a}$

A.

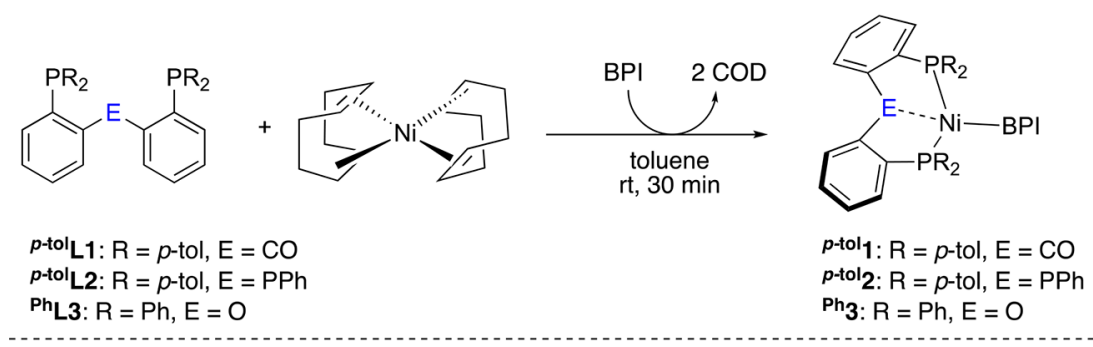

B.

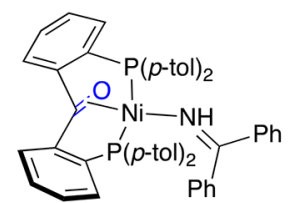

p-tol 1

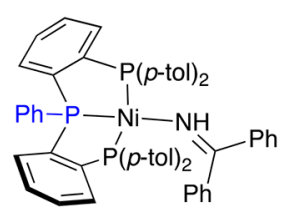

p-tol2

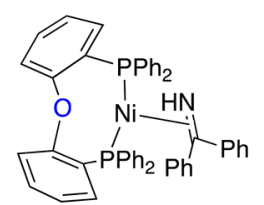

$\mathrm{Ph}_{3}$

${ }^{a}(\mathrm{~A})$ General synthetic route. (B) Isolated complexes. BPI = benzophenone imine.

close to that of the free imine at $177.3 \mathrm{ppm}$, consistent with retention of $\mathrm{C}=\mathrm{N}$ double bond character. In the ${ }^{1} \mathrm{H}$ NMR spectra, slight deshielding of the $\mathrm{C}=\mathrm{N}-\mathrm{H}$ proton by 0.24 ppm with respect to free BPI is also in accordance with $\eta^{1}(\mathrm{~N})$ binding. Moreover, the ATR-IR spectrum displays a signal at $3152 \mathrm{~cm}^{-1}$ in the region corresponding the $\mathrm{N}-\mathrm{H}$ stretch. In contrast, the backbone $\mathrm{C}=\mathrm{O}$ moiety is bound side-on: the corresponding ${ }^{13} \mathrm{C}$ NMR signal appears at $119.0 \mathrm{ppm}\left(\mathrm{t},{ }^{3} J_{\mathrm{C}, \mathrm{P}}=\right.$ $5.1 \mathrm{~Hz})$, considerably shifted from the value of $197.4 \mathrm{ppm}$ found in the free ligand. ${ }^{25}$ This large shift is useful as a diagnostic tool to determine whether the $\mathrm{CO}$ moiety is coordinated to the Ni center. The ${ }^{31} \mathrm{P}$ NMR spectra of ${ }^{p \text {-tol } 1}$ consist of a single singlet signal at $15.5 \mathrm{ppm}$, indicating that the two phosphorus atoms are equivalent on the NMR time scale. However, from ${ }^{1} \mathrm{H}$ and ${ }^{13} \mathrm{C} \mathrm{NMR}$ analysis, it appears that

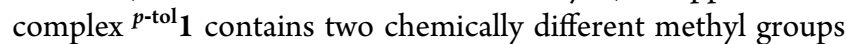
from the para-tolyl substituents (2.01 and $1.91 \mathrm{ppm}$ in ${ }^{1} \mathrm{H}$ NMR, 21.3 and $21.1 \mathrm{ppm}$ in $\left.{ }^{13} \mathrm{C} \mathrm{NMR}\right)$. Therefore, the paratolyl substituents belonging to a single P-donor site are not equivalent on the NMR time scale, which can be used as a secondary indication for ketone coordination.
In a similar fashion, NMR data support $\eta^{1}$ binding of the BPI ligand in the triphosphine complex ${ }^{p \text {-tol }} 2$. The ${ }^{13} \mathrm{C}$ NMR signal corresponding to the $\mathrm{N}=\mathrm{C}$ bond is a doublet of triplets at $168.9 \mathrm{ppm}\left({ }^{3} J_{\mathrm{C}, \mathrm{P}}=8.1 \mathrm{~Hz},{ }^{3} J_{\mathrm{C}, \mathrm{P}}=7.4 \mathrm{~Hz}\right)$. The imine proton appears at $10.25 \mathrm{ppm}$ in the ${ }^{1} \mathrm{H}$ NMR spectrum (deshielding of $0.48 \mathrm{ppm}$ compared to the free BPI ligand) and couples with the phosphorus nuclei $\left(\mathrm{dt},{ }^{3} J_{\mathrm{H}, \mathrm{P}}=3.2 \mathrm{~Hz},{ }^{3} J_{\mathrm{H}, \mathrm{P}}=2.7 \mathrm{~Hz}\right)$. The ${ }^{31} \mathrm{P}$ NMR spectrum is consistent with an $\mathrm{AK}_{2}$ system $(\Delta \nu \approx$ $\left.5 J_{\mathrm{A}, \mathrm{K}}\right)^{48}$ with a coupling constant ${ }^{2} J_{\mathrm{A}, \mathrm{K}}=85 \mathrm{~Hz}$. From ${ }^{1} \mathrm{H}$ and ${ }^{13} \mathrm{C}$ NMR analysis, it appears that the complex contains two chemically different para-tolyl substituents $(2.14$ and $1.95 \mathrm{ppm}$ in ${ }^{1} \mathrm{H}$ NMR, 21.4 and $21.1 \mathrm{ppm}$ in ${ }^{13} \mathrm{C} \mathrm{NMR}$ ), as also observed with complex ${ }^{p \text {-tol }} \mathbf{1}$.

In the ${ }^{1} \mathrm{H}$ NMR of ${ }^{\mathrm{Ph}} 3$, the $\mathrm{N}-H$ signal from the coordinated imine appears as a broad singlet at $\delta_{\mathrm{H}}=9.71$ in the expected 1:38 ratio compared to the aromatic region of the spectrum. The ${ }^{31} \mathrm{P}$ NMR spectrum exhibits a single resonance at $32.4 \mathrm{ppm}$. No satisfactory ${ }^{13} \mathrm{C}$ NMR data could be obtained due to the low solubility of the complex and its progressive decomposition, making the assignment of the binding mode of BPI in solution uncertain. The side-on binding of BPI observed in the solid state (see below) may be preserved in solution, in 


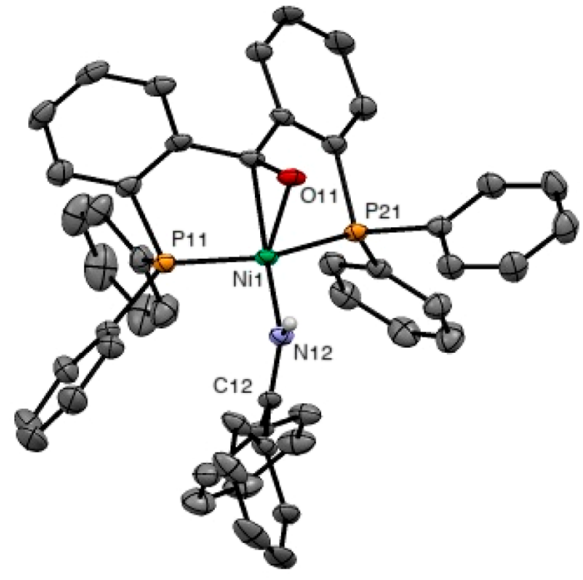

$\mathrm{Ph} 1$

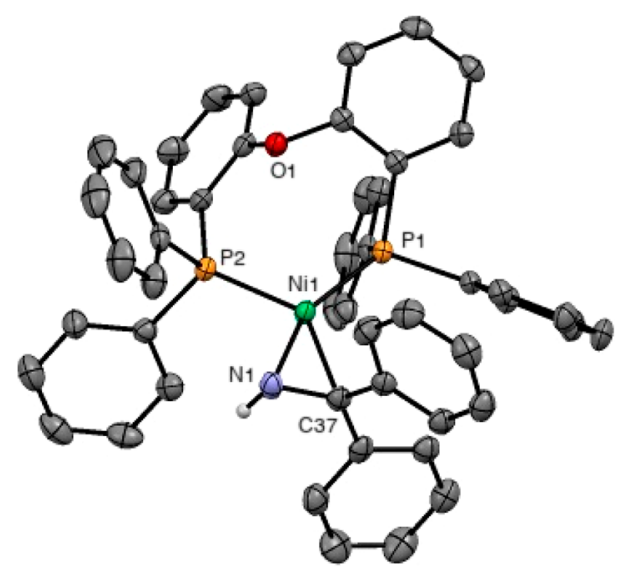

$\mathrm{Ph}_{3}$

Figure 4. Molecular structures of $\left[\left({ }^{\mathrm{Ph}} \mathbf{L} 1\right) \mathrm{Ni}(\mathrm{BPI})\right]\left({ }^{\mathrm{Ph}} \mathbf{1}\right)$ and $\left[\left({ }^{\mathrm{Ph}} \mathrm{L} 3\right) \mathrm{Ni}(\mathrm{BPI})\right]\left({ }^{\mathrm{Ph}} 3\right)$ in the crystal (50\% probability level). Hexane solvent molecules $\left({ }^{\mathrm{Ph}} \mathbf{1}\right)$ and $\mathrm{C}-\mathrm{H}$ hydrogen atoms are omitted for clarity.

\section{Scheme 3. $\mathrm{Ni}^{0}$-Terminal Alkyne Complexes ${ }^{a}$}

A.

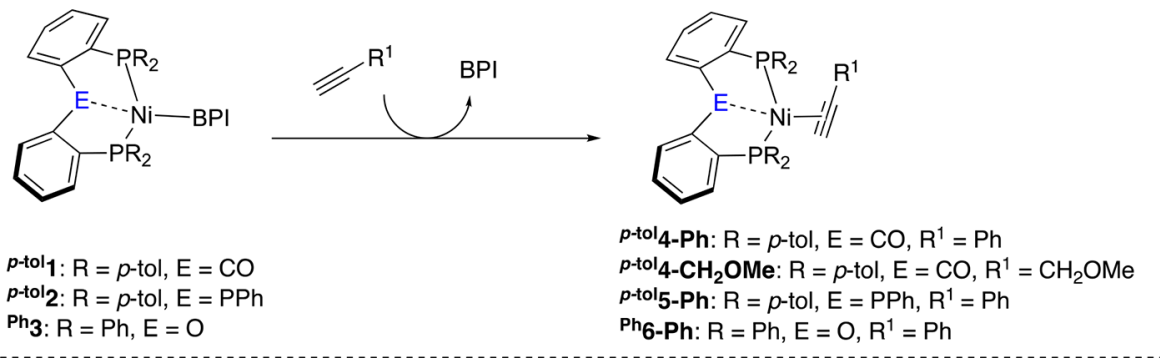

B.
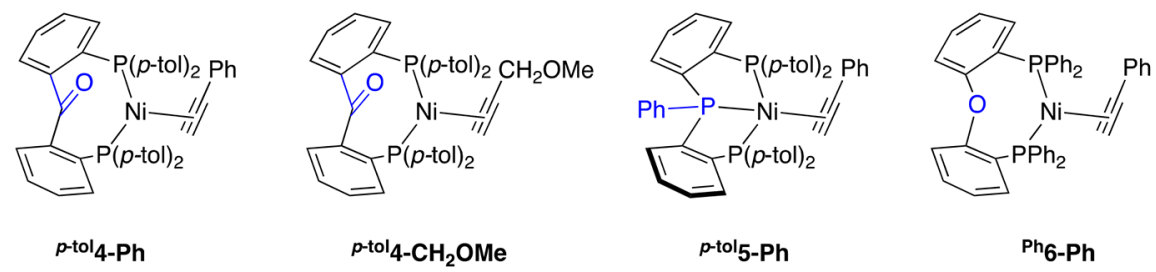

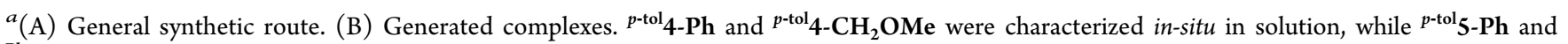
${ }^{\mathrm{Ph}}$ 6-Ph were isolated. $\mathrm{BPI}=$ benzophenone imine.

which case fast rotation of BPI ligand on the ${ }^{1} \mathrm{H}$ NMR time scale would render the two phosphorus atoms equivalent. The $\mathrm{N}-\mathrm{H}$ stretch from the bound imine appears as a broad weak band in the ATR-IR spectrum, located at $3200 \mathrm{~cm}^{-1}$.

More insights into the structural and electronic properties of nickel complexes ${ }^{p \text {-tol }} \mathbf{1}$ and ${ }^{\mathrm{Ph}_{3}}$ were obtained by X-ray crystal structure determination (Figure 4). Crystals suitable for X-ray diffraction were not accessible with ${ }^{p \text {-tol } 1}$ but with the structurally related complex ${ }^{\mathrm{Ph}} \mathbf{1}$, in which the para-tolyl ligand ${ }^{p \text {-tol }} \mathbf{L} \mathbf{1}$ is replaced by the phenyl analogue $2,2^{\prime}$-bis(di(phenyl)phosphino)-benzophenone ( $\left.{ }^{\mathrm{Ph}} \mathbf{L} \mathbf{1}\right)$.

In accord with NMR data, the structure of ${ }^{\mathrm{Ph}} 1$ (Figure 4; left) exhibits a side-on bound ketone moiety with $\mathrm{Ni1}-\mathrm{O} 11$ and Ni1-C71 bond lengths of 2.0217(14) and 1.9760(19) $\AA$, respectively. The C71-O11 bond length $(1.320(2) \AA)$ is found between those of unbound ${ }^{\mathrm{Ph}} \mathbf{L 1}(1.213(3) \AA)^{23}$ and a $\mathrm{C}-\mathrm{O}$ single bond $\left(1.43 \AA\right.$ in ethanol $\left.{ }^{50}\right)$. The ketone is slightly less activated than in $\left[\left({ }^{\mathrm{Ph}} \mathbf{L} \mathbf{1}\right) \mathrm{Ni}\left(\mathrm{PPh}_{3}\right)\right],{ }^{24}$ which displays a $\mathrm{C}-\mathrm{O}$ bond length of $1.310(2) \AA$, consistent with less pronounced $\pi$-back-donation arising from the weaker donor character of BPI with respect to $\mathrm{PPh}_{3}$. The sum of bond angles $\left(351.3(3)^{\circ}\right)$ around the carbon atom lies between those expected for $\mathrm{sp}^{2}\left(328.5^{\circ}\right)$ and $\mathrm{sp}^{3}\left(360^{\circ}\right)$ hybridization at the carbon, in accordance with the Dewar-Chatt-Duncanson model. The N12-C12 bond length of $1.289(2) \AA$ is close to the value of a $\mathrm{C}-\mathrm{N}$ double bond (ca. $1.28 \AA)^{50}$ and comparable to the value found by Zhao et al. (1.294(3) $\AA)^{51 \mathrm{a}}$ for $\eta^{1}$-coordination mode in their synthesized NHCbased nickel $(0)$ complex, [(IPr) Ni $\left.\left(\eta^{2}-\mathrm{BPI}\right)\left(\eta^{1}-\mathrm{BPI}\right)\right](\mathrm{IPr}=$ 1,3-bis(diisopropylphenyl)-imidazolium), showing that the $\pi$ back-donation to the BPI ligand is small. Accordingly, the valence angles around the imine carbon add up to $360.0(3)^{\circ}$. Finally, the torsion angle $(\angle \mathrm{Ni} 1-\mathrm{N} 12-\mathrm{C} 12-\mathrm{CPh})$ of 


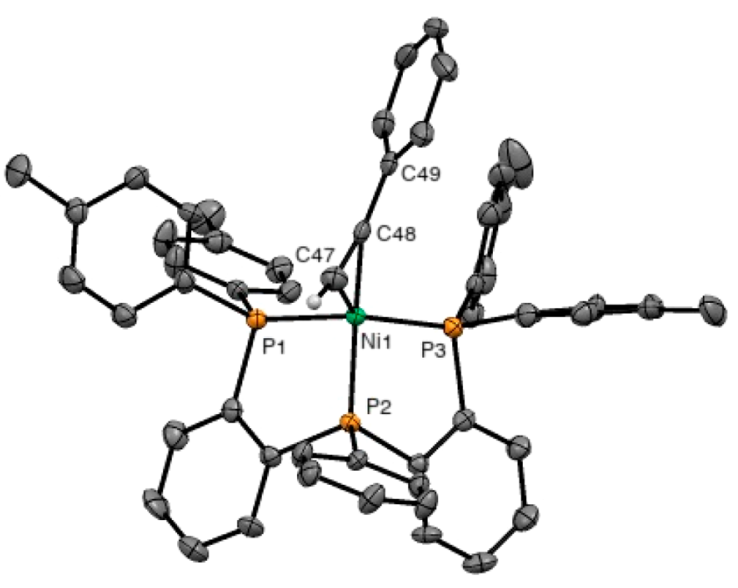

p-tol5-Ph

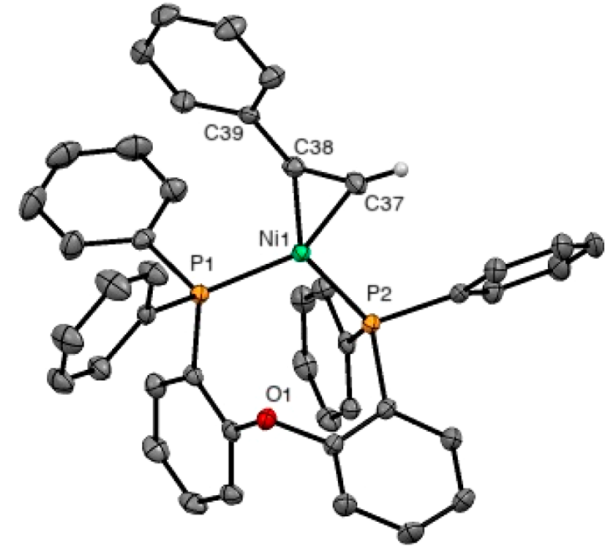

Ph6-Ph

Figure 5. Molecular structure of $\left[\left({ }^{p-t o l} \mathbf{L} 2\right) \mathrm{Ni}(\mathrm{HC} \equiv \mathrm{CPh})\right]\left({ }^{p \text {-tol }} \mathbf{5}\right.$ - $\left.\mathbf{P h}\right)$ and $\left[\left({ }^{\mathrm{Ph}} \mathbf{L} \mathbf{3}\right) \mathrm{Ni}(\mathrm{HC} \equiv \mathrm{CPH})\right]\left({ }^{\mathrm{Ph}} \mathbf{6}-\mathbf{P h}\right)$ in the crystal $(50 \%$ probability level $)$. Toluene solvent molecules $\left({ }^{\mathrm{Ph}} \mathbf{6}-\mathrm{Ph}\right)$ and hydrogen atoms (except alkyne) have been omitted for clarity.

$20.0(3)^{\circ}$ shows that the nickel atom is slightly out of the plane of BPI, which is probably sterically driven.

In contrast to that of ${ }^{\mathrm{Ph}} \mathbf{1}$, the crystal structure of ${ }^{\mathrm{Ph}_{3}}$ (Figure 4 , right) reveals a trigonal planar complex in which the imine coligand is coordinated to the nickel in an $\eta^{2}$ fashion (Ni1$\mathrm{C} 37=2.018(2) \AA, \mathrm{Ni1}-\mathrm{N} 1=1.8985(19) \AA)$. The $\mathrm{C}-\mathrm{N}$ bond axis is parallel to the metal coordination plane, which is thought to maximize $\pi$-back-donation from the high-lying inplane d orbital with significant $\sigma^{*}(\mathrm{P}-\mathrm{Ni})$ character. Accordingly, strong $\pi$-back-donation into the $\pi^{*}(\mathrm{~N}-\mathrm{C})$ orbital is evidenced by an elongated C37-N1 bond (1.373(3) Å vs 1.28 $\AA^{50}$ in the free imine) and the pyramidalization of the C37 atom, which displays a sum of valence angles of $355.3(3)^{\circ}$, in line with known $\eta^{2}(\mathrm{C}, \mathrm{N})-\mathrm{Ni}(0)$ complexes. ${ }^{51}$ As expected, the central oxygen atom from the ligand is not binding to the metal center $(\mathrm{Ni1}-\mathrm{O} 1=3.3668(16) \AA)$, as also confirmed by a Wiberg bond index lower than 0.01 calculated by NBO analysis at a B3LYP/def2TZVP level of theory. The distance between the nickel and oxygen atoms is similar to the values reported from $\mathrm{Ni}(0)$ complexes bearing this ligand. ${ }^{52}$ Finally, the measured $\mathrm{P} 1-\mathrm{Ni} 1-\mathrm{P} 2$ bite angle of $108.59(2)^{\circ}$ and the Ni1-O1 distance of $3.3668(16) \AA$ are in the same range as those found for $\left[\left({ }^{\mathrm{Ph}} \mathbf{L} \mathbf{1}\right) \mathrm{Ni}\left(\mathrm{Cl}_{2}\right)\right],{ }^{24}$ in which the $\mathrm{C}=\mathrm{O}$ unit is not bound to the $\mathrm{Ni}$ ion $\left(\mathrm{P} 1-\mathrm{Ni}-\mathrm{P} 2112.996(13)^{\circ}\right.$; $\mathrm{Ni}-\mathrm{C}=$ 3.4031(12) $\AA$; $\mathrm{Ni}-\mathrm{O}=3.1012(10) \AA$ ), supporting the use of $\mathrm{Ph}_{3}$ as a model complex for the unbound state of ${ }^{p \text { tol }} \mathbf{L} \mathbf{1}$.

In summary, complexes ${ }^{p \text {-tol } 1}$ and ${ }^{p \text {-tol }} \mathbf{2}$ are geometrically similar and mainly differ by the central coordinating unit the ligand $(\mathrm{C}=\mathrm{O}$ vs $\mathrm{P})$. Complex ${ }^{\mathrm{Ph}_{3}}$ differs in that the central oxygen atom is not coordinated and can be seen as a structural analogue of the unbound state of ligand ${ }^{\mathrm{R}} \mathrm{L} \mathbf{1}(\mathrm{R}=p$-tolyl or $\mathrm{Ph})$. Interestingly, moving from tridentate to bidentate mode is coupled to a change in binding mode of the BPI ligand from end-on to side-on, which can be understood from enhanced $\pi$ back-donation from a $\mathrm{d}^{10} \mathrm{~L}_{2} \mathrm{Ni}$ fragment (see Supporting Information for more insight by $\mathrm{NBO}$ analysis into the different coordination modes of the imine coligand; Table S8).

$\mathrm{Ni}(\mathbf{0})-$ Alkyne Complexes. With complexes ${ }^{p \text {-tol }} 1{ }^{{ }^{\mathrm{Ph}}} \mathbf{3}$ in hand, their reactivity toward terminal alkynes was investigated, leading to the generation of $\mathrm{Ni}$-alkyne complexes $\left[\left({ }^{p \text {-tol }} \mathbf{L 1}\right)\right.$ $\mathrm{Ni}(\mathrm{HC} \equiv \mathrm{CPh})]\left({ }^{p \text {-tol }} \mathbf{4 - P h}\right), \quad\left[\left({ }^{p \text {-tol }} \mathbf{L} \mathbf{1}\right) \mathrm{Ni}\left(\mathrm{HC} \equiv \mathrm{CCH}_{2} \mathrm{OMe}\right)\right]$ $\left({ }^{p \text { tol }} 4-\mathrm{CH}_{2} \mathrm{OMe}\right), \quad\left[\left({ }^{p \text {-tol }} \mathbf{L} 2\right) \mathrm{Ni}(\mathrm{HC} \equiv \mathrm{CPh})\right]\left({ }^{p \text {-tol }} 5-\mathrm{Ph}\right)$, and $\left[\left({ }^{\mathbf{P h}} \mathbf{L} \mathbf{3}\right) \mathrm{Ni}(\mathrm{HC} \equiv \mathrm{CPh})\right]\left({ }^{\mathbf{P h}} \mathbf{6}-\mathbf{P h}\right)$ (Scheme 3). Ni-complexes

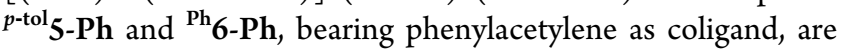
sufficiently stable to be isolated and are discussed first.

The ${ }^{31} \mathrm{P}$ NMR spectrum of ${ }^{p \text {-tol }} \mathbf{5}$-Ph displays two signals at $78.7 \mathrm{ppm}\left(\mathrm{t},{ }^{2} J_{\mathrm{P}, \mathrm{P}}=35.4 \mathrm{~Hz}\right)$ and at $28.1 \mathrm{ppm}\left(\mathrm{d},{ }^{2} J_{\mathrm{P}, \mathrm{P}}=35.4\right.$ $\mathrm{Hz}$ ) in a ratio of $2: 1$, indicating that the ligand binds in a tridentate fashion. Two ${ }^{1} \mathrm{H}$ NMR singlets of the same intensity at 2.12 and $1.91 \mathrm{ppm}$ correspond to the methyl group from diastereotopic para-tolyl substituents bound to the same phosphorus atom. A single alkyne is bound to $\mathrm{Ni}$ as indicated by the terminal proton signal at $6.30 \mathrm{ppm}$, which appears as a doublet of triplets $\left({ }^{3} J_{\mathrm{H}, \mathrm{P}}=25.6 \mathrm{~Hz},{ }^{3} J_{\mathrm{H}, \mathrm{P}}=7.2 \mathrm{~Hz}\right)$ and couples with a carbon nucleus at $92.9 \mathrm{ppm}$ in $\mathrm{HMQC}\left({ }^{1} \mathrm{H}-{ }^{13} \mathrm{C}\right)$. Further confirmation of this assignment is provided by treatment of ${ }^{p \text {-tol } 2}$ with $d$-phenylacetylene, resulting in the disappearance of the signal at $6.30 \mathrm{ppm}$ in an otherwise identical ${ }^{1} \mathrm{H}$ NMR spectrum (Supporting Information; Figure S68 and S76). In agreement with the spectroscopic character-

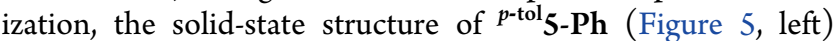
reveals a pseudo-tetrahedral geometry in which the alkyne moiety is coordinated in $\eta^{2}$ fashion.

Compound ${ }^{\mathrm{Ph}} \mathbf{6}-\mathbf{P h}$, supported by the bidentate diphosphine ether ligand ${ }^{\mathrm{Ph}} \mathbf{L} 3$, displays two signals at $29.2 \mathrm{ppm}$ and at 27.3 ppm coupling to each other $\left({ }^{2} J_{P, P}=14.0 \mathrm{~Hz}\right)$ and in a ratio of $1: 1$ in the ${ }^{31} \mathrm{P}$ NMR spectrum. This is consistent with a trigonal planar geometry in which rotation of the alkyne ligand is slow on the ${ }^{1} \mathrm{H}$ NMR time scale; warming up the sample up to $100{ }^{\circ} \mathrm{C}$ does not result in coalescence of the two ${ }^{31} \mathrm{P}$ NMR signals. This interpretation is supported by reaction of ${ }^{\mathrm{Ph}_{3}}$ with 1 equiv of the symmetric alkyne diphenylacetylene, resulting in a symmetrical analogue of ${ }^{\mathrm{Ph}} \mathbf{6}$-Ph displaying a single ${ }^{31} \mathrm{P}$ NMR singlet at $28.1 \mathrm{ppm}$ (Supporting Information; Figure S98). The proton from the alkyne gives a ${ }^{1} \mathrm{H}$ NMR signal at $6.9 \mathrm{ppm}$, as revealed by HMQC $\left({ }^{1} \mathrm{H}-{ }^{13} \mathrm{C}\right)$ and comparison with deuterated analogue. The solid state structure (Figure 5, right) of ${ }^{\mathrm{Ph}} \mathbf{6 - P h}$ is in accord with the NMR data and reveals a trigonal planar geometry with a $\mathrm{P} 1-\mathrm{Ni}-\mathrm{P} 2$ bite angle of $104.94(2)^{\circ}$, where the oxygen atom is not bound to the nickel center $(\mathrm{Ni1}-\mathrm{O} 1=3.3317(15) \AA)$. The alkyne is bound in an $\eta^{2}$-coordination mode, the $\mathrm{C} 37-\mathrm{C} 38$ axis being in the $\mathrm{Ni}$ coordination plane. 
While stable tricoordinate $\mathrm{Ni}(0)$ alkyne complexes with formally 16 valence electrons analogous to ${ }^{\mathbf{P h}} \mathbf{6}-\mathbf{P h}$ are well

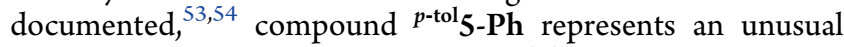
example of tetracoordinate, $18 \mathrm{VE} \mathrm{Ni(0)-alkyne} \mathrm{complex,} \mathrm{to}$ the best of our knowledge the first to be structurally characterized. Spectroscopic and structural data point toward a considerably weaker activation of the $\mathrm{C} \equiv \mathrm{C}$ triple bond in this geometry (Table 1 ). First, the ${ }^{13} \mathrm{C}$ NMR chemical shifts of

Table 1. Selected Spectroscopic and X-ray Crystal Structure Values of Phenylacetylene, ${ }^{p \text {-tol }} 5-\mathrm{Ph}$ and ${ }^{\mathrm{Ph}} 6-\mathrm{Ph}^{a}$

\begin{tabular}{llll} 
& phenylacetylene & ${ }^{p-\text { tol }} \mathbf{5 - P h}$ & \multicolumn{1}{c}{${ }^{\text {Ph }}$ 6-Ph } \\
$\delta_{\mathrm{C}}(\mathrm{C} \equiv \mathrm{C}-\mathrm{H})[\mathrm{ppm}]$ & 77.5 & 92.9 & 125.7 \\
$\delta_{\mathrm{C}}(\mathrm{C} \equiv \mathrm{C}-\mathrm{Ph})[\mathrm{ppm}]$ & 83.3 & 101.1 & 136.4 \\
$\delta_{\mathrm{H}}(\mathrm{C} \equiv \mathrm{C}-\mathrm{H})[\mathrm{ppm}]$ & 2.73 & 6.30 & 6.9 \\
$\nu(\mathrm{C} \equiv \mathrm{C})\left[\mathrm{cm}^{-1}\right]$ & 2126 & 1823 & 1749 \\
$\mathrm{C} \equiv \mathrm{C}[\AA]$ & $1.182-1.190^{55}$ & $1.231(8)$ & $1.269(3)$ \\
$\angle \mathrm{C} \equiv \mathrm{C}-\mathrm{C}_{\mathrm{Ph}}[\mathrm{deg}]$ & $177.39-179.49^{55}$ & $152.0(6)$ & $144.07(19)$
\end{tabular}

${ }^{a}$ Vibrational frequencies are measured with ATR-IR (neat). NMR chemical shifts are given in $\mathrm{C}_{6} \mathrm{D}_{6}$.

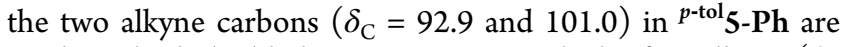
moderately deshielded in comparison with the free alkyne $\left(\delta_{\mathrm{C}}\right.$ $=77.5$ and 83.3), indicating relatively weak rehybridization from $\mathrm{sp}$ to $\mathrm{sp}^{2}$. This contrasts with a stronger activation of the $\mathrm{C} \equiv \mathrm{C}$ triple bond of phenylacetylene in ${ }^{\mathrm{Ph}} \mathbf{6}-\mathrm{Ph}$ evidenced by the ${ }^{13} \mathrm{C}$ NMR signals from the coordinated phenylacetylene at $125.7 \mathrm{ppm}\left(\mathrm{C} \equiv \mathrm{C}-\mathrm{H}, \mathrm{dd},{ }^{2} J_{\mathrm{C}, \mathrm{P}}=40.1 \mathrm{~Hz},{ }^{2} J_{\mathrm{C}, \mathrm{P}}=7.1 \mathrm{~Hz}\right)$ and $136.4 \mathrm{ppm}\left(\mathrm{C} \equiv \mathrm{C}-\mathrm{Ph}, \mathrm{dd},{ }^{2} J_{\mathrm{C}, \mathrm{P}}=38.9 \mathrm{~Hz},{ }^{2} J_{\mathrm{C}, \mathrm{P}}=8.4 \mathrm{~Hz}\right)$, which were assigned with the assistance of APT ${ }^{13} \mathrm{C} N M R$ and by comparison with the $d$-phenylacetylene complex. Second, the acetylic hydrogen signal of ${ }^{p \text {-tol }} 5$-Ph $\left(\delta_{\mathrm{H}}=6.30\right)$ is less shifted than that of ${ }^{\mathbf{P h}} \mathbf{6}-\mathbf{P h}\left(\delta_{\mathrm{H}}=6.9\right)$, consistent with a stronger rehybridization toward $\mathrm{sp}^{2}$. Third, the $\mathrm{C} \equiv \mathrm{C}$ stretch vibration from the alkyne in ${ }^{p \text {-tol }} 5$ - Ph is found at $1823 \mathrm{~cm}^{-1}$ in the FT-IR spectrum versus $2126 \mathrm{~cm}^{-1}$ for free phenylacetylene and versus $1749 \mathrm{~cm}^{-1}$ for ${ }^{\mathrm{Ph}} \mathbf{6}-\mathbf{P h}$. Finally, the slightly elongated C47-C48 distance at 1.231(8) $\AA$ (vs 1.182-1.190 $\AA$ in free phenylacetylene $)^{55}$ and the rather large C47-C48-C49 angle at $152.0(6)^{\circ}$ are also consistent with a relatively weak activation of the $\mathrm{C}-\mathrm{C}$ triple bond, contrasting with the longer C37-C38 bond length (1.269(3) $\AA$ ) and the more acute the C37-C38-C39 angle $\left(144.07(19)^{\circ}\right)$ found for ${ }^{\mathrm{Ph}} \mathbf{6 - P h}$. The

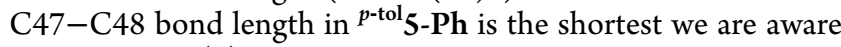
of for nickel(0)-alkyne complexes. Together, these data suggest that the $\pi$-back-donation from the nickel to phenylacetylene is more pronounced in ${ }^{\mathrm{Ph}} \mathbf{6}$ - $\mathbf{P h}$, resulting in a stronger rehybridization toward $\mathrm{sp}^{2}$.

The observations made for complex ${ }^{\mathbf{P h}} \mathbf{6}-\mathbf{P h}$ parallel those reported for mononuclear, 16 valence electron, tricoordinate $\mathrm{Ni}-$ alkyne, in which the $\mathrm{C}-\mathrm{C}$ bond is significantly more elongated than in ${ }^{p \text {-tol }} \mathbf{5}-\mathbf{P h}$, regardless of substituent groups on the alkyne. For example, strong activation of the alkyne is observed for bidentate diimine and mixed P,N supported species (up to $1.296(6) \AA$ ),,${ }^{c, 53 a, b, i, l, n, r}$ while bidentate phosphorus ligands afford $\mathrm{C}-\mathrm{C}$ bond lengths from 1.260(4) to $1.283(3) \AA .^{52 \mathrm{~b}, 53 \mathrm{~d}-\mathrm{f}, \mathrm{h}, \mathrm{j}, \mathrm{m}, \mathrm{o}-\mathrm{q}}$ The substantially weaker rehybridization observed in ${ }^{p \text {-tol }} \mathbf{5}$-Ph can be assigned to its unique coordination geometry (i.e., tetracoordinate complex; 3 donor ligands; pseudo- $T_{d}$ geometry) compared to ${ }^{\mathrm{Ph}} \mathbf{6}-\mathbf{P h}$ and the reported $\mathrm{Ni}-$ alkyne complexes (i.e., tricoordinate complexes; 2 donor ligands; trigonal planar geometry). The weak activation of phenylacetylene in ${ }^{p \text {-tol }} \mathbf{5}-\mathbf{P h}$ is presumably a consequence of the smaller splitting of the d-orbitals in its pseudo-tetrahedral geometry (3 donor ligands), resulting in less pronounced $\pi$-back-donation from $\mathrm{Ni}$ to the antibonding orbitals of the alkyne. Similar considerations were used by Lee and co-workers to explain the rather weak activation of $\mathrm{CO}_{2}$ in the tetracoordinate pseudo-tetrahedral nickel complex $\left[\left(\mathrm{PP}^{\mathrm{Me}} \mathrm{P}\right) \mathrm{Ni}\left(\eta^{2}-\mathrm{CO}_{2}\right)\right]\left(\mathrm{PP}^{\mathrm{Me}} \mathrm{P}=\mathrm{PMe}\left[2-\mathrm{P}^{i} \mathrm{Pr}_{2}-\mathrm{C}_{6} \mathrm{H}_{4}\right]_{2}\right)^{56}$ with respect to tricoordinate $\mathrm{Ni}-\eta^{2}-\mathrm{CO}_{2}$ adducts supported by bidentate phosphines such as $\left[(\mathrm{dtbpe}) \mathrm{Ni}\left(\eta^{2}-\mathrm{CO}_{2}\right)\right]$ (dtbpe = 1,2-bis (di-tert-butylphophino)-ethane). ${ }^{57}$

Finally, reaction of the diphosphine-ketone complex ${ }^{p \text {-tol } 1}$ with terminal alkynes generally led to a mixture containing the alkyne complex, $\left[\left({ }^{p \text {-tol }} \mathbf{L} \mathbf{1}\right) \mathrm{Ni}\left(\mathrm{HC} \equiv \mathrm{CR}^{1}\right)\right] \quad\left({ }^{p \text {-tol }} \mathbf{4}-\mathrm{R}^{\mathbf{1}} ; \mathrm{R}^{1}=\right.$ substituent on the alkyne), the starting material ${ }^{p \text {-tol }} 1$, BPI, the substrate, and cyclotrimerization products. This indicates that cyclotrimerization occurs concomitantly with ligand exchange, precluding the isolation of pure alkyne complexes. Nonetheless, in situ characterization of alkyne complexes was possible. Interestingly, ${ }^{13} \mathrm{C} \mathrm{NMR}$ of ${ }^{p \text {-tol }} \mathbf{4}$-Ph indicates that the ketone moiety is not bound to the metal center: addition of phenylacetylene to ${ }^{p \text {-tol }} \mathbf{1}$ causes the disappearance of the triplet at $119.0 \mathrm{ppm}$, characteristic of the $\eta^{2}(\mathrm{C}, \mathrm{O})$ coordination to nickel and the appearance of a triplet at $202.7 \mathrm{ppm}\left({ }^{3} J_{\mathrm{C}, \mathrm{P}}=4.9\right.$

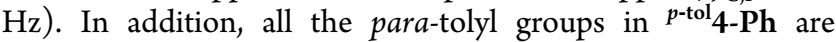
equivalent at room temperature, with singlets appearing at 2.00 and at $21.2 \mathrm{ppm}$ in ${ }^{1} \mathrm{H}$ and ${ }^{13} \mathrm{C} \mathrm{NMR}$, respectively. This is consistent with an unbound ketone allowing fast ring inversion of the chelate macrocycle. A single ${ }^{31} \mathrm{P}$ NMR singlet at 33.0 ppm down to $-80{ }^{\circ} \mathrm{C}$ indicates fast rotation of the alkyne, exchanging the two phosphorus atoms on the NMR time scale even at low temperature (Supporting Information; Figure S59).

The $\mathrm{C} \equiv \mathrm{C}-\mathrm{H}^{1} \mathrm{H}$ NMR signal of the coordinating phenylacetylene could not be located, presumably hidden in the crowded aromatic region of the spectrum. In contrast, the assignment of the acetylic proton of the bound alkyne was possible in the ${ }^{1} \mathrm{H}$ NMR spectrum of ${ }^{p \text {-tol }} \mathbf{4}-\mathbf{C H}_{2} \mathbf{O M e}$ where it appears as a triplet of triplets at $6.34 \mathrm{ppm}\left({ }^{3} \mathrm{~J}_{\mathrm{H}, \mathrm{P}}=15.6,{ }^{4} \mathrm{~J}_{\mathrm{H}, \mathrm{H}}=\right.$ $1.6 \mathrm{~Hz}$ ) and integrates in a ratio of 1:12 compared to the four $\mathrm{CH}_{3}$ groups of the ligand, confirming that a single alkyne molecule is bound. The integrals, coupling constants, and multiplicity of $\mathrm{CH}_{2}\left(4.63 \mathrm{ppm}, \mathrm{d},{ }^{4} J_{\mathrm{H}, \mathrm{H}}=1.6 \mathrm{~Hz}\right)$ and $\mathrm{OCH}_{3}$ (3.32 ppm, s) of the bound alkyne are in agreement with the proposed structure. Similar to ${ }^{p \text {-tol }} 4-\mathrm{Ph}$, both ${ }^{1} \mathrm{H}$ and ${ }^{13} \mathrm{C}$ NMR

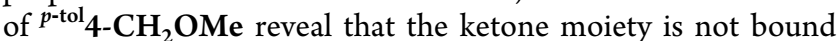
to the metal center: the ketone resonance appears as a triplet at $203.1 \mathrm{ppm}\left({ }^{3} J_{\mathrm{C}, \mathrm{P}}=4.7 \mathrm{~Hz}\right)$ and the methyl groups from the para-tolyl are all equivalent, with a singlet at 2.03 and a doublet $22.2 \mathrm{ppm}\left({ }^{4} J_{\mathrm{C}, \mathrm{P}}=2.3 \mathrm{~Hz}\right)$ in ${ }^{1} \mathrm{H}$ and ${ }^{13} \mathrm{C}$ NMR, respectively. A singlet ${ }^{31} \mathrm{P}$ NMR signal at $32.7 \mathrm{ppm}$ at room temperature is consistent with fast rotation of the methyl propargyl ether

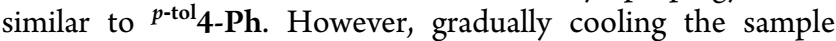
down to $-85{ }^{\circ} \mathrm{C}$ first shows the appearance of a new unsymmetrical species at ca. $-10{ }^{\circ} \mathrm{C}$, as characterized by two doublets $\left({ }^{2} J_{\mathrm{P}, \mathrm{P}}=23.3 \mathrm{~Hz}\right.$ ) at 32.1 and $34.1 \mathrm{ppm}$ (Supporting Information; Figure S67). The central signal corresponding to $p$-tol $4-\mathrm{CH}_{2} \mathrm{OMe}$ does split into two new doublets $\left({ }^{2} J_{\mathrm{P}, \mathrm{P}}=23.3\right.$ $\mathrm{Hz}$ ) with a coalescence temperature between -50 and $-60{ }^{\circ} \mathrm{C}$. This indicates that the rotation of methyl propargyl ether can be frozen on the NMR time scale, but also that two distinct species are formed at low temperature. This is tentatively attributed to a secondary interaction of the oxygen atom from 


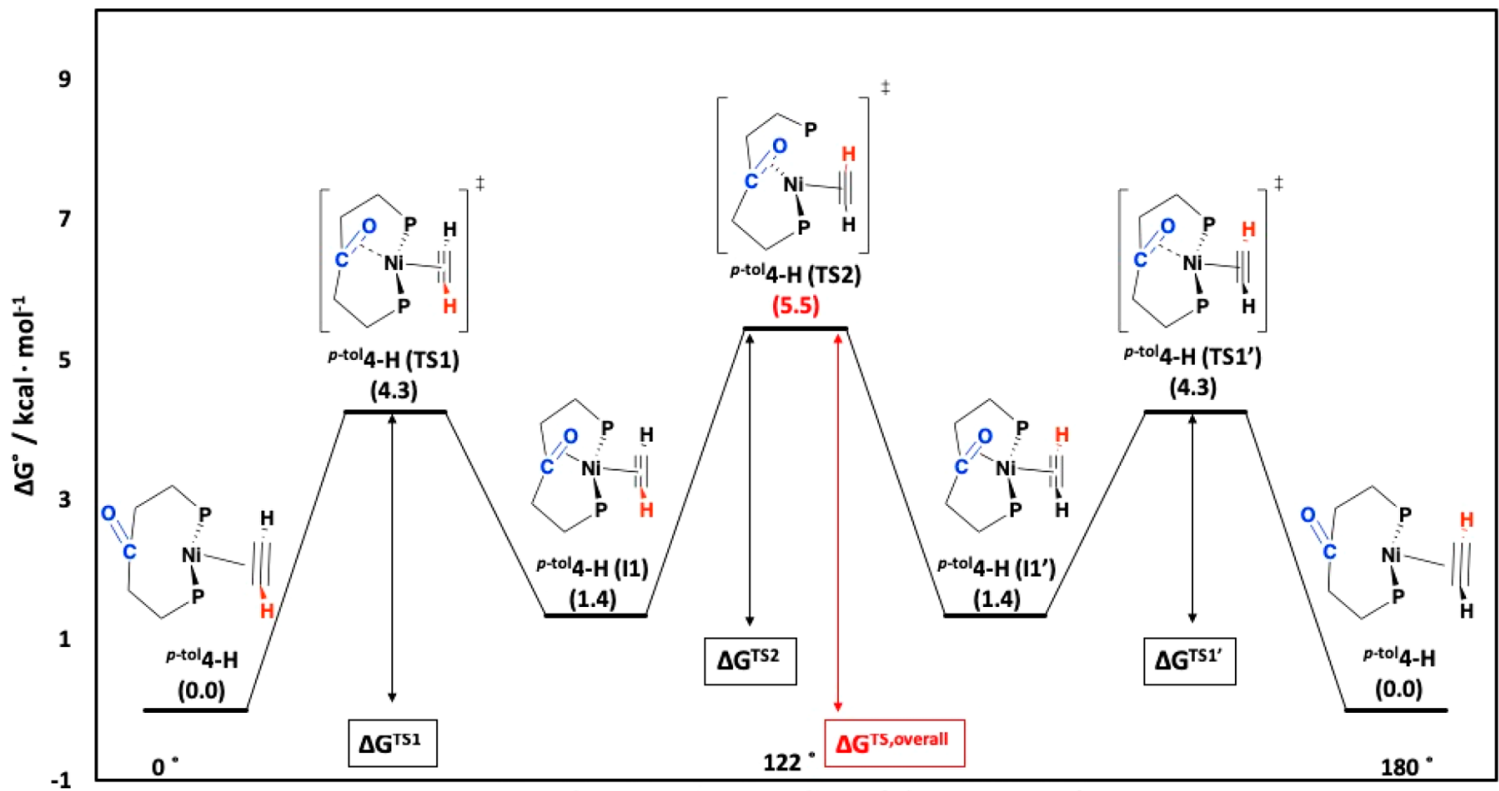

Acetylene Rotation Coordinate $(\angle \mathrm{C} 1-\mathrm{C} 2-\mathrm{Ni}-\mathrm{P} 1)$

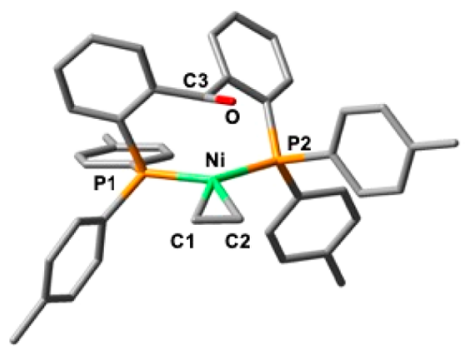

p-tol4-H (TS1)

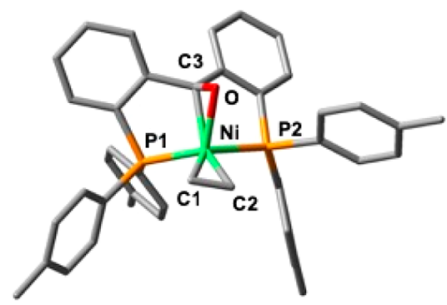

p-tol4-H (I1)

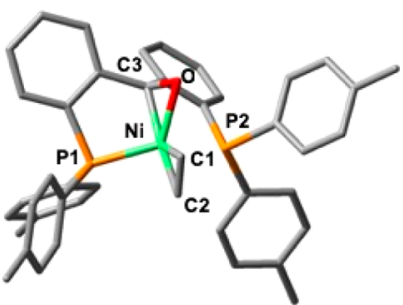

p-tol4-H (TS2)

Figure 6. (top) Energy diagram for the rotation of acetylene around the Ni-coordination plane $(\angle \mathrm{C} 1-\mathrm{C} 2-\mathrm{Ni}-\mathrm{P} 1)$ of ${ }^{p \text {-tol }} 4-\mathrm{H}$ through two different transition states, ${ }^{p \text {-tol }} 4$-H(TS1) $={ }^{p \text {-tol }} 4$-H(TS1 $\left.1^{\prime}\right)$ and ${ }^{p \text {-tol }} 4$-H(TS2), and one intermediate, ${ }^{p \text {-tol }} 4$-H(I1) $=p^{p \text {-tol }} 4$-H( (1 $\left.^{\prime}\right)$. Numbers in parentheses are $G^{\circ}$ values given in $\mathrm{kcal} / \mathrm{mol} . \Delta G^{\mathrm{TS} 1}=4.3 \mathrm{kcal} / \mathrm{mol} . \Delta G^{\mathrm{TS} 1 \prime}=2.9 \mathrm{kcal} / \mathrm{mol} . \Delta G^{\mathrm{TS} 2}=4.1 \mathrm{kcal} / \mathrm{mol} . \Delta G^{\mathrm{TS}, \text { overall }}=5.5 \mathrm{kcal} / \mathrm{mol}$.

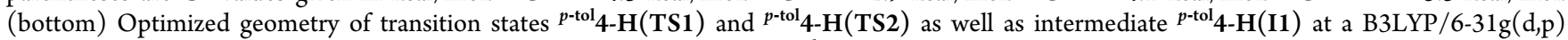

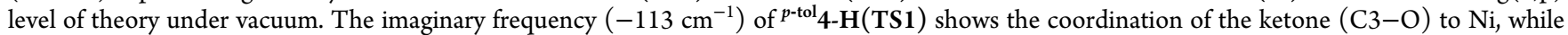
the imaginary frequency $\left(-95 \mathrm{~cm}^{-1}\right)$ of ${ }^{p \text {-tol }} 4-\mathrm{H}$ (TS2) is the rotation of acetylene around the $\mathrm{C} 1-\mathrm{C} 2-\mathrm{Ni}-\mathrm{P} 1$ torsion angle. Selected bond lengths $[\AA]$ for ${ }^{p \text {-tol }} 4-\mathrm{H}(\mathrm{TS} 1)$ : $\mathrm{C} 3-\mathrm{O}=1.25 ; \mathrm{Ni}-\mathrm{C} 3=2.35 ; \mathrm{Ni}-\mathrm{O}=2.55 ; \mathrm{Ni}-\mathrm{P} 1=2.17 ; \mathrm{Ni}-\mathrm{P} 2=2.19 ; \mathrm{C} 1-\mathrm{C} 2=1.27$. Selected bond lengths $[\AA]$ for

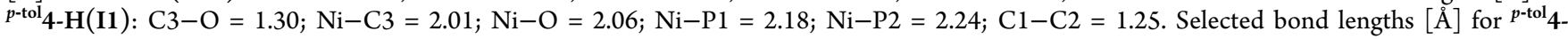
$\mathrm{H}(\mathrm{TS} 2): \mathrm{C} 3-\mathrm{O}=1.32 ; \mathrm{Ni}-\mathrm{C} 3=1.96 ; \mathrm{Ni}-\mathrm{O}=1.92 ; \mathrm{Ni}-\mathrm{P} 1=2.14 ; \mathrm{Ni}-\mathrm{P} 2=2.45 ; \mathrm{C} 1-\mathrm{C} 2=1.24$. Hydrogen atoms have been omitted for clarity.

$\mathrm{H}-\mathrm{C} \equiv \mathrm{C}-\mathrm{CH}_{2} \mathrm{OMe}$ with $\mathrm{Ni}$. In addition, the second species observed at low temperature may be either a diastereomeric conformer or an isomeric structure in which the central ketone fragment binds to the nickel center.

The fast rotation of the alkyne fragment in complex ${ }^{p \text {-tol } 4-\mathbf{P h}}$ contrasts with the observed behavior of the tricoordinate ${ }^{\mathrm{Ph}} \mathbf{6}$ Ph. DFT calculations on the acetylene complex ${ }^{p \text {-tol } 4-H}$ reveal that the rotation of acetylene is assisted by transient coordination of the ketone moiety to the $\mathrm{Ni}$ center, resulting in a low overall rotation energy barrier of $5.5 \mathrm{kcal} / \mathrm{mol}$ (Figure 6). The first transition state, ${ }^{p \text {-tol }} 4-\mathbf{H}$ (TS1), from the unbound ketone state $p^{p \text {-tol }} 4-\mathrm{H}$ to the bound state ${ }^{p \text {-tol }} 4-\mathrm{H}(\mathrm{I1})$, is characterized by the coordination of the ketone moiety $(\nu=$ $\left.-113 \mathrm{~cm}^{-1} ; \Delta G^{\mathrm{TS} 1}=4.3 \mathrm{kcal} / \mathrm{mol}\right)$ to generate a fourcoordinate intermediate ${ }^{p \text {-tol }} \mathbf{4 - H}(\mathbf{I} 1)$. The second transition state, ${ }^{p \text {-tol }} 4-\mathbf{H}$ (TS2), corresponds to the rotation of acetylene $\left(\nu=-95 \mathrm{~cm}^{-1} ; \Delta G^{\mathrm{TS} 2}=4.1 \mathrm{kcal} / \mathrm{mol}\right)$ accompanied by partial decoordination of one of the phosphine arms. The low overall energy barrier of $\Delta G^{\mathrm{TS} \text {,overall }}=5.5 \mathrm{kcal} / \mathrm{mol}$ is in qualitative agreement with the observed fast rotation of alkynes at room temperature. For comparison, a rotation energy barrier of 25.0 $\mathrm{kcal} / \mathrm{mol}$ was calculated for the rotation of acetylene in the diphosphine ether complex ${ }^{\mathrm{Ph}} \mathbf{6 - H}$ (Supporting Information; Figure S112), in qualitative agreement with the observation of two ${ }^{31} \mathrm{P}$ NMR signals for ${ }^{\mathrm{Ph}} \mathbf{6}-\mathrm{Ph}$ up to $100{ }^{\circ} \mathrm{C}$.

The differences in electronic and structural properties of $\mathrm{Ni}$-alkyne complexes ${ }^{p \text {-tol }} \mathbf{4 - P h}-{ }^{\mathrm{Ph}} \mathbf{6}$-Ph were further investigated by DFT calculations (geometry optimization and NBO analysis), as summarized in Table 2 . The optimized geometries

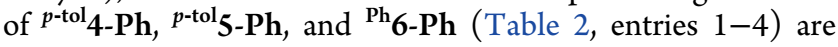
consistent with the obtained crystal structures in which the $\mathrm{C} 1-\mathrm{C} 2$ bond length, $\mathrm{C} 1-\mathrm{C} 2-\mathrm{C} 3$ angle and $\mathrm{Ni}-\mathrm{C} 1$ and $\mathrm{Ni}-$ $\mathrm{C} 2$ distances calculated for ${ }^{p \text {-tol }} \mathbf{5}$ - $\mathbf{P h}$ indicate weaker activation of the $\mathrm{HC} \equiv \mathrm{CPh}$ substrate. Accordingly, Wiberg bond indexes (WBIs) calculated in the NBO basis at a B3LYP/def2TZVP level of theory show that the binding of phenylacetylene induces a decrease of the C1-C2 WBI (Table 2, entry 5) from 2.82 to 2.30 in $^{p \text {-tol }} \mathbf{5}$-Ph versus 2.20 in ${ }^{p \text {-tol }} 4-\mathbf{P h}$ and 2.17 in 
Table 2. Selected DFT Bond Distances and Angles and Wiberg Bond Indexes (WBI) ${ }^{a}$

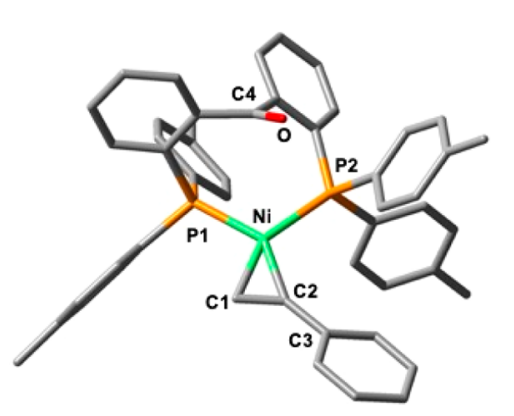

$\left[\left({ }^{p-t o l} \mathrm{~L} 1\right) \mathrm{Ni}(\mathrm{HC} \equiv \mathrm{CPh})\right]\left({ }^{p-\text { tol }}\right.$-Ph $)$

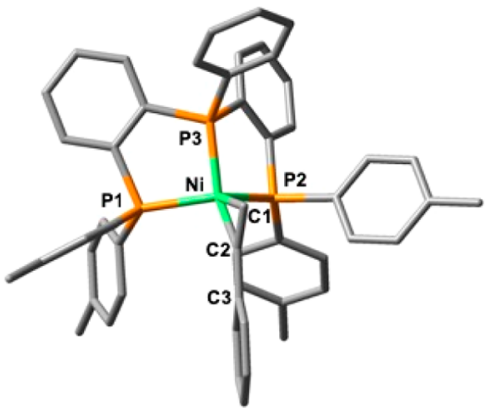

$\left[\left(p^{\text {-tol }} \mathbf{L} 2\right) \mathrm{Ni}(\mathrm{HC} \equiv \mathrm{CPh})\right]($ p-tol $5-\mathrm{Ph})$

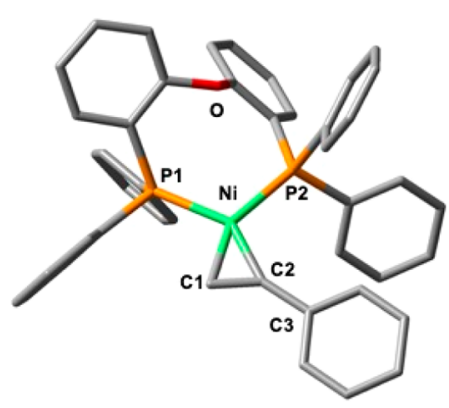

$\left[\left(\mathrm{Ph}^{2} \mathbf{)}\right) \mathrm{Ni}(\mathrm{HC} \equiv \mathrm{CPh})\right]\left(\mathrm{Ph}^{\mathrm{6}-\mathrm{Ph}}\right)$

\section{entry}

property

\begin{abstract}
$\mathrm{HC} \equiv \mathrm{CPh}$
\end{abstract}
${ }^{p-\text { tol }} 4-\mathrm{Ph}$

DFT Bond Length and Angle [in $\AA$ and deg]

$\mathrm{C} 1-\mathrm{C} 2$
$\angle \mathrm{C} 1-\mathrm{C} 2-\mathrm{C} 3$
$\mathrm{Ni}-\mathrm{C} 1$

$\mathrm{Ni}-\mathrm{C} 2$

$\mathrm{C} 1-\mathrm{C} 2$

$\mathrm{Ni}-\mathrm{C} 1$

$\mathrm{Ni}-\mathrm{C} 2$

1.21
180

1.29

141

1.84

1.89

Wiberg Bond Index (WBI)

2.82

2.20

0.43

0.39
${ }^{\mathrm{Ph}}$ 6-Ph

$\begin{array}{ll}1.26 & 1.30 \\ 150 & 141 \\ 1.94 & 1.84 \\ 1.97 & 1.89 \\ & \\ 2.30 & 2.17 \\ 0.31 & 0.42 \\ 0.31 & 0.39\end{array}$

${ }^{a}$ Geometry optimizations of $\left[\left({ }^{p}\right.\right.$-tol $\left.\left.\mathbf{L} \mathbf{1}\right) \mathrm{Ni}(\mathrm{HC} \equiv \mathrm{CCPh})\right]\left({ }^{p \text {-tol }} \mathbf{4}\right.$-Ph $),\left[\left({ }^{p \text {-tol }} \mathbf{L} \mathbf{2}\right) \mathrm{Ni}(\mathrm{HC} \equiv \mathrm{CPh})\right]\left({ }^{p \text {-tol }} \mathbf{5}\right.$ - $\left.\mathbf{P h}\right)$, and $\left[\left({ }^{\mathrm{Ph}} \mathbf{L} \mathbf{3}\right) \mathrm{Ni}(\mathrm{HC} \equiv \mathrm{CPh})\right]\left({ }^{\mathbf{P h}} \mathbf{6}-\mathbf{P h}\right)$ were performed at a B3LYP/6-3 $\lg (\mathrm{d}, \mathrm{p})$ level of theory. WBIs were calculated by NBO analysis at a B3LYP/def2TZVP level of theory from the optimized geometries. Hydrogen atoms have been omitted for clarity.

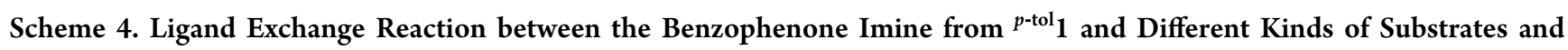
Coligands<smiles>O=P(O)(c1ccccc1)N(c1ccccc1)P(c1ccccc1)c1ccccc1-c1ccccc1</smiles>
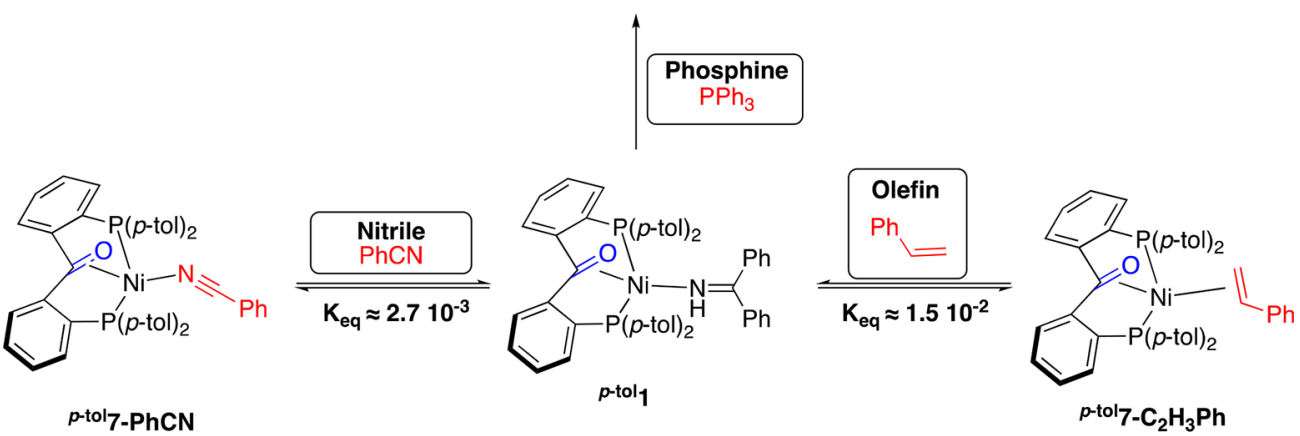

$$
\mathrm{K}_{\text {eq }} \approx 6.1 \mathbf{1 0}^{-3}
$$


Table 3. Catalytic Comparison for the Cyclotrimerization of Phenylacetylene (8), Methyl Propiolate (9), and Methyl Propargyl Ether (10), Using Catalysts ${ }^{p \text {-tol } 1}$ to ${ }^{\mathrm{Ph}} 3$, and the ${ }^{\mathrm{Ph}} \mathrm{L} 4$ System ${ }^{a}$

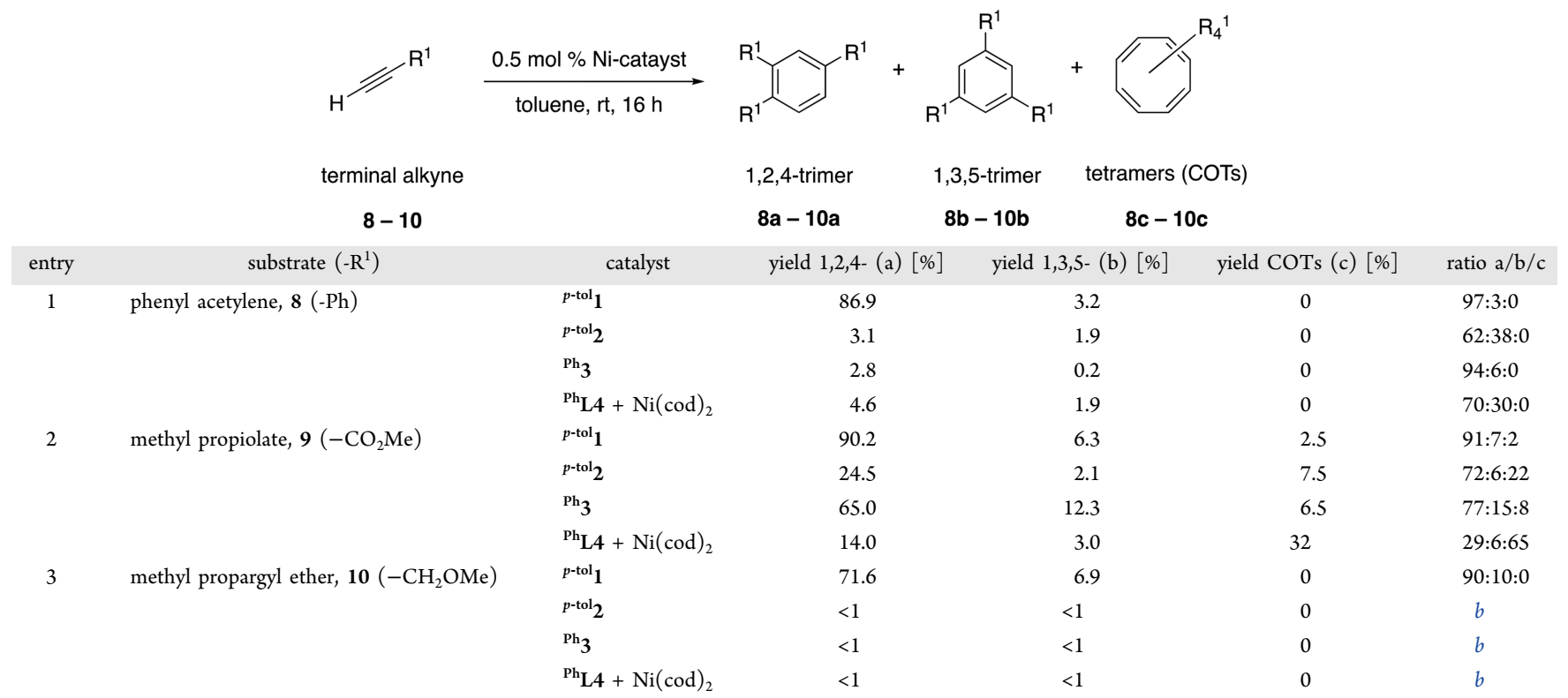

${ }^{a}$ Similar results were obtained when the active catalysts were generated in situ using ${ }^{p \text {-tol }} \mathbf{L} \mathbf{1}$ to ${ }^{\mathrm{Ph}} \mathbf{L} 3,1$ equiv of $\mathrm{Ni}(\operatorname{cod})_{2}$, and the corresponding terminal alkyne (Supporting Information; Table S4). Yields and ratios were averaged over two runs (Supporting Information; Tables S2 and S3). Yields are isolated yields. Ratios were determined by ${ }^{1} \mathrm{H} \mathrm{NMR} .{ }^{b}$ For systems ${ }^{p \text {-tol }} \mathbf{2},{ }^{\mathrm{Ph}} 3$, and ${ }^{\mathrm{Ph}} \mathrm{L} 4$, only trace amounts of products $10 \mathrm{a}$ and $\mathbf{1 0 b}$ were detected in which an accurate determination of the ratio between the two regio-isomers was not possible.

Ph6-Ph. The smaller $\mathrm{Ni}-\mathrm{C} 1$ and $\mathrm{Ni}-\mathrm{C} 2$ WBIs (Table 2,

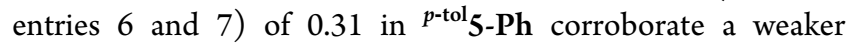
orbital interaction between the $\mathrm{HC} \equiv \mathrm{CPh}$ ligand and the $\mathrm{Ni}$ center in the triphosphine complex ${ }^{p \text {-tol }} \mathbf{5}$-Ph compared ${ }^{p \text {-tol }} \mathbf{4}$ $\mathbf{P h}$ (WBIs of 0.43 and 0.39 ) and ${ }^{\mathrm{Ph}} \mathbf{6 - P h}$ (WBIs of 0.42 and $0.39)$.

In summary, we showed in this section that ligands

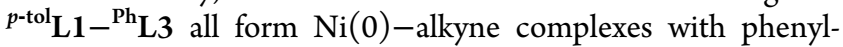
acetylene. The triphosphine ${ }^{p \text {-tol }} \mathbf{L} \mathbf{2}$ binds in a tridentate mode in ${ }^{p \text {-tol }} 5-\mathbf{R}^{1}$, resulting in unusually weak activation of the alkyne, while ${ }^{\mathrm{Ph}} \mathbf{L} \mathbf{3}$ acts as a bidentate ligand in the tricoordinate ${ }^{{ }^{\mathrm{Ph}}} \mathbf{6}$ $\mathbf{R}^{\mathbf{1}}$, in which a strong $\mathrm{Ni}-$ alkyne interaction causes a high rotation barrier around the $\mathrm{Ni}-$ alkyne axis. The hemilabile ligand ${ }^{p \text {-tol }} \mathbf{L} \mathbf{1}$ is able to sample both binding modes: it binds as a bidentate ligand in ${ }^{p \text {-tol }} \mathbf{4 - R ^ { 1 }}$, resulting in a similar geometry as that of ${ }^{{ }^{\mathbf{h}}} \mathbf{6}-\mathbf{R}^{\mathbf{1}}$, but the observed low rotation barrier around the Ni-alkyne axis is indicative of the ability of ${ }^{p \text {-tol }} \mathbf{L} \mathbf{1}$ to transiently adopt a tridentate mode.

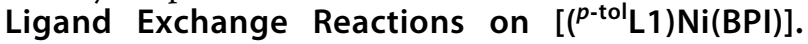
Having observed that the ketone moiety decoordinates upon binding of an alkyne to the $\left({ }^{p \text {-tol }} \mathbf{L} \mathbf{1}\right) \mathrm{Ni}$ fragment, we sought to probe the generality of this hemilabile behavior. NMR-tube experiments showed that the BPI coligand can be reversibly exchanged with several types of ligands, such as benzonitrile $\left(K_{\mathrm{eq}} \approx 2.7 \times 10^{-3} ; \Delta G_{298.15} \approx 3.5 \mathrm{kcal} / \mathrm{mol}\right)$, styrene $\left(K_{\mathrm{eq}} \approx\right.$ $\left.1.5 \times 10^{-2} ; \Delta G_{298.15} \approx 2.4 \mathrm{kcal} / \mathrm{mol}\right)$, and diphenylacetylene $\left(K_{\mathrm{eq}} \approx 6.1 \times 10^{-3} ; \Delta G_{298.15} \approx 3.1 \mathrm{kcal} / \mathrm{mol}\right)$, as depicted in Scheme 4 (see Supporting Information for more details). The proposed mode of coordination of the benzonitrile ligand in $p$-tol7-PhCN relies on DFT calculations, which predict the $\eta^{2}$ (C,N) binding to be $9.4 \mathrm{kcal} / \mathrm{mol}$ energetically less stable than the $\eta^{1}-(\mathrm{N})$ coordination mode (Supporting Information; Table $\mathrm{S} 11)$. With triphenylphosphine, the exchange is irreversible. In every case, with the exception of diphenylacetylene, ${ }^{13} \mathrm{C}$ NMR demonstrates that the ketone moiety is still bound to nickel (no peaks between 190 and $210 \mathrm{ppm}$ ). The coordinated ketone appears at $120.4 \mathrm{ppm}\left(\mathrm{dt},{ }^{2} J_{\mathrm{C}, \mathrm{P}}=13.8 \mathrm{~Hz},{ }^{2} J_{\mathrm{C}, \mathrm{P}}=4.4\right.$

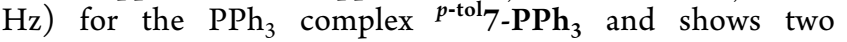
chemically different methyl groups from the para-tolyl substituents at $1.97 \mathrm{ppm}(\mathrm{s}, 6 \mathrm{H})$ and $1.96 \mathrm{ppm}(\mathrm{s}, 6 \mathrm{H})$ in ${ }^{1} \mathrm{H}$ NMR and at 21.2 and $21.1 \mathrm{ppm}$, respectively, in ${ }^{13} \mathrm{C}$ NMR. Unfortunately for the PhCN complex ${ }^{p \text {-tol } 7-P h C N}$ and for the styrene complex ${ }^{p \text {-tol }} 7-\mathrm{C}_{2} \mathrm{H}_{3} \mathrm{Ph}$, the carbon resonance of the bound ketone could not be assigned, as the weak signal is covered by those of the substrate and the starting complex ${ }^{p \text {-tol }} 1$. However, for all of these complexes, ${ }^{1} \mathrm{H}$ NMR shows that the two methyl groups from the para-tolyl substituents on the

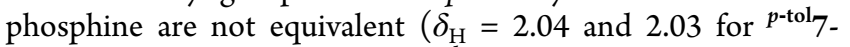
PhCN, 2.05 and 2.01 for $\left.{ }^{p \text {-tol }} 7-\mathrm{C}_{2} \mathrm{H}_{3} \mathbf{P h}\right)$, which is also

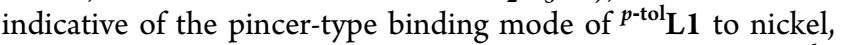
with the central ketone moiety bound, as observed with ${ }^{p \text {-tol } 1}$ and ${ }^{p \text {-tol }} 7-\mathbf{P P h}_{3}$ and in opposition to ${ }^{p \text {-tol }} \mathbf{4}-\mathbf{R}^{1}$. With the diphenylacetylene complex ${ }^{p \text {-tol } 7-\mathbf{C}_{2}} \mathbf{P h}_{2}$, the absence of interaction of the ketone is demonstrated by the presence of a triplet at 198.3 of ${ }^{3} \mathrm{~J}_{\mathrm{C}, \mathrm{P}}=4.7 \mathrm{~Hz}$ and with all four $\mathrm{C}-\mathrm{H}_{3}$ being chemically equivalent $\left(\delta_{\mathrm{H}}=1.95 ; \delta_{\mathrm{C}}=21.2\right)$, similar to the closely related terminal alkyne complex ${ }^{p \text {-tol }} 4-\mathrm{CH}_{2} \mathrm{OMe}$. The difference in coordination between olefin and alkyne complexes is consistent with alkynes being stronger $\pi$ acceptors than olefins and illustrates the ability of the diphosphine ketone framework to adapt its binding mode to the electronic properties of a substrate.

Catalytic Comparison. Having shown that the hemilabile diphosphine-ketone ligand ${ }^{p \text {-tol }} \mathbf{L} \mathbf{1}$ is able to adapt its coordination mode to a substrate bound to $\mathrm{Ni}(0)$, we turn to its performance as a supporting ligand in the cyclotrimerization of alkynes. We compare hemilabile ${ }^{p \text {-tol } 1} \mathbf{1}$ with the strong tridentate ${ }^{p \text {-tol } 2}$ and the bidentate ${ }^{\mathrm{Ph}_{3}}$ to delineate specific effects of the hemilabile behavior. In addition, the smaller bite-angle rac-BINAP $\left({ }^{\mathrm{Ph}} \mathbf{L} 4\right)$ system was also tested. ${ }^{58}$ 
Table 4. Additional Substrates for Alkyne Cyclotrimerization Catalyzed by ${ }^{p \text {-tol }} 1^{c}$

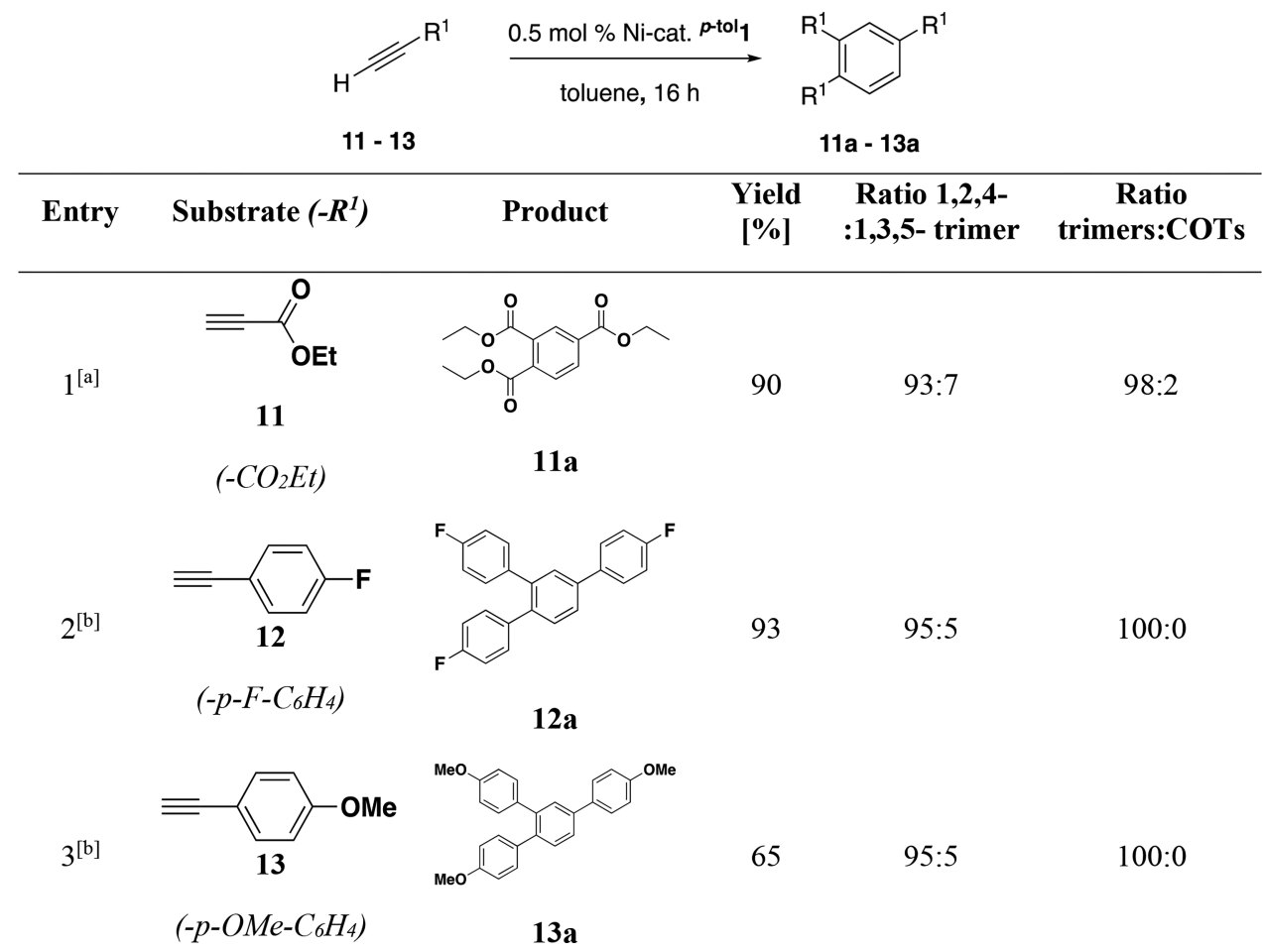

${ }^{a}$ Reaction temperature $=$ room temperature. ${ }^{b}$ Reaction temperature $=50{ }^{\circ} \mathrm{C} .{ }^{c}$ Reported yields are isolated yield for the $1,2,4$-trisubstituted benzene isomer. Isomeric ratios between the 1,2,4 and 1,3,5 isomer and between the trimers and tetramers were determined by ${ }^{1} \mathrm{H}$ NMR. Yields and ratios were averaged over two runs (Supporting Information; Table S5). Catalytic method $A$ was applied (see experimental part).

Terminal alkyne substrate with diverse electronic properties were selected for comparison: first, phenylacetylene $(\mathbf{8})$, as a standard aryl-substituted substrate; second, methyl propiolate (9), as electron poor alkyne and since its additional oligomerization into cyclooctatetraene (COT) regio-isomers is commonly observed; ${ }^{59}$ and finally, methyl propargyl ether (10) as an electron rich substrate. The catalytic outcome of the reaction of these alkynes with $0.5 \mathrm{~mol} \%$ of isolated BPIcatalysts ${ }^{p \text {-tol }} 1,{ }^{p \text {-tol }} \mathbf{2}$, and ${ }^{\mathrm{Ph}} \mathbf{3}$ and in situ generated ${ }^{\mathrm{Ph}} \mathbf{L} \mathbf{4}$ catalyst at room temperature was analyzed. The organic products were separated from the reaction mixture as a mixture of 1,2,4- (a) and $1,3,5-$ (b) substituted arenes, in addition to cyclotetramerization products (when applicable), COTs (c), in which their relative ratio was determined by ${ }^{1} \mathrm{H}$ NMR, as described in Table 3. To exclude a particular role of the BPI or cod coligands, the active catalysts were also generated in situ by mixing ${ }^{p \text {-tol }} \mathbf{L} 1-{ }^{\mathrm{Ph}} \mathbf{L} 3$ with 1 equiv of $\mathrm{Ni}(\operatorname{cod})_{2}$ and 200 equiv of the corresponding alkyne. The reactions display similar activity as the values reported in Table 3 (Supporting Information;

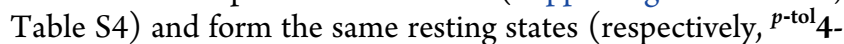

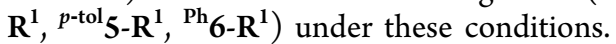

Mixing phenylacetylene (8) with $0.5 \mathrm{~mol} \%$ of ${ }^{p \text {-tol } 1} \mathbf{1}$ in toluene at room temperature for $16 \mathrm{~h}$ yields $86.9 \%$ of $1,2,4-$ triphenylbenzene (8a) and $3.2 \%$ of 1,3,5-triphenylbenzene $(\mathbf{8 b})$, in an isomeric ratio of 97:3. Under the same conditions, the complexes ${ }^{p \text {-tol } 2}$ and ${ }^{\mathrm{Ph}_{3}}$ and the ${ }^{\mathrm{Ph}} \mathrm{L} 4-\mathrm{Ni}$ system afforded only low yields of $8 \mathrm{a}: 3.1 \%, 2.8 \%$, and $4.6 \%$, respectively. In addition, a lower regioselectivity toward the 1,2,4 isomers of $62: 38$ and 70:30 compared to the 1,3,5 isomer was observed with ${ }^{p \text {-tol }} \mathbf{2}$ and ${ }^{\mathrm{Ph}} \mathbf{L} 4+\mathrm{Ni}(\operatorname{cod})_{2}$, respectively. With the more electron poor alkyne methyl propiolate (9), the reaction

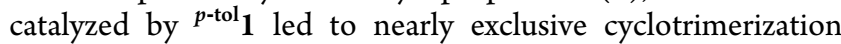

with the formation of the 1,2,4-isomer 9a in a ratio of 91:7 compared to its $1,3,5$ analogue $9 b$ and with a yield of $90.2 \%$. Only small amounts of the cyclotetramers, tetramethylcyclooctatetraene-tetracarboxylates (9c) are observed, in a ratio of 2:98 compared to the trimerization products. In contrast, the yields obtained for $9 \mathbf{a}$ with the other catalysts in the series range from $14.0 \%$ to $65.0 \%$. More importantly, catalysts ${ }^{p \text {-tol }} \mathbf{2}$ and ${ }^{\mathrm{Ph}_{3}}$ and the ${ }^{\mathrm{Ph}} \mathrm{L} \mathbf{4}$ system display lower selectivity. The tridentate triphosphine catalyst ${ }^{p \text {-tol } 2}$ exhibits a regioselectivity of 92:8 (1,2,4-/1,3,5-isomer) and produces cyclotetramers in a 22:78 ratio compared to the cyclotrimerization products. The bidentate systems ${ }^{\mathrm{Ph}_{3}}$ and ${ }^{{ }^{\mathrm{Ph}}} \mathbf{L} \mathbf{4}$ are also less selective and lead to the formation of $9 a$ in $84: 16$ and 82:18, respectively, compared to $1,3,5$-benzene product 9b. The bidentate catalyst ${ }^{\mathrm{Ph}_{3}} \mathbf{3}$ displays good chemoselectivity (92:8) toward cyclotrimerization, whereas the other diphosphine system ${ }^{\mathrm{Ph}} \mathbf{L} \mathbf{4}$ appears to even favor cyclotetramerization products 9c (35:65). Finally, methyl propargyl ether (10), bearing an electron rich substituent was also tested and afforded lower yields than $\mathbf{8}$ and $\mathbf{9}$. With the ketone-based

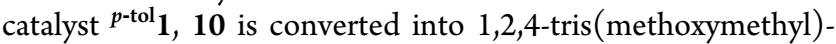
benzene (10a) in a yield of $71.6 \%$, and the regioselectivity toward 10a remains high (90:10). Under the same conditions, the other complexes showed poor activity (less than $1 \%$ total yield). Overall, for the three examined substrates, catalyst ${ }^{p \text {-tol }} \mathbf{1}$, bearing the hemilabile diphosphine benzophenone ligand ${ }^{p \text {-tol }} \mathbf{L 1}$, was shown to be more active and more selective toward the formation of the 1,2,4-trisubstituted benzene product.

Additional Substrates. In addition to the substrates

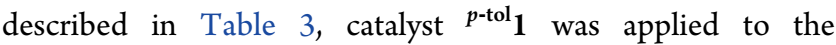
cyclotrimerization of terminal alkynes 11a to 13a with high 
Scheme 5. Proposed Intermediates for the Transition-Metal-Catalyzed $[2+2+2]$ Cyclotrimerization of Acetylene, as Commonly Reported in Literature ${ }^{33}$

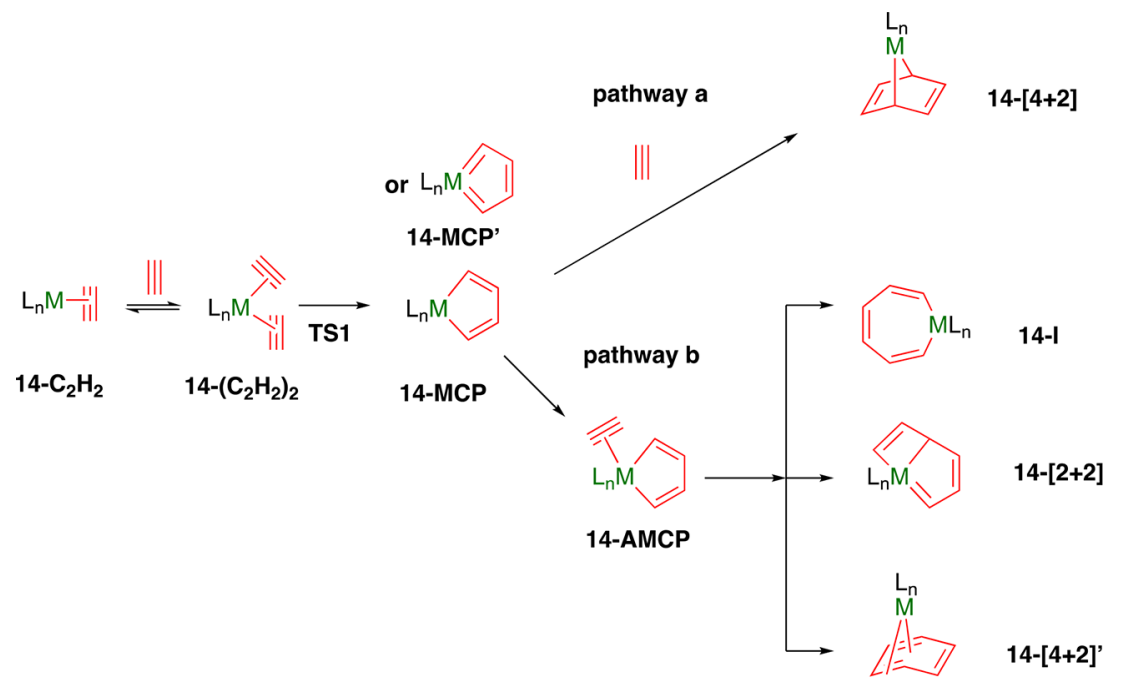

selectivity for 1,2,4-substituted benzenes and in good isolated yields (>65\%, Table 4). Ethyl propiolate (11) (entry 1) affords triethylbenzene-1,2,4-tricarboxylate (11a) at room temperature. At $50{ }^{\circ} \mathrm{C}$, 4-ethynylanisole (13) produces the desired $1,2,4$-cyctrotrimerization product in a lower yield than the weakly electron-withdrawing analogue 1-ethynyl-4-fluorobenzene (12), supporting a preference for electron-withdrawing substrate (entries 2 and 3). The preference for electron poor alkynes is commonly observed in Ni-catalyzed cyclotrimerization of terminal alkynes. ${ }^{37 \mathrm{~m}, \mathrm{v}-\mathrm{y}}$ In comparison with the $\mathrm{Ni}$ catalysts reported in literature, ${ }^{37}$ complex ${ }^{p \text {-tol }} \mathbf{1}$ is a competitive catalyst in terms of activity and regioselectivity (from 90:10 to 97:3). A catalyst loading of ${ }^{p \text {-tol }} \mathbf{1}$ of $0.05 \mathrm{~mol} \%$ mediated the cyclotrimerization of ethyl propiolate (11) into triethylbenzene-1,2,4-tricarboxylate (11a) in $87 \%$ isolated yield, reaching a TON of 1740 after $16 \mathrm{~h}$.

Mechanistic Considerations. The comparison study

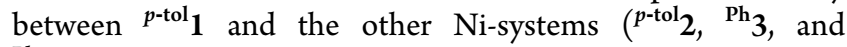
$\left.{ }^{\mathrm{Ph}} \mathrm{L4}\right)$ strongly suggests that the hemilabile $\pi$-acceptor moiety contributes to the high catalytic performance. In this section, the role of the ketone fragment in the improved catalytic performance of ${ }^{p \text {-tol }} \mathbf{1}$ is studied and supported by computational modeling of some targeted compounds. To address the question, an overview of the general mechanism in metalcatalyzed $[2+2+2]$ alkyne cyclotrimerization is discussed first (Scheme 5), followed by differences in reactivity among the three catalysts tested in the comparison study.

Scheme 5 shows a commonly proposed mechanism for the cyclotrimerization of acetylene catalyzed by transition metals. ${ }^{33}$ For base metals, most mechanistic studies have been carried out using cobalt complexes as catalysts. ${ }^{60}$ From the acetylene metal complex 14- $\mathrm{C}_{2} \mathrm{H}_{2}$, the association of a second molecule of acetylene generates complex 14- $\left(\mathrm{C}_{2} \mathrm{H}_{2}\right)_{2}$, which requires an open coordination site in $\mathbf{1 4}-\mathbf{C}_{2} \mathbf{H}_{2}$. Next, the oxidative coupling of the two coordinated alkyne fragments from 14$\left(\mathrm{C}_{2} \mathrm{H}_{2}\right)_{2}$ gives rise to the key metallacyclopentadiene intermediate. This step is generally thought to be rate determining. The metallacyclopentadiene intermediate can be best described as one of two resonance structures, 14-MCP or 14-MCP', depending on the nature of metal complex used. For example Saá et al. calculated that $\mathrm{CpRuCl}(\mathrm{Cp}=$ cyclo- pentadiene)-catalyzed alkyne cyclotrimerization proceeds via 14-MCP', while the cobalt system CpCo proceeds via 14MCP. ${ }^{60 d}$ Late transitions metals tend to favor the concertedoxidative cyclization between two alkynes and the low-valent metal center. ${ }^{60 a}$ However, a stepwise zwitterionic diradical pathway, involving the formation of a $\sigma(\mathrm{C}-\mathrm{C})$ bond and one $\mathrm{Ni}-\mathrm{C}$ bond cannot be excluded. When acetylene is substituted, the formation of the substituted metallacyclopentadiene is of importance as different 14-MCP regio-isomers can be generated. The substituted 14-MCP will thus dictate the overall selectivity toward the product formation of the 1,2,4- or 1,3,5-trisubstituted benzene regio-isomer (more precisely the transition state TS1 between the bisalkyne and metallacyclopentadiene intermediate). ${ }^{61}$ In the last step (insertion of the third alkyne), different mechanisms have been proposed. ${ }^{62}$ The insertion of a third alkyne could either proceed via a Diels-Alder type $[4+2]$ cycloaddition, in which the metal does not participate in the bond formation (Scheme 5 , pathway a), ${ }^{60}$ or with the assistance of the metal, prior to the new $\mathrm{C}-\mathrm{C}$ bond formation (Scheme 5 ; pathway b). 7Metallanorbornadiene $(14-[4+2])^{63}$ is frequently presented as an unstable species and immediately collapses to arene, forming a metal-arene adduct. As regards pathway $b$, the coordination of the third alkyne is followed by either migratory insertion (metallacycloheptatriene 14-I) or $[2+2]$ cycloaddition (cycloadduct 14-[2+2]). These complexes can also be formed in a concerted way, without involving the direct formation of an acetylene metallacyclopentadiene complex 14AMCP, but still with participation of the metal center. It has also been suggested that an additional pathway could occur via an intermolecular $[4+2]$ cycloaddition forming the $\eta^{4}$-bound intermediate, $\mathbf{1 4}-[\mathbf{4}+\mathbf{2}]^{\prime}$. ${ }^{60 \mathrm{~d}}$ Pathway a is likely to happen for strong donor ligands or solvents. ${ }^{60 \mathrm{~d}}$ The insertion of a fourth alkyne (especially if the intermediate formed is 14-I) leads to formation of COT side products. ${ }^{61 a}$ Eventually, the formation of the benzene product happens by either reductive elimination or ligand exchange of benzene with a molecule of acetylene (cycloadduct 14-[2+2] rearranges itself prior to the reductive elimination).

In this overall picture, several effects of the hemilabile $\pi$ -

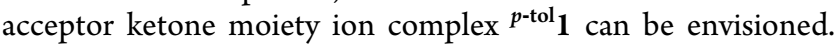
First, the hemilabile interaction of the ketone unit can be 
thought to facilitate the alkyne uptake, especially in

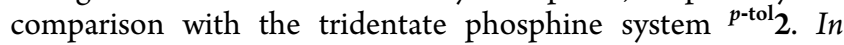
situ NMR spectroscopy experiments with the three complexes

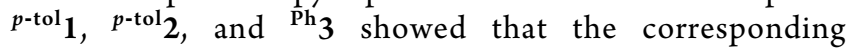

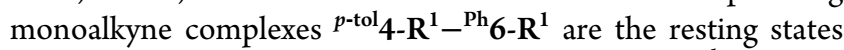
of the catalyst in all cases. For the ketone catalyst ${ }^{p \text {-tol }} \mathbf{1}$ and the bidentate catalysts ${ }^{\mathrm{Ph}^{3}} \mathbf{3}$, these resting states $\left({ }^{p \text {-tol }} \mathbf{4}-\mathbf{R}^{\mathbf{1}}\right.$ and ${ }^{\mathrm{Ph}} \mathbf{6}$ $\mathbf{R}^{1}$ ) are $16 \mathrm{VE}$ species that can readily accept an incoming alkyne molecule, while the corresponding triphosphine complex ${ }^{p \text {-tol }} \mathbf{5}-\mathbf{R}^{1}$ is saturated $(18 \mathrm{VE})$. Most probably, coordination of a second equivalent of alkyne to ${ }^{p \text {-tol }} \mathbf{5}-\mathbf{R}^{1}$ requires decoordination of one of the phosphorus atoms, which is likely to raise the overall reaction barrier and result in lower activity under the same conditions (Supporting Information; Scheme S4). The unique feature of the ketone unit is that the tricoordinate alkyne complex can be accessed directly from the tetracoordinate precursor ${ }^{p \text {-tol }} \mathbf{1}$. A similar process can be thought to happen at the end of the catalytic cycle: the ketone may accelerate product release by transient coordination to $\mathrm{Ni}(0)$, which would explain the lower

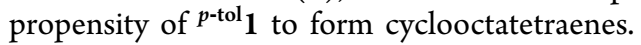

Second, the interaction of the ketone with the nickel center could help to stabilize transient intermediates, such as the key metallacycle 14-MCP species. In order to assess structural differences between the metallacyclopentadiene supported by the different ligands, ${ }^{p \text {-tol }} \mathbf{L} 1,{ }^{p \text {-tol }} \mathbf{L} 2$, and ${ }^{\mathrm{Ph}} \mathbf{L} 3$, we made use of geometry optimization by DFT calculation at a B3LYP/6$3 \lg (\mathrm{d}, \mathrm{p})$ level of theory using acetylene as a model substrate.

Unsurprisingly, the ketone moiety is not bound in the bisalkyne diphosphine benzophenone complex ${ }^{p \text {-tol }} 15-\left(\mathrm{C}_{2} \mathrm{H}_{2}\right)_{2}$. However, geometry optimization of the metallacyclopentadiene intermediate formed by oxidative coupling reveals a pentacoordinate geometry in which the ketone is bound to the metal ( $\left.{ }^{p \text {-tol } 16-M C P, ~ S c h e m e ~} 6\right)$, suggesting hemilabile behavior

Scheme 6. C-C Coupling Reaction Step, as Modeled by DFT Calculations ${ }^{a}$
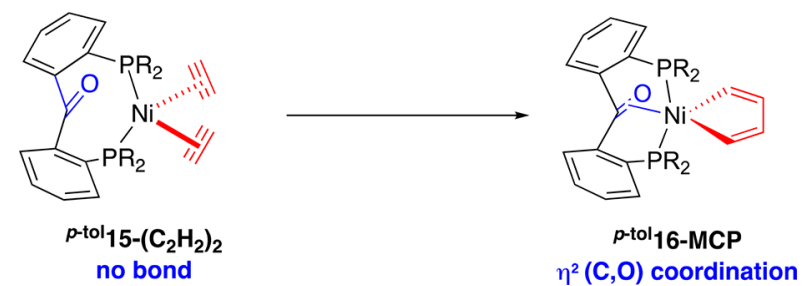

${ }^{a} \mathrm{R}=$ para-tolyl.

of ${ }^{p \text {-tol }} \mathbf{L} \mathbf{1}$ in the key oxidative coupling step. Respective $\mathrm{Ni}-\mathrm{O}$ and $\mathrm{Ni}-\mathrm{C}$ distances of 1.93 and $1.99 \AA$, as well as an elongated $\mathrm{C}-\mathrm{O}$ bond $(1.35 \AA)$, indicate a strong interaction with the metal center. In addition, a $\mathrm{P} 1-\mathrm{Ni}-\mathrm{P} 2$ angle of $171^{\circ}$ results in an approximate trigonal-bipyramidal geometry with apical $\mathrm{P}$ atoms. The fact that the $\mathrm{C}=\mathrm{O}$ unit binds side-on to a formal $\mathrm{Ni}$ (II) center can be surprising at first sight in view of its low propensity to bind to divalent metal halides. ${ }^{24,25}$ This can be understood by a synergistic interaction between a strongly $\sigma$ donating bidentate hydrocarbyl ligand and the strongly $\pi$ accepting ketone ligand in the equatorial plane of the trigonal bipyramid.

For comparison, the geometry of the metallacycles supported by the triphosphine ${ }^{p \text {-tol } L 2}$ and the diphosphine ether ${ }^{\mathrm{Ph}} \mathrm{L} 3$ ligands were also optimized (Figure 7 ). The triphosphine-supported $\left[\left({ }^{p \text {-tol }} \mathbf{L} 2\right) \mathrm{Ni}\left(\mathrm{C}_{4} \mathrm{H}_{4}\right)\right] \quad\left({ }^{p \text {-tol }} \mathbf{1 7 - M C P}\right)$

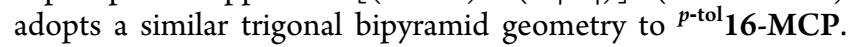
This binding mode may contribute to explain the differences in reactivity with the rac-BINAP system, for which this mode is inaccessible. In contrast, $\left[\left({ }^{\mathrm{Ph}} \mathbf{L} 3\right) \mathrm{Ni}\left(\mathrm{C}_{4} \mathrm{H}_{4}\right)\right]\left({ }^{\mathbf{P h}} \mathbf{1 8 - M C P}\right)$ exhibits a distorted square planar geometry, in which the ${ }^{\mathrm{Ph}} \mathrm{L} 3$ is bound in bidentate manner $(\mathrm{N}-\mathrm{O}=3.20 \AA$; $\mathrm{WBI}(\mathrm{Ni}-$ $\mathrm{O})<0.01)$. Hence, the metallacycle in ${ }^{\mathrm{Ph}} \mathbf{1 8}-\mathbf{M C P}$ is not stabilized by its central ether donor group, ${ }^{64}$ which may partly explain the lower regioselectivity of ${ }^{\mathrm{Ph}_{3}}$ is toward the $1,2,4$ trisubstituted arene cyclotrimerization product. Furthermore, no significant modifications of the $\mathrm{P} 1-\mathrm{O}-\mathrm{P} 2$ bite angle from phenylacetylene analogue ${ }^{\mathrm{Ph}} \mathbf{6}$-Ph are visible.

At this point, we showed that the hemilabile character of the ketone ligand ${ }^{p \text {-tol }} \mathbf{L} \mathbf{1}$ contributes to higher activity and selectivity in the cyclotrimerization of terminal alkynes. The combination of the two effects presented in this section, that is, decoordination and coordination of the $\mathrm{C}=\mathrm{O}$ unit to assist the substrate uptake and stabilize the key metallacyclopentadiene intermediate, can explain its superior performance.

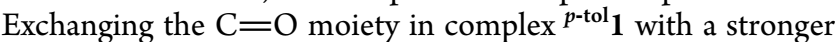
donor atom, like a phosphine group $(\mathrm{P}-\mathrm{Ph})$ or with a bidentate ligand ( $\mathrm{O}$ as central atom) decreases either the activity or the selectivity of the overall process.

Therefore, based on the computational and experimental observations obtained from this study, a simplified catalytic cycle is proposed for the cyclotrimerization of terminal alkynes catalyzed by the nickel diphosphine benzophenone system (Scheme 7 ). The resting state, ${ }^{p \text {-tol }} \mathbf{4}-\mathbf{R}^{1}$, can be generated by ligand exchange from ${ }^{p \text {-tol } 1}$ or in situ from the ligand and $\mathrm{Ni}(\operatorname{cod})_{2}(1)$. The in situ system and ${ }^{p \text {-tol }} \mathbf{1}$ operate at similar rates of product formation under the same tested conditions (similar percentage of isolated yields), showing that the dissociation of the coligand (cod vs BPI) and competitive binding with the metal center does not affect the final yields, as long as ${ }^{p \text {-tol }} \mathbf{4}-\mathbf{R}^{1}$ can be formed. At this step, the ketone is not bound, which facilitates coordination of the second alkyne molecule to generate Ni-bisalkyne ${ }^{p \text {-tol }} \mathbf{1 5}-\left(\mathbf{C}_{2} \mathbf{H R}^{\mathbf{1}}\right)_{2}$ (2). The next step (3) involves the $\mathrm{C}-\mathrm{C}$ oxidative coupling, which is coupled to coordination of the ketone to nickel in $\eta^{2}$-fashion. This interaction may favor the formation of the 2,5disubstituted metallacyclopentadiene ${ }^{p \text {-tol }} \mathbf{1 6}-\mathrm{MCP}-\mathrm{R}^{1}$. The $\mathrm{R}^{1}$ substituents have been arbitrarily positioned in 2,5 positions as they promote the selective formation of the 1,2,4-trisubstituted benzene. From this intermediate, the insertion of the third alkyne to form the final benzene product could go via either [ 4 $+2]$ cycloaddition, migratory insertion, or $[2+2]$ cycloaddition, followed by reductive elimination of the trisubsti-

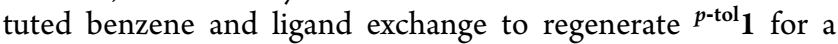
new turnover (4). Throughout the reaction coordinate, the ligand can adapt its geometry by the labile interaction of $\mathrm{C}=\mathrm{O}$ to $\mathrm{Ni}$ and stabilize intermediates.

\section{CONCLUSIONS}

In conclusion, we have reported here the synthesis and characterizations of $\mathrm{Ni}(0)$ complexes, incorporating a diphosphine ketone $\left({ }^{p \text {-tol }} \mathbf{L} \mathbf{1}\right)$, trisphosphine $\left({ }^{p \text {-tol }} \mathbf{L} 2\right)$, and diphosphine ether $\left({ }^{\mathrm{Ph}} \mathbf{L} \mathbf{3}\right)$ ligand, in which the binding mode of the stabilizing imine or alkyne coligand can change according to the structural and electronic characteristics of the supporting ligand. The characterization of $\left[\left({ }^{p \text {-tol }} \mathbf{L} 2\right) \mathrm{Ni}\right.$ $(\mathrm{HC} \equiv \mathrm{CPh})]\left({ }^{p \text {-tol }} 5\right.$ - $\left.\mathbf{P h}\right)$ provides a rare example of weak activation of alkynes by nickel complexes, attributed to its 


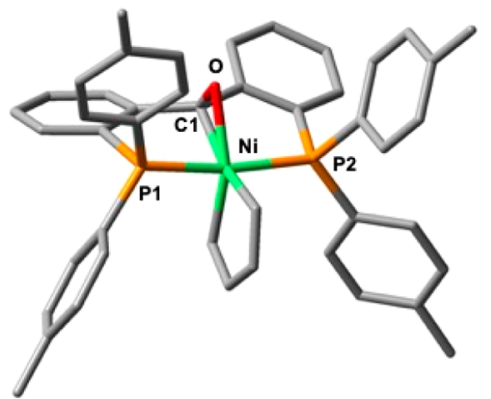

$\left[\left({ }^{p-t o l} \mathrm{~L} 1\right) \mathrm{Ni}\left(\mathrm{C}_{4} \mathrm{H}_{4}\right)\right] \mathbf{( p}^{(\text {-tol } 16-\mathrm{MCP})}$

C1-0: $1.35 \AA$

$\mathrm{Ni}-0: 1.93 \AA$

Ni-C1: $1.99 \AA$

Ni-P1: $2.18 \AA$

Ni-P2: $2.19 \AA$

Ł P1-Ni-P2: $171^{\circ}$

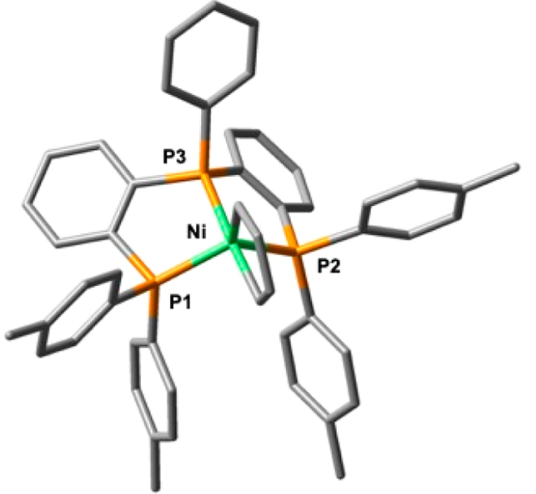

$\left[\left({ }^{p-t o l} \mathrm{~L} 2\right) \mathrm{Ni}\left(\mathrm{C}_{4} \mathrm{H}_{4}\right)\right]\left(\right.$ (p-tol17-MCP) $^{-}$

Ni-P1: $2.23 \AA$

Ni-P2: $2.20 \AA$

Ni-P3: $2.16 \AA$

\ P1-Ni-P3: $117^{\circ}$

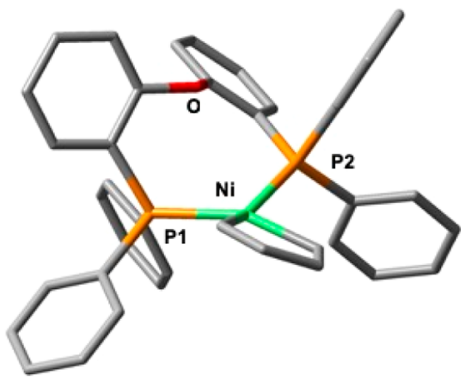

$\left[\left({ }^{\mathrm{Ph} L 3}\right) \mathrm{Ni}\left(\mathrm{C}_{4} \mathrm{H}_{4}\right)\right]\left({ }^{\mathrm{Ph} 18-\mathrm{MCP})}\right.$

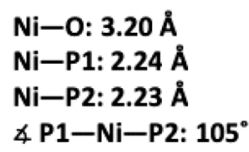

$\mathrm{Ni}-\mathrm{P} 1: 2.24 \AA$

$\Varangle$ P1-Ni-P2: $105^{\circ}$

Figure 7. C-C coupling reaction step. Comparison of metallacyclopentadiene molecular structures bearing the ${ }^{p \text {-tol }} \mathbf{L 1},{ }^{p \text {-tol }} \mathbf{L} 2$, and ${ }^{\mathrm{Ph}} \mathbf{L} 3$ ligands, optimized at a B3LYP/6-31g $(\mathrm{d}, \mathrm{p})$ level of theory. Hydrogen atoms have been omitted for clarity.

Scheme 7. Proposed Simplified Catalytic Cycle for Cyclotrimerization of Terminal Alkynes Catalyzed by $\left[\left({ }^{p-t o l} \mathrm{L1}\right) \mathrm{Ni}(\mathrm{BPI})\right]$ or by in Situ Generation of the Active Intermediate with ${ }^{p \text {-tol }} \mathrm{L1}+\mathrm{Ni}(\operatorname{cod})_{2}{ }^{a}$
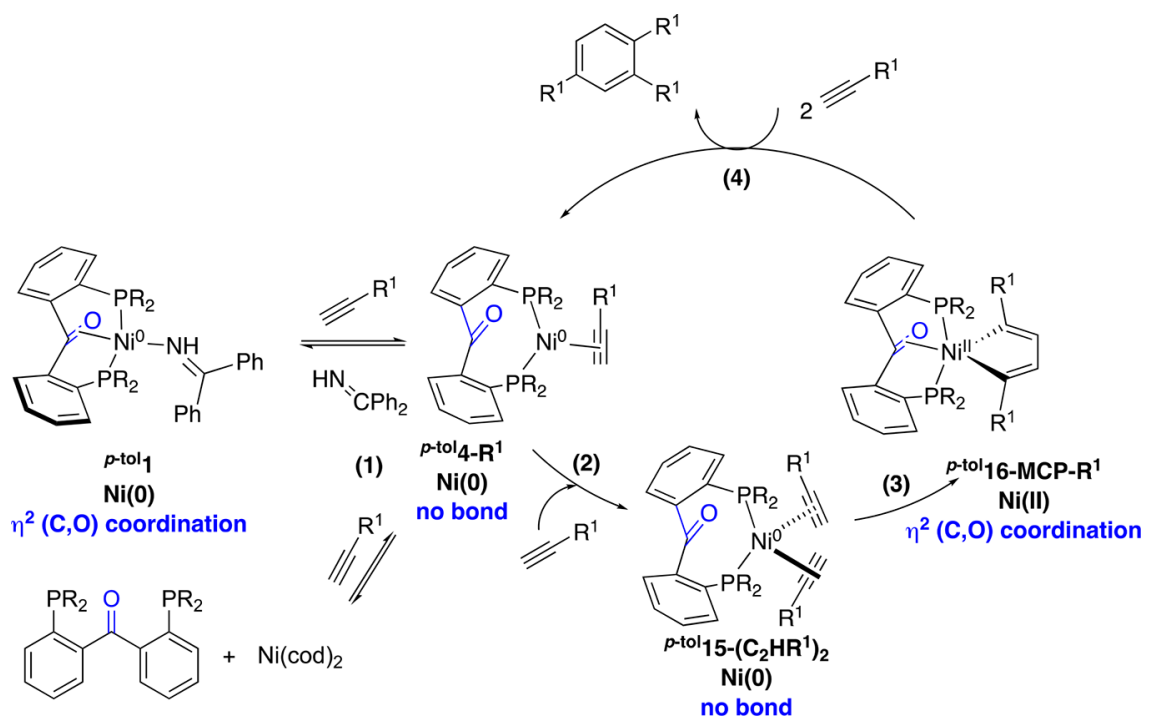

${ }^{a} \mathrm{R}=$ para-tolyl.

unique coordination geometry. We show in this study that $\left[\left({ }^{p \text {-tol }} \mathbf{L} \mathbf{1}\right) \mathrm{Ni}(\mathrm{BPI})\right]\left(\boldsymbol{p}^{\text {-tol }} \mathbf{1}\right)$ is an effective catalyst in the $[2+2$ $+2]$ cyclotrimerization of terminal alkynes. In contrast, related $\mathrm{Ni}(0)$ complexes $\left[\left({ }^{p \text {-tol }} \mathbf{L 2}\right) \mathrm{Ni}(\mathrm{BPI})\right]\left({ }^{p \text {-tol }} 2\right)$ and $\left[\left({ }^{\mathrm{Ph}} \mathrm{L} 3\right) \mathrm{Ni}\right.$ (BPI)] ( ${ }^{\mathrm{Ph}_{3}}$ ) are less active or less selective toward the 1,2,4trisubstitued benzene cyclotrimerization product under similar conditions. We attribute the enhanced reactivity of ${ }^{p \text {-tol }} \mathbf{1}$ to the hemilabile character of its diphosphine benzophenone ligand. In situ NMR spectroscopy and DFT calculations suggest that $\mathrm{C}=\mathrm{O}$ hemilability may facilitate substrate uptake and assist the key oxidative coupling step. A more detailed mechanistic study of the reaction and applications of diphosphine-ketone ligands to other catalytic processes are actively investigated in our laboratories.

\section{EXPERIMENTAL SECTION}

Chemicals and Reagents. Unless otherwise noted, all reactions were carried out under an inert $\mathrm{N}_{2}(\mathrm{~g})$ atmosphere, using standard Schlenk line or glovebox techniques, and stirred magnetically. Silica gel $\mathrm{P}_{60}$ (SiliCycle) was used for column chromatography. Analytical thin layer chromatography was performed using SiliCycle $60 \mathrm{~F}_{254}$ silica gel (precoated sheets, $0.20 \mathrm{~mm}$ thick) from Merck KGaA (Darmstadt, Germany). Deuterated solvents were purchased from Cambridge Isotope Laboratory Incorporation (Cambridge, USA) and were degassed by standard freeze-thaw-pump procedure ${ }^{65}$ and subsequently stored over molecular sieves. Common solvents were purified using a MBRAUN MB SPS-80 purification system or by standard distillation techniques or both. ${ }^{65}$ They were degassed by bubbling $\mathrm{N}_{2}(\mathrm{~g})$ through the liquid for at least 
$30 \mathrm{~min}$ and then stored over molecular sieves. Nonhalogenated solvents were tested with a standard purple solution of sodium benzophenone ketyl in tetrahydrofuran to confirm effective oxygen and moisture removal. Other solvents were checked for water content by the Karl Fischer titration or by ${ }^{1} \mathrm{H}$ NMR. Liquid chemicals were first degassed by standard freeze-pump-thaw procedures or purged with $\mathrm{N}_{2}(\mathrm{~g})$ and then stored over molecular sieves prior to use. Phosphoruscontaining compounds were checked for oxidation by ${ }^{31} \mathrm{P}$ NMR before use. O-(Bromophenyl)-diphenylphosphine, ${ }^{24,47}$ $o$-(bromophenyl)-di-p-tolylphosphine, ${ }^{25} 2,2^{\prime}$-bis (diphenylphosphino)benzophenone $\left({ }^{\mathrm{Ph}} \mathbf{L} \mathbf{1}\right),{ }^{24}$ and 2,2'-bis(di-

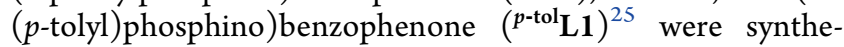
sized according to reported procedures. All other reagents and starting materials were purchased from commercial sources and used without further purification, except when specified.

Physical Methods. The ${ }^{1} \mathrm{H},{ }^{13} \mathrm{C},{ }^{31} \mathrm{P}$, and ${ }^{19} \mathrm{~F}$ NMR (400, 100,161 , and $400 \mathrm{MHz}$, respectively) spectra were recorded at $297 \mathrm{~K}$ on an Agilent MRF 400 spectrometer. All chemical shifts are reported in the standard $\delta$ notation of parts per million, referenced to residual peak of the solvent, as determined relative to $\mathrm{Me}_{4} \mathrm{Si}(\delta=0 \mathrm{ppm}){ }^{66}$ Variabletemperature (VT) NMR were recorded in $d$-toluene from $-85{ }^{\circ} \mathrm{C}$ to room temperature. Infrared spectra were recorded using a PerkinElmer Spectrum Two FT-IR spectrometer. For air-sensitive compounds, a $\mathrm{N}_{2}$ flow was used. Absorption spectra were recorded using a Lambda $35 \mathrm{UV}-$ vis spectrometer. The UV-vis solutions were prepared in the glovebox, using degassed and dried solvent, and then stored in a cuvette sealed with a Teflon cap. The acquisition and analysis of the UV-vis data were performed with PerkinElmer UW WinLab and UV WinLab Data Processor and Viewer software. GC-MS measurements were conducted on a PerkinElmer Clarus 680 GC (column PE, Elite 5MS, $15 \mathrm{~m} \times 0.25 \mathrm{~mm}$ ID $\times$ $0.25 \mu \mathrm{m}$ ) equipped with Clarus SQ8T MS and analyzed with TurboMass software. ESI-MS analysis was recorded with a Water LCT Premier XE spectrometer. Elemental analysis was provided by Mikroanalytisches Laboratorium Kolbe, Mülheim an der Ruhr, Germany, and Medac Ltd., Surrey, UK.

Computational Methods. DFT (density functional theory) results were obtained using the Gaussian 09 software package. $^{67}$ Restricted (R) geometry optimizations use the B3LYP (Becke, three-parameter, Lee-Yang-Parr) functional and the $6-3 \lg (\mathrm{d}, \mathrm{p})$ basis set on all atoms. The structures were optimized without any symmetry restraints and are either minima or transition states. Frequency analyses were performed on all calculations. The transition states search was performed using the QST3 (synchronous transit-guided quasi Newton number 3) method. For NBO (natural bond orbital) calculation, the NBO6 program, ${ }^{68}$ up to the NLMO (natural localized molecular orbital) basis set, was used at B3LYP/def2TZVP level of theory from the optimized geometry. Pictures derived from DFT calculations have been generated using the GaussView software. The B3LYP functional was chosen as it has been shown to be accurate for geometry optimization of related metal compounds, ${ }^{69}$ including closely related ${ }^{\mathrm{Ph}} \mathbf{L} \mathbf{1}-$ metal systems. ${ }^{24,25}$

Synthetic Methods. Ligand: Bis(2-di-p-tolyl)phosphinophenyl) Phenylphosphine ( $\left.{ }^{p-t o l} L 2\right)$. Adapted from the procedure by Koshevoy et al. $^{46}$ To a suspension of (obromophenyl)di-p-tolylphosphine $(5.01 \mathrm{~g}, 16.6 \mathrm{mmol})$ in dried and degassed THF $(76 \mathrm{~mL})$, a hexane solution of $n$-BuLi (1.6
$\mathrm{M}, 8.50 \mathrm{~mL}, 13.5 \mathrm{mmol}$ ) was added dropwise within $10 \mathrm{~min}$ at $-78{ }^{\circ} \mathrm{C}$ under a $\mathrm{N}_{2}$ atmosphere. The reaction mixture was stirred at $-78{ }^{\circ} \mathrm{C}$ for $1 \mathrm{~h}$, and $\mathrm{PPhCl}_{2}(0.92 \mathrm{~mL}, 6.77 \mathrm{mmol})$ was added dropwise. The mixture was stirred at this temperature for one additional hour and then allowed to slowly warm up to room temperature. The solution was stirred at room temperature for three more hours and then quenched with $\mathrm{MeOH}(30 \mathrm{~mL})$. The volatiles were removed in vacuo, and the yellow amorphous residue was washed with $\mathrm{MeOH}(5$ $\times 15 \mathrm{~mL}$ ) to afford ${ }^{p \text {-tol }} \mathbf{L 2}$ as a white solid, which was dried overnight under vacuum (3.52 g, $5.10 \mathrm{mmol}, 76 \%) .{ }^{1} \mathrm{H}$ NMR $\left(400 \mathrm{MHz}, \mathrm{C}_{6} \mathrm{D}_{6}, 25{ }^{\circ} \mathrm{C}\right): \delta_{\mathrm{H}} 7.40-7.33(\mathrm{ArH}, \mathrm{m}, 6 \mathrm{H}), 7.33-$ 7.25 (ArH, m, 6H), 7.19-7.16 (ArH, m, 2H), 7.01-6.94 $(\mathrm{ArH}, \mathrm{m}, 5 \mathrm{H}), 6.93-6.87(\mathrm{ArH}, \mathrm{m}, 6 \mathrm{H}), 6.84\left(\mathrm{ArH}, \mathrm{d},{ }^{3} J_{\mathrm{H}, \mathrm{H}}=\right.$ $7.9 \mathrm{~Hz}, 4 \mathrm{H}), 2.03\left(\mathrm{CH}_{3}, \mathrm{~s}, 6 \mathrm{H}\right), 2.01\left(\mathrm{CH}_{3}, \mathrm{~s}, 6 \mathrm{H}\right) .{ }^{31} \mathrm{P}$ NMR $\left(161 \mathrm{MHz}, \mathrm{C}_{6} \mathrm{D}_{6}, 25^{\circ} \mathrm{C}\right): \delta_{\mathrm{P}}-14.8(p$-tolP, $2 \mathrm{P}),-16.9(\mathrm{Ph} P$, 1P) $\left[\mathrm{AB}_{2}\right.$ system, $\left.{ }^{2} J_{\mathrm{A}, \mathrm{B}}=155 \mathrm{~Hz}\right] .{ }^{13} \mathrm{C}$ NMR $\left(100 \mathrm{MHz}, \mathrm{C}_{6} \mathrm{D}_{6}\right.$, $\left.25^{\circ} \mathrm{C}\right): \delta_{\mathrm{C}} 145.6-144.8(\mathrm{~m}), 138.4-138.1(\mathrm{~m}), 138.0\left(\mathrm{~d}, J_{\mathrm{C}, \mathrm{P}}\right.$ $=12.7 \mathrm{~Hz}), 135.2-134.9(\mathrm{~m}), 134.7\left(\mathrm{t}, J_{\mathrm{C}, \mathrm{P}}=4.4 \mathrm{~Hz}\right), 134.6-$ $134.3(\mathrm{~m}), 129.6,129.4\left(\mathrm{t}, J_{\mathrm{C}, \mathrm{P}}=3.3 \mathrm{~Hz}\right), 129.1,128.9,128.2$, 129.9, $21.2\left(\mathrm{CH}_{3}\right), 21.2\left(\mathrm{CH}_{3}\right)$. ATR-IR: $\nu\left[\mathrm{cm}^{-1}\right]=3043$, 1494, 1439, 1184, 1090, 806, 752, 504. HRMS (ESI, $\mathrm{CH}_{3} \mathrm{CN}$, $\left.\mathrm{AgNO}_{3}\right): \mathrm{m} / z$ calcd for $[\mathrm{M}+\mathrm{Ag}]^{+}$793.1472; found 793.1605.

Nickel Complexes. [( $\left.\left.{ }^{P h} L 1\right) N i(B P I)\right]\left({ }^{P h} 1\right) . \mathrm{Ni}(\operatorname{cod})_{2}(249 \mathrm{mg}$, $0.91 \mathrm{mmol}),{ }^{\mathrm{Ph}} \mathrm{L} 1$ (502 $\left.\mathrm{mg}, 0.91 \mathrm{mmol}\right)$, and benzophenone imine (181 mg, $0.92 \mathrm{mmol}$ ) were dissolved in dried degassed toluene $(10 \mathrm{~mL})$ under an inert atmosphere. The reaction mixture was stirred at room temperature for $20 \mathrm{~min}$. Dried and degassed hexane $(5 \mathrm{~mL})$ was added to the resulting black solution, causing the precipitation of a black solid. The precipitate was collected by filtration, washed with hexane $(3 \times$ $4 \mathrm{~mL}$ ), and dried under vacuum to afford ${ }^{\mathrm{Ph}} \mathbf{1}$ as a black powder (597 mg, $0.76 \mathrm{mmol}, 83 \%)$. Single crystals suitable for $\mathrm{X}$-ray diffraction and elemental analysis were obtained by slow exchange of hexane into a concentrated THF solution of ${ }^{\mathbf{P h}} \mathbf{1}$. ${ }^{1} \mathrm{H}$ NMR $\left(400 \mathrm{MHz}, \mathrm{C}_{6} \mathrm{D}_{6}, 25{ }^{\circ} \mathrm{C}\right): \delta_{\mathrm{H}} 9.88(\mathrm{NH}$, br s, $1 \mathrm{H})$, $7.90\left(\mathrm{ArH}, \mathrm{d},{ }^{3} \mathrm{~J}_{\mathrm{H}, \mathrm{H}}=7.2 \mathrm{~Hz}, 2 \mathrm{H}\right), 7.83\left(\mathrm{ArH}, \mathrm{d},{ }^{3} \mathrm{~J}_{\mathrm{H}, \mathrm{H}}=7.6 \mathrm{~Hz}\right.$, $2 \mathrm{H}), 7.75-7.70(\mathrm{ArH}, \mathrm{m}, 4 \mathrm{H}), 7.23-7.19(\mathrm{ArH}, \mathrm{m}, 2 \mathrm{H})$ 7.09-6.79 (ArH, m, 26H), $6.73\left(\mathrm{ArH}, \mathrm{t},{ }^{3} J_{\mathrm{H}, \mathrm{H}}=7.6 \mathrm{~Hz}, 2 \mathrm{H}\right)$. ${ }^{31} \mathrm{P}$ NMR (161 MHz, $\left.\mathrm{C}_{6} \mathrm{D}_{6}, 25{ }^{\circ} \mathrm{C}\right): \delta_{\mathrm{P}} 16.4(\mathrm{~s}, 2 \mathrm{P}) .{ }^{13} \mathrm{C} \mathrm{NMR}$ $\left(100 \mathrm{MHz}, d_{8}\right.$-THF, $\left.25^{\circ} \mathrm{C}\right): \delta_{\mathrm{C}} 170.7\left(\mathrm{C}=\mathrm{N}, \mathrm{t},{ }^{3} J_{\mathrm{C}, \mathrm{P}}=5.4\right.$ $\mathrm{Hz}), 156.0\left(\mathrm{t}, J_{\mathrm{C}, \mathrm{P}}=18.0 \mathrm{~Hz}\right), 141.1,140.2\left(\mathrm{t}, J_{\mathrm{C}, \mathrm{P}}=17.0 \mathrm{~Hz}\right)$, 138.7, 136.7 (t, $\left.J_{\mathrm{C}, \mathrm{P}}=11.2 \mathrm{~Hz}\right), 136.4\left(\mathrm{t}, J_{\mathrm{C}, \mathrm{P}}=13.7 \mathrm{~Hz}\right), 132.9$ $\left(\mathrm{t}, J_{\mathrm{C}, \mathrm{P}}=7.7 \mathrm{~Hz}\right), 132.6,131.8\left(\mathrm{t}, J_{\mathrm{C}, \mathrm{P}}=6.6 \mathrm{~Hz}\right), 129.62\left(\mathrm{t} . J_{\mathrm{C}, \mathrm{P}}\right.$ $=4.0 \mathrm{~Hz}), 128.9-126.7(\mathrm{~m}) 125.8,125.5\left(\mathrm{t}, J_{\mathrm{C}, \mathrm{P}}=8.1 \mathrm{~Hz}\right)$, $117.2\left(\mathrm{C}=\mathrm{O}, \mathrm{t},{ }^{3} \mathrm{~J}_{\mathrm{C}, \mathrm{P}}=7.6 \mathrm{~Hz}\right)$. ATR-IR: $\nu\left[\mathrm{cm}^{-1}\right]: 3163$, 3050, 1583, 1404, 1432, 1478, 1432, 1303, 1249, 1091, 912, 778, 739, 692, 515. UV-vis (toluene): $\lambda_{\max }[\mathrm{nm}] 365,574$. Elemental analysis, Anal. Calcd for $\mathrm{C}_{50} \mathrm{H}_{39} \mathrm{NNiOP}_{2} \cdot 1 / 2$ hexane: C, 76.37; H, 5.56; N, 1.68. Found: C, 76.33; H, $5.58 ; \mathrm{N}, 1.52$. The crystal structure contains channels along the $c$-axis, which are filled with disordered hexane molecules (Supporting Information; Figure S110).

$\left.\left[\left(^{p \text {-tol }} L 1\right) \mathrm{Ni}(B P I)\right] \quad{ }^{p-t o l} 1\right) . \mathrm{Ni}(\operatorname{cod})_{2}(108 \mathrm{mg}, 0.39 \mathrm{mmol})$,

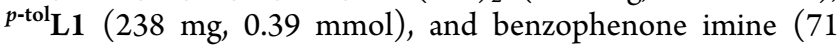
$\mathrm{mg}, 0.39 \mathrm{mmol}$ ) were dissolved in dried degassed toluene (10 $\mathrm{mL}$ ) under inert atmosphere. The reaction mixture was stirred at room temperature for $20 \mathrm{~min}$. The solvent was evaporated, and the crude mixture was subsequently dissolved in dried and degassed THF $(5 \mathrm{~mL})$. Dried and degassed hexane $(5 \mathrm{~mL})$ was added to the resulting black solution, causing the precipitation of a black solid. The precipitate was filtered, washed with 
hexane $(3 \times 4 \mathrm{~mL})$, and dried under vacuum to afford ${ }^{p \text {-tol } 1}$ as a black powder $(221 \mathrm{mg}, 0.31 \mathrm{mmol}, 79 \%)$. Single crystals for elemental analysis were obtained by slow exchange of hexane into a concentrated toluene solution of ${ }^{p \text {-tol }} 1 .{ }^{1} \mathrm{H}$ NMR (400 $\left.\mathrm{MHz}, \mathrm{C}_{6} \mathrm{D}_{6}, 25{ }^{\circ} \mathrm{C}\right): \delta_{\mathrm{H}} 10.01(\mathrm{NH}, \mathrm{s}, 1 \mathrm{H}), 7.98\left(\mathrm{ArH}, \mathrm{d},{ }^{3} J_{\mathrm{H}, \mathrm{H}}\right.$ $=7.4 \mathrm{~Hz}, 2 \mathrm{H}), 7.88\left(\mathrm{ArH}, \mathrm{dd},{ }^{3} J_{\mathrm{H}, \mathrm{H}}=7.7,{ }^{4} J_{\mathrm{H}, \mathrm{H}}=1.3,2 \mathrm{H}\right)$, $7.66\left(\mathrm{ArH}, \mathrm{dt},{ }^{3} \mathrm{~J}_{\mathrm{H}, \mathrm{H}}=7.9,{ }^{4} J_{\mathrm{H}, \mathrm{P}}=4.6,4 \mathrm{H}\right), 7.30-7.25(\mathrm{ArH}, \mathrm{m}$, $2 \mathrm{H}), 7.05\left(\mathrm{ArH}, \mathrm{dt},{ }^{3} J_{\mathrm{H}, \mathrm{H}}=7.9 \mathrm{~Hz},{ }^{4} J_{\mathrm{H}, \mathrm{P}}=4.4 \mathrm{~Hz}\right), 6.97-6.88$ (ArH, m, 6H), 6.86-6.73 ( $\mathrm{ArH}, \mathrm{m}, 14 \mathrm{H}), 2.11\left(\mathrm{CH}_{3}, \mathrm{~s}, 6 \mathrm{H}\right)$, $2.09\left(\mathrm{CH}_{3}, \mathrm{~s}, 6 \mathrm{H}\right) .{ }^{31} \mathrm{P}$ NMR $\left(161 \mathrm{MHz}, \mathrm{C}_{6} \mathrm{D}_{6}, 25^{\circ} \mathrm{C}\right): \delta_{\mathrm{P}} 15.5$ (s, 2P). ${ }^{13} \mathrm{C}$ NMR $\left(100 \mathrm{MHz}, \mathrm{C}_{6} \mathrm{D}_{6}, 25^{\circ} \mathrm{C}\right): \delta_{\mathrm{C}} 169.8(\mathrm{C}=\mathrm{N}$, $\left.\mathrm{t},{ }^{3} J_{C, P}=6.1 \mathrm{~Hz}\right), 156.7\left(\mathrm{t}, J_{C, P}=18.1 \mathrm{~Hz}\right), 141.6\left(\mathrm{t}, J_{C, P}=2.3\right.$ $\mathrm{Hz}), 141.2\left(\mathrm{t}, J_{C, P}=16.9 \mathrm{~Hz}\right), 138.6\left(\mathrm{Ar}, \mathrm{t}, J_{C, P}=2.4 \mathrm{~Hz}\right)$, 138.1, 137.2, $134.7\left(\mathrm{t}, J_{C, P}=12.1 \mathrm{~Hz}\right), 133.9\left(\mathrm{t}, J_{C, P}=14.7 \mathrm{~Hz}\right)$, 133.6, 133.5, 133.5, 133.4, $132.7\left(\mathrm{t}, J_{C, P}=6.8 \mathrm{~Hz}\right), 130.5\left(\mathrm{t}, J_{C, P}\right.$ $=4.3 \mathrm{~Hz}), 129.1\left(\mathrm{t}, J_{C, P}=4.4 \mathrm{~Hz}\right), 129.0\left(\mathrm{t}, J_{C, P}=4.0 \mathrm{~Hz}\right)$, $128.8,127.5,126.8,126.5\left(\mathrm{t}, J_{C, P}=8.1 \mathrm{~Hz}\right), 119.0(C=\mathrm{O}, \mathrm{t}$, $\left.J_{C, P}=5.1 \mathrm{~Hz}\right), 21.3\left(\mathrm{CH}_{3}\right), 21.1\left(\mathrm{CH}_{3}\right)$. ATR-IR: $\nu\left[\mathrm{cm}^{-1}\right]$ : 3152, 3053, 2917, 2860, 1598, 1496, 1448, 1394, 1250, 1185, 1092, 1018, 912, 803, 693, 627, 514. Elemental analysis, Anal. Calcd for $\mathrm{C}_{54} \mathrm{H}_{47} \mathrm{NNiOP}_{2}$ : C, 76.61; H, 5.66. Found: C, 76.55; $\mathrm{H}, 5.93$.

$\left.\left.\left[{ }^{p-t o l} L 2\right) \mathrm{Ni}(\mathrm{BPI})\right]{ }^{\left(p^{\text {-tol }}\right.} 2\right) . \mathrm{Ni}(\operatorname{cod})_{2}(163 \mathrm{mg}, 0.59 \mathrm{mmol})$, ${ }^{p \text {-tol }} \mathbf{L} 2$ (405 $\mathrm{mg}, 0.59 \mathrm{mmol}$ ), and benzophenone imine (108 $\mathrm{mg}, 0.59 \mathrm{mmol}$ ) were combined together and dissolved in dried degassed toluene $(7 \mathrm{~mL})$ under inert atmosphere. The reaction mixture was stirred at room temperature for $1 \mathrm{~h}$, and dried degassed hexane $(7 \mathrm{~mL})$ was added. The resulting solution was left in the freezer at $-35{ }^{\circ} \mathrm{C}$ for $16 \mathrm{~h}$, during which the precipitation of a black solid was observed. The solid was filtered, washed with cold hexane $(5 \times 4 \mathrm{~mL})$, and dried under vacuum to afford ${ }^{p \text {-tol }} 2$ as a black powder $(315 \mathrm{mg}, 0.34$ mmol, 58\%). ${ }^{1} \mathrm{H}$ NMR (400 MHz, $\left.\mathrm{C}_{6} \mathrm{D}_{6}, 25^{\circ} \mathrm{C}\right): \delta_{\mathrm{H}} 10.25$ $\left(\mathrm{NH}, \mathrm{dt},{ }^{3} J_{\mathrm{H}, \mathrm{P}}=3.2 \mathrm{~Hz},{ }^{3} J_{\mathrm{H}, \mathrm{P}}=2.7 \mathrm{~Hz}, 1 \mathrm{H}\right), 8.49\left(\mathrm{ArH}, \mathrm{d},{ }^{3} J_{\mathrm{H}, \mathrm{H}}\right.$ $=7.6 \mathrm{~Hz}, 2 \mathrm{H}), 8.05\left(\mathrm{ArH}, \mathrm{dd},{ }^{3} J_{\mathrm{H}, \mathrm{H}}=7.2 \mathrm{~Hz},{ }^{3} \mathrm{~J}_{\mathrm{H}, \mathrm{P}}=4.4 \mathrm{~Hz}\right.$, $2 \mathrm{H}), 7.66-7.60(\mathrm{ArH}, \mathrm{m}, 5 \mathrm{H}), 7.55\left(\mathrm{ArH}, \mathrm{t},{ }^{3} J_{\mathrm{H}, \mathrm{H}}=8.0 \mathrm{~Hz}\right.$, $2 \mathrm{H}), 7.12-6.86(\mathrm{ArH}, \mathrm{m}, 18 \mathrm{H}), 6.83\left(\mathrm{ArH}, \mathrm{d},{ }^{3} \mathrm{~J}_{\mathrm{H}, \mathrm{H}}=8.4 \mathrm{~Hz}\right.$, $6 \mathrm{H}), 6.72\left(\mathrm{ArH}, \mathrm{d},{ }^{3} J_{\mathrm{H}, \mathrm{H}}=7.6 \mathrm{~Hz}, 4 \mathrm{H}\right), 2.14\left(\mathrm{CH}_{3}, \mathrm{~s}, 6 \mathrm{H}\right)$, $1.95\left(\mathrm{CH}_{3}, \mathrm{~s}, 6 \mathrm{H}\right) \cdot{ }^{31} \mathrm{P}$ NMR $\left(161 \mathrm{MHz}, \mathrm{C}_{6} \mathrm{D}_{6}, 25^{\circ} \mathrm{C}\right): \delta_{\mathrm{p}} 37.1$ $\left(p\right.$-tolP, 2P) $28.7(\mathrm{Ph} P, 1 \mathrm{P})\left[\mathrm{AK}_{2}\right.$ system, $\left.{ }^{2} \mathrm{~J}_{\mathrm{A}, \mathrm{K}}=85 \mathrm{~Hz}\right] .{ }^{13} \mathrm{C}$ NMR $\left(100 \mathrm{MHz}, \mathrm{C}_{6} \mathrm{D}_{6}, 25{ }^{\circ} \mathrm{C}\right): \delta_{\mathrm{C}} 168.5\left(\mathrm{C}=\mathrm{N}, \mathrm{dt},{ }^{3} J_{\mathrm{C}, \mathrm{P}}=\right.$ $\left.8.1 \mathrm{~Hz},{ }^{3} J_{\mathrm{C}, \mathrm{P}}=7.4 \mathrm{~Hz}\right), 149.6-147.8(\mathrm{~m}), 143.2,141.3\left(\mathrm{dt}, J_{\mathrm{C}, \mathrm{P}}\right.$ $\left.=11.1 \mathrm{~Hz}, J_{\mathrm{C}, \mathrm{P}}=2.7 \mathrm{~Hz}\right), 137.8\left(\mathrm{dt}, J_{\mathrm{C}, \mathrm{P}}=13.9 \mathrm{~Hz}, J_{\mathrm{C}, \mathrm{P}}=4.0\right.$ $\mathrm{Hz}), 137.2$, 137.1-136.4 (m), 136.3, 132.8-132.6 (m), 132.4 $\left(\mathrm{d}, J_{\mathrm{C}, \mathrm{P}}=14.1 \mathrm{~Hz}\right), 131.8\left(\mathrm{t}, J_{\mathrm{C}, \mathrm{P}}=6.7 \mathrm{~Hz}\right), 131.3\left(\mathrm{~d}, J_{\mathrm{C}, \mathrm{P}}=\right.$ $13.8 \mathrm{~Hz}), 130.6,129.9-129.5(\mathrm{~m}), 129.1\left(\mathrm{t}, J_{\mathrm{C}, \mathrm{P}}=4.2 \mathrm{~Hz}\right)$, 128.8-128.6 (m) 127.6, 127.1, 126.3, $21.4\left(\mathrm{CH}_{3}\right), 21.1\left(\mathrm{CH}_{3}\right)$. ATR-IR: $\nu\left[\mathrm{cm}^{-1}\right]$ 3048, 2972, 2917, 2864, 1664, 1598, 1496, 1445, 1187, 1114, 804, 695, 513. Elemental analysis, Anal. Calcd for $\mathrm{C}_{59} \mathrm{H}_{52} \mathrm{NNiP}_{3}$ : C, 76.47; H, 5.66; N, 1.51. Found: $\mathrm{C}$ 75.97 H $5.49 \mathrm{~N} 1.56$.

$\left.\left[{ }^{P h} L 3\right) N i(B P I)\right]\left({ }^{P h} 3\right)$. Under inert atmosphere, a dried and degassed toluene solution $(7 \mathrm{~mL})$ of benzophenone imine $(169 \mathrm{mg}, 0.93 \mathrm{mmol})$ was added to a vial containing $\mathrm{Ni}(\mathrm{cod})_{2}$ (255 mg, $0.93 \mathrm{mmol}$ ), and ${ }^{\mathrm{Ph}} \mathrm{L} 3$ (500 mg, $0.93 \mathrm{mmol}$ ). The reaction mixture was stirred at room temperature for $16 \mathrm{~h}$ in which a solid spontaneously precipitated. The resulting solid was filtered, washed with cold hexane $(5 \times 4 \mathrm{~mL})$, and dried under vacuum to afford ${ }^{\mathrm{Ph}_{3}}$ as an orange powder (582 mg, 0.75 mmol, $81 \%$ ). Single crystals suitable for X-ray diffraction and elemental analysis were obtained by slow diffusion of hexane into a $\mathrm{C}_{6} \mathrm{D}_{6}$ solution of ${ }^{\mathrm{Ph}} 3 .{ }^{1} \mathrm{H}$ NMR $\left(400 \mathrm{MHz}, \mathrm{C}_{6} \mathrm{D}_{6}, 25\right.$ $\left.{ }^{\circ} \mathrm{C}\right): \delta_{\mathrm{H}} 9.71(\mathrm{NH}, \mathrm{s}, 1 \mathrm{H}), 8.00-7.85(\mathrm{ArH}$, br s, $2 \mathrm{H}), 7.70-$
7.64, (ArH, br s, 2H), 7.61-7.53 (ArH, br s, 6H), 7.13-6.90 (ArH, br s, 22H), 6.78-6.72 (ArH, br m, 4H), 6.56-6.52 $\left(\mathrm{ArH}\right.$, br m, 2H). ${ }^{31} \mathrm{P}$ NMR $\left(161 \mathrm{MHz}, \mathrm{C}_{6} \mathrm{D}_{6}, 25^{\circ} \mathrm{C}\right): \delta_{\mathrm{P}} 32.4$ (s, 2P). ATR-IR: $\nu\left[\mathrm{cm}^{-1}\right] 3200,3052,1589,1565,1462$, 1434, 1363, 1259, 1216, 1095, 880, 747, 693, 622, 505. Elemental analysis, Anal. Calcd for $\mathrm{C}_{49} \mathrm{H}_{29} \mathrm{NNiOP}_{2}$ : C, 75.60; H, 5.05; N, 1.80. Found: C, 75.22; H, 5.69; N, 2.05. Due to poor solubility and progressive decomposition of $\mathrm{Ph}_{3}$ in common solvents, no ${ }^{13} \mathrm{C}$ NMR was recorded.

In Situ Generation of $\left[\left(^{p \text {-tol }} L 1\right) N i\left(H C \equiv C R^{1}\right)\right] \quad\left({ }^{p-t o l} 4-R^{1}\right)$. Under an inert atmosphere, 1 equiv of $\left[\left({ }^{p-t o l} \mathrm{~L} 1\right) \mathrm{Ni}(\mathrm{BPI})\right]$ $\left({ }^{p \text {-tol } 1)}\right.$ was mixed with 1 equiv of a terminal alkyne and dissolved in dried degassed $\mathrm{C}_{6} \mathrm{D}_{6}(0.6 \mathrm{~mL})$. The solution was transferred into a Young-type NMR tube, and the mixture was analyzed. ${ }^{31} \mathrm{P}$ and ${ }^{1} \mathrm{H}$ NMR show the appearance of one new single species, $\left[\left({ }^{p \text {-tol }} \mathbf{L} \mathbf{1}\right) \mathrm{Ni}\left(\mathrm{HC} \equiv \mathrm{CR}^{1}\right)\right]\left({ }^{\text {-tol }} 4-\mathrm{R}^{1}\right)$, in addition to the partial release of BPI. High in situ yield was obtained with methyl propargyl ether $\left(\mathrm{R}^{1}=\mathrm{CH}_{2} \mathrm{OMe}\right)$ as alkyne reactant, leading to the formation of $\left[\left({ }^{p-\text { tol }} \mathbf{L} \mathbf{1}\right) \mathrm{Ni}(\mathrm{HC} \equiv\right.$ $\left.\left.\mathrm{CH}_{2} \mathrm{OMe}\right)\right]$ ( ${ }^{p \text {-to }}$ 4- $\left.\mathrm{CH}_{2} \mathrm{OMe}\right)$. The solution contains a mixture of ${ }^{p \text {-tol }} 4-\mathrm{CH}_{2} \mathrm{OMe},{ }^{p \text {-tol }} \mathbf{1}$, BPI, and methyl propargyl ether. ${ }^{1} \mathrm{H}$ NMR (400 MHz, $\left.\mathrm{C}_{6} \mathrm{D}_{6}, 25^{\circ} \mathrm{C}\right): \delta_{\mathrm{H}} 10.01\left(p^{\text {-tol }} \mathbf{1}, \mathrm{NH}, \mathrm{s}, 1 \mathrm{H}\right)$, 9.82 (BPI, NH, br. s, $1 \mathrm{H}) 8.03\left({ }^{p \text {-tol }} \mathbf{1}, \mathrm{ArH}, \mathrm{d},{ }^{3} J_{\mathrm{H}, \mathrm{H}}=7.4 \mathrm{~Hz}\right.$, $2 \mathrm{H}), 7.92\left({ }^{p \text {-tol }} \mathbf{1}, \mathrm{ArH}, \mathrm{dd},{ }^{3} \mathrm{~J}_{\mathrm{H}, \mathrm{H}}=7.7,{ }^{4} J_{\mathrm{H}, \mathrm{H}}=1.3,2 \mathrm{H}\right), 7.70$ $\left({ }^{p \text {-tol }} 1, \mathrm{ArH}, \mathrm{dt},{ }^{3} J_{\mathrm{H}, \mathrm{H}}=7.9,{ }^{4} J_{\mathrm{H}, \mathrm{P}}=4.6,4 \mathrm{H}\right), 7.54\left({ }^{p \text {-tol }} 4\right.$ $\mathrm{CH}_{2} \mathrm{OMe}, p$-tol-ArH, td, $\left.{ }^{3} J_{\mathrm{H}, \mathrm{P}}=8.0 \mathrm{~Hz},{ }^{3} J_{\mathrm{H}, \mathrm{P}}=7.2 \mathrm{~Hz}, 8 \mathrm{H}\right)$, 7.35-7.29 ( ${ }^{p \text {-tol } 1, ~ A r H, ~ m, ~ 2 H), ~} 7.10\left({ }^{p \text {-tol } 1, ~ A r H, ~ d t, ~}{ }^{3} J_{\mathrm{H}, \mathrm{H}}=7.9\right.$ $\left.\mathrm{Hz},{ }^{4} J_{\mathrm{H}, \mathrm{P}}=4.4 \mathrm{~Hz}\right), 7.02-6.92\left({ }^{p \text {-tol }} \mathbf{1}, \mathrm{ArH}, \mathrm{m}, 6 \mathrm{H}\right), 6.91-6.76$ $\left({ }^{p \text {-tol }} 1, \mathrm{ArH}, \mathrm{m}, 14 \mathrm{H}\right), 6.74\left({ }^{p \text {-tol }} 4-\mathrm{CH}_{2} \mathrm{OMe}, \mathrm{ArH}, \mathrm{t},{ }^{3} J_{\mathrm{H}, \mathrm{H}}=7.6\right.$ $\mathrm{Hz}, 2 \mathrm{H}), 6.66\left({ }^{p \text {-tol }} 4-\mathrm{CH}_{2} \mathrm{OMe}, \mathrm{ArH}, \mathrm{td},{ }^{3} J_{\mathrm{H}, \mathrm{H}}=7.6 \mathrm{~Hz},{ }^{4} J_{\mathrm{H}, \mathrm{H}}=\right.$ $1.6 \mathrm{~Hz}, 2 \mathrm{H}), 6.34 \mathrm{ppm}\left({ }^{p \text {-tol }} 4-\mathrm{CH}_{2} \mathbf{O M e}, \equiv \mathrm{CH},{ }^{3} J_{\mathrm{H}, \mathrm{P}} 15.6\right.$, $\left.{ }^{4} J_{\mathrm{H}, \mathrm{H}}=1.6 \mathrm{~Hz}, 1 \mathrm{H}\right) 4.63\left({ }^{p \text {-tol }} 4-\mathrm{CH}_{2} \mathbf{O M e}, \mathrm{CH}_{2}, \mathrm{~d},{ }^{4} J_{\mathrm{H}, \mathrm{H}}=1.6\right.$ $\mathrm{Hz}, 2 \mathrm{H}), 3.70\left(\mathrm{HC} \equiv \mathrm{CCH}_{2} \mathrm{OMe}, \mathrm{CH}_{2},{ }^{4} \mathrm{~J}_{\mathrm{H}, \mathrm{H}}=1.6 \mathrm{~Hz}, 2 \mathrm{H}\right)$ $3.32\left({ }^{p \text {-tol }} 4-\mathrm{CH}_{2} \mathrm{OMe}, \mathrm{OCH}_{3}, \mathrm{~s}, 3 \mathrm{H}\right), 3.03\left(\mathrm{HC} \equiv \mathrm{CCH}_{2} \mathrm{OMe}\right.$, $\left.\mathrm{OCH}_{3}, \mathrm{~s}, 1 \mathrm{H}\right) ; 2.10\left({ }^{p \text {-tol }} \mathbf{1}, \mathrm{CH}_{3}, \mathrm{~s}, 6 \mathrm{H}\right), 2.03\left({ }^{p \text {-tol }} 4-\mathrm{CH}_{2} \mathbf{O M e}\right.$, $\left.\mathrm{CH}_{3}, \mathrm{~s}, 12 \mathrm{H}\right), 1.96\left(\mathrm{HC} \equiv \mathrm{CCH}_{2} \mathrm{OMe}, \equiv \mathrm{CH},{ }^{4} \mathrm{~J}_{\mathrm{H}, \mathrm{H}}=1.6 \mathrm{~Hz}\right.$, $1 \mathrm{H}), 1.91\left({ }^{p \text {-tol }} \mathbf{1}, \mathrm{CH}_{3}, \mathrm{~s}, 6 \mathrm{H}\right) .{ }^{31} \mathrm{P}$ NMR (161 MHz, $\mathrm{C}_{6} \mathrm{D}_{6}, 25$ $\left.{ }^{\circ} \mathrm{C}\right): \delta_{\mathrm{P}} 33.3\left({ }^{p \text {-tol }} 4-\mathrm{CH}_{2} \mathrm{OMe}, \mathrm{s}, 2 \mathrm{P}\right), 15.5\left({ }^{p \text {-tol }} \mathbf{1}, \mathrm{s}, 2 \mathrm{P}\right)$.

${ }^{13} \mathrm{C}$ NMR was acquired in order to locate the resonances

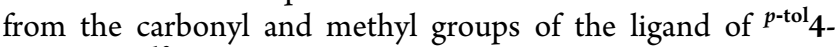
$\mathrm{CH}_{2}$ OMe. ${ }^{13} \mathrm{C}$ NMR $\left(100 \mathrm{MHz}, \mathrm{C}_{6} \mathrm{D}_{6}, 25{ }^{\circ} \mathrm{C}\right): \delta_{\mathrm{C}} 203.1(\mathrm{C}=$ $\left.\mathrm{O}, \mathrm{t},{ }^{4} J_{\mathrm{C}, \mathrm{P}}=4.7 \mathrm{~Hz}\right), 22.2\left(\mathrm{H}_{3} \mathrm{C}, \mathrm{d},{ }^{4} J_{\mathrm{C}, \mathrm{P}}=2.3 \mathrm{~Hz}\right)$.

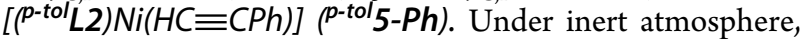

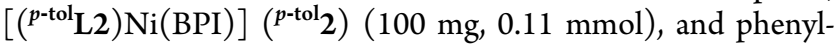
acetylene $(11 \mathrm{mg}, 0.11 \mathrm{mmol})$ were mixed together and dissolved in dried degassed toluene $(5 \mathrm{~mL})$. The reaction mixture was subsequently stirred at room temperature for $1 \mathrm{~h}$. The solvent was removed under vacuum, and the crude residue was dissolved in dried degassed THF $(3 \mathrm{~mL})$. Dried degassed hexane $(3 \mathrm{~mL})$ was added, and the mixture was put in the freezer at $-35{ }^{\circ} \mathrm{C}$ for $16 \mathrm{~h}$, after which a red precipitate was observed. The solid was isolated by filtration and washed with cold hexane $(5 \times 2 \mathrm{~mL})$ to afford ${ }^{p \text {-tol }} 5$-Ph as a red powder $(59$ $\mathrm{mg}, 0.07 \mathrm{mmol}, 66 \%)$. Single crystals suitable for X-ray diffraction were obtained by slow evaporation of a concentrated THF solution of ${ }^{p \text {-tol }} \mathbf{5}$-Ph. ${ }^{1} \mathrm{H}$ NMR (400 MHz, $\mathrm{C}_{6} \mathrm{D}_{6}$, $\left.25^{\circ} \mathrm{C}\right): \delta_{\mathrm{H}} 7.92\left(\mathrm{ArH}, \mathrm{dd},{ }^{3} \mathrm{~J}_{\mathrm{H}, \mathrm{H}}=8.0 \mathrm{~Hz},{ }^{3} \mathrm{~J}_{\mathrm{H}, \mathrm{P}}=6.8 \mathrm{~Hz}, 2 \mathrm{H}\right)$, 7.63-7.53 (ArH, m, 9H), 7.45-7.39 (ArH, m, 2H), 7.10-6.95 $(\mathrm{ArH}, \mathrm{m}, 1 \mathrm{H}), 6.88\left(\mathrm{ArH}, \mathrm{tt},{ }^{3} J_{\mathrm{H}, \mathrm{H}}=7.2 \mathrm{~Hz},{ }^{4} \mathrm{~J}_{\mathrm{H}, \mathrm{P}} 1.2 \mathrm{~Hz}, 1 \mathrm{H}\right)$, $6.83\left(\mathrm{ArH}, \mathrm{d},{ }^{3} \mathrm{~J}_{\mathrm{H}, \mathrm{H}}=7.6 \mathrm{~Hz}, 4 \mathrm{H}\right), 6.72\left(\mathrm{ArH}, \mathrm{d},{ }^{3} \mathrm{~J}_{\mathrm{H}, \mathrm{H}}=7.6 \mathrm{~Hz}\right.$, $4 \mathrm{H}), 6.29$ (三CH, dt, $\left.{ }^{3} J_{\mathrm{H}, \mathrm{P}}=25.6 \mathrm{~Hz},{ }^{3} J_{\mathrm{H}, \mathrm{P}}=7.2 \mathrm{~Hz}, 1 \mathrm{H}\right), 2.12$ $\left(\mathrm{CH}_{3}, \mathrm{~s}, 6 \mathrm{H}\right), 1.91\left(\mathrm{CH}_{3}, \mathrm{~s}, 6 \mathrm{H}\right) .{ }^{31} \mathrm{P}$ NMR $\left(161 \mathrm{MHz}, \mathrm{C}_{6} \mathrm{D}_{6}\right.$, $\left.25{ }^{\circ} \mathrm{C}\right): \delta_{\mathrm{P}} 78.7\left(\mathrm{Ph} P, \mathrm{t},{ }^{2} J_{\mathrm{P}, \mathrm{P}}=35.4 \mathrm{~Hz}, 1 \mathrm{P}\right), 28.1(p$-tolP, d, 
$\left.{ }^{2} J_{\mathrm{P}, \mathrm{P}}=35.4 \mathrm{~Hz}, 2 \mathrm{P}\right) .{ }^{13} \mathrm{C} \mathrm{NMR}\left(100 \mathrm{MHz}, \mathrm{C}_{6} \mathrm{D}_{6}, 25{ }^{\circ} \mathrm{C}\right): \delta_{\mathrm{C}}$ $150.0\left(\mathrm{dt}, J_{\mathrm{C}, \mathrm{P}}=47.1 \mathrm{~Hz}, J_{\mathrm{C}, \mathrm{P}}=16.4 \mathrm{~Hz}\right), 146.9\left(\mathrm{~d}, J_{\mathrm{C}, \mathrm{P}}=36.0\right.$ $\mathrm{Hz}) 146.4\left(\mathrm{dd}, J_{\mathrm{C}, \mathrm{P}}=61.6 \mathrm{~Hz}, J_{\mathrm{C}, \mathrm{P}}=34.3 \mathrm{~Hz}\right), 140.1\left(\mathrm{dt}, J_{\mathrm{C}, \mathrm{P}}=\right.$ $\left.41.6 \mathrm{~Hz}, J_{\mathrm{C}, \mathrm{P}}=26.0 \mathrm{~Hz}\right), 137.9,137.0-136.6(\mathrm{~m}), 136.8$, 133.7, $133.1\left(\mathrm{t}, J_{\mathrm{C}, \mathrm{P}}=28.0\right) \mathrm{Hz}, 132.5\left(\mathrm{t}, J_{\mathrm{C}, \mathrm{P}}=28.0 \mathrm{~Hz}\right)$, 131.8-131.5 (m), 129.8, 129.7-128.9 (m) 101.1 (三CPh, d, $\left.{ }^{2} J_{\mathrm{C}, \mathrm{P}}=20.0 \mathrm{~Hz}\right), 92.9(\mathrm{CH}, \mathrm{br} \mathrm{s}), 21.3\left(\mathrm{CH}_{3}, \mathrm{~d}, J_{\mathrm{C}, \mathrm{P}}=4.0 \mathrm{~Hz}\right)$, $21.1\left(\mathrm{CH}_{3}, \mathrm{~d}, J_{\mathrm{C}, \mathrm{P}}=4.0 \mathrm{~Hz}\right)$. ATR-IR: $\nu\left[\mathrm{cm}^{-1}\right] 3042,2918$, 2861, 1823, 1589, 1479, 1440,1425, 1394, 1185, 1100, 1085, $1118,805,758,690,666,625,612,539,519$. Due to the high sensitivity of ${ }^{p \text {-tol }} \mathbf{6 - P h}$, no elemental analysis data was obtained. The purity and identity of the compound was established by NMR and by its X-ray diffraction structure.

Alternative Synthesis of ${ }^{\boldsymbol{p} \text {-tol }} \mathbf{5}$-Ph. Under inert atmosphere, $\mathrm{Ni}(\text { cod })_{2}(80 \mathrm{mg}, 0.29 \mathrm{mmol}),{ }^{p \text {-tol }} \mathbf{L 2}(200 \mathrm{mg}, 0.29 \mathrm{mmol})$, and phenylacetylene $(32 \mathrm{mg}, 0.31 \mathrm{mmol})$ were mixed together and dissolved in dried degassed toluene $(5 \mathrm{~mL})$. The reaction mixture was subsequently stirred at room temperature for $1 \mathrm{~h}$. Precipitation of a red solid was observed after adding dried degassed hexane $(10 \mathrm{~mL})$ and leaving the solution to stand overnight in the freezer at $-35{ }^{\circ} \mathrm{C}$. The resulting solid was filtered, washed with cold hexane $(5 \times 5 \mathrm{~mL})$, and dried under vacuum to afford ${ }^{p \text {-tol }} \mathbf{5}$-Ph as a red powder $(169 \mathrm{mg}, 0.20$ mmol, 70\%).

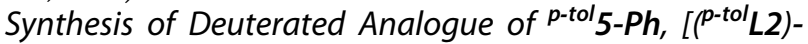
$\mathrm{Ni}(D C \equiv C P h)]$. The same procedure as for the synthesis of $p_{\text {-tol }} 5$-Ph was applied from $\mathrm{Ni}(\mathrm{cod})_{2}(30 \mathrm{mg}, 0.10 \mathrm{mmol})$, ${ }^{p \text {-tol }} \mathbf{L 2}(70 \mathrm{mg}, 0.10 \mathrm{mmol})$, and $d$-phenylacetylene $(11 \mathrm{mg}$, $0.10 \mathrm{mmol}) .\left[\left({ }^{p \text {-tol }} \mathrm{L} 2\right) \mathrm{Ni}(\mathrm{DC} \equiv \mathrm{CPh})\right]$ was isolated as a red solid in a $74 \%$ yield $(63 \mathrm{mg}, 0.07 \mathrm{mmol}) .\left[\left({ }^{p \text {-tol }} \mathrm{L2}\right) \mathrm{Ni}(\mathrm{DC} \equiv\right.$ $\mathrm{CPh})$ ] can also be generated from reaction of ${ }^{p \text {-tol } 2}$ with $d$ acetylene in a 1:1 stoichiometry. ${ }^{1} \mathrm{H}$ NMR $\left(400 \mathrm{MHz}, \mathrm{C}_{6} \mathrm{D}_{6}\right.$, $\left.25^{\circ} \mathrm{C}\right): \delta_{\mathrm{H}} 7.92\left(\mathrm{ArH}, \mathrm{dd},{ }^{3} J_{\mathrm{H}, \mathrm{H}}=8.0 \mathrm{~Hz},{ }^{3} \mathrm{~J}_{\mathrm{H}, \mathrm{P}}=6.8 \mathrm{~Hz}, 2 \mathrm{H}\right)$, 7.63-7.53 (ArH, m, 9H), 7.45-7.39 (ArH, m, 2H), 7.10-6.95 $(\mathrm{ArH}, \mathrm{m}, 14 \mathrm{H}), 6.88\left(\mathrm{ArH}, \mathrm{tt},{ }^{3} \mathrm{~J}_{\mathrm{H}, \mathrm{H}}=7.2 \mathrm{~Hz},{ }^{4} J_{\mathrm{H}, \mathrm{P}} 1.2 \mathrm{~Hz}\right.$, $1 \mathrm{H}), 6.83\left(\mathrm{ArH}, \mathrm{d},{ }^{3} \mathrm{~J}_{\mathrm{H}, \mathrm{H}}=7.6 \mathrm{~Hz}, 4 \mathrm{H}\right), 6.72\left(\mathrm{ArH}, \mathrm{d},{ }^{3} \mathrm{~J}_{\mathrm{H}, \mathrm{H}}=\right.$ $7.6 \mathrm{~Hz}, 4 \mathrm{H}), 2.12\left(\mathrm{CH}_{3}, \mathrm{~s}, 6 \mathrm{H}\right), 1.91\left(\mathrm{CH}_{3}, \mathrm{~s}, 6 \mathrm{H}\right) .{ }^{31} \mathrm{P}$ NMR $\left(161 \mathrm{MHz}, \mathrm{C}_{6} \mathrm{D}_{6}, 25^{\circ} \mathrm{C}\right): \delta_{\mathrm{P}} 78.7\left(\mathrm{PhP}, \mathrm{t},{ }^{2} J_{\mathrm{P}, \mathrm{P}}=35.4 \mathrm{~Hz}, 1 \mathrm{P}\right)$, $28.1\left(p\right.$-tolP, d, $\left.{ }^{2} J_{\mathrm{P}, \mathrm{P}}=35.4 \mathrm{~Hz}, 2 \mathrm{P}\right) .{ }^{13} \mathrm{C}$ NMR $(100 \mathrm{MHz}$, $\left.\mathrm{C}_{6} \mathrm{D}_{6}, 25{ }^{\circ} \mathrm{C}\right): \delta_{\mathrm{C}} 150.0\left(\mathrm{dt}, J_{\mathrm{C}, \mathrm{P}}=47.1 \mathrm{~Hz}, J_{\mathrm{C}, \mathrm{P}}=16.4 \mathrm{~Hz}\right)$, $146.9\left(\mathrm{~d}, J_{\mathrm{C}, \mathrm{P}}=36.0 \mathrm{~Hz}\right) 146.4\left(\mathrm{dd}, J_{\mathrm{C}, \mathrm{P}}=61.6 \mathrm{~Hz}, J_{\mathrm{C}, \mathrm{P}}=34.3\right.$ $\mathrm{Hz}), 140.1\left(\mathrm{dt}, J_{\mathrm{C}, \mathrm{P}}=41.6 \mathrm{~Hz}, J_{\mathrm{C}, \mathrm{P}}=26.0 \mathrm{~Hz}\right), 137.9,137.0-$ $136.6(\mathrm{~m}), 136.8,133.7,133.1\left(\mathrm{t}, J_{\mathrm{C}, \mathrm{P}}=28.0\right) \mathrm{Hz}, 132.5\left(\mathrm{t}, J_{\mathrm{C}, \mathrm{P}}\right.$ $=28.0 \mathrm{~Hz}), 131.8-131.5(\mathrm{~m}), 129.8,129.7-128.9(\mathrm{~m}) 101.1$ (三CPh, br m, $21.3\left(\equiv \mathrm{CH}_{3}, \mathrm{~d}, J_{\mathrm{C}, \mathrm{P}}=4.0 \mathrm{~Hz}\right), 21.1\left(\mathrm{CH}_{3}, \mathrm{~d}\right.$, $\left.J_{\mathrm{C}, \mathrm{P}}=4.0 \mathrm{~Hz}\right)$. ATR-IR: $\nu\left[\mathrm{cm}^{-1}\right] 3333,3042,2918,2861$, $1823,1761,1589,1479,1440,1425,1394,1185,1100,1085$, 1118, 805, 758, 690, 666, 625, 612, 539, 519.

$\left[\left({ }^{P h} \mathrm{L3}\right) \mathrm{Ni}(\mathrm{HC} \equiv \mathrm{CPh})\right]\left({ }^{P h}\right.$ 6-Ph). Under inert atmosphere and at room temperature, a suspension of $\left[\left({ }^{\mathrm{Ph}} \mathrm{L} 3\right) \mathrm{Ni}(\mathrm{BPI})\right]\left({ }^{\mathrm{Ph}} \mathbf{3}\right)$ $(200 \mathrm{mg}, 0.26 \mathrm{mmol})$ in dried degassed toluene $(3 \mathrm{~mL})$ was combined with a toluene solution $(3 \mathrm{~mL})$ of phenylacetylene (26 mg, $0.26 \mathrm{mmol})$, resulting in a light yellow solution. The reaction mixture was subsequently stirred at room temperature for $10 \mathrm{~min}$. Precipitation of a yellow solid was observed after adding dried degassed hexane $(6 \mathrm{~mL})$ and leaving the solution to stand overnight. The resulting solid was filtered, washed with hexane $(5 \times 5 \mathrm{~mL})$, and dried under vacuum to afford ${ }^{\mathrm{Ph}}$ 6-Ph as a yellow powder (112 mg, $\left.0.16 \mathrm{mmol}, 74 \%\right)$. Single crystals suitable for X-ray diffraction were obtained by slow diffusion of hexane into a concentrated toluene solution of ${ }^{\mathrm{Ph}} \mathbf{6}$ Ph. ${ }^{1} \mathrm{H}$ NMR $\left(400 \mathrm{MHz}, \mathrm{C}_{6} \mathrm{D}_{6}, 25{ }^{\circ} \mathrm{C}\right): \delta_{\mathrm{H}} 7.94-7.87(\mathrm{ArH}$, m, 4H), 7.46-7.40 (ArH, m, 4H), $7.30\left(\mathrm{ArH}, \mathrm{dd},{ }^{3} J_{\mathrm{H}, \mathrm{H}}=6.8\right.$ $\left.\mathrm{Hz},{ }^{4} \mathrm{~J}_{\mathrm{H}, \mathrm{H}}=1.4 \mathrm{~Hz}, 2 \mathrm{H}\right), 7.05-6.80(\mathrm{ArH}$ and $\equiv \mathrm{CH}, \mathrm{m}, 18 \mathrm{H})$, $6.75\left(\mathrm{ArH}, \mathrm{ddd},{ }^{3} \mathrm{~J}_{\mathrm{H}, \mathrm{H}}=7.6 \mathrm{~Hz},{ }^{4} \mathrm{~J}_{\mathrm{H}, \mathrm{P}}=4.4 \mathrm{~Hz},{ }^{4} \mathrm{~J}_{\mathrm{H}, \mathrm{H}}=1.2 \mathrm{~Hz}\right.$, $1 \mathrm{H}), 6.66-6.56(\mathrm{ArH}, \mathrm{m}, 3 \mathrm{H}), 6.39\left(\mathrm{ArH}, \mathrm{ddd},{ }^{3} \mathrm{~J}_{\mathrm{H}, \mathrm{H}}=7.2 \mathrm{~Hz}\right.$, $\left.{ }^{4} J_{\mathrm{H}, \mathrm{P}}=4.4 \mathrm{~Hz},{ }^{4} J_{\mathrm{H}, \mathrm{H}}=1.2 \mathrm{~Hz}, 1 \mathrm{H}\right), 6.32\left(\mathrm{ArH}, \mathrm{tt},{ }^{3} J_{\mathrm{H}, \mathrm{H}}=7.6\right.$ $\left.\mathrm{Hz},{ }^{4} \mathrm{~J}_{\mathrm{H}, \mathrm{H}}=1.0 \mathrm{~Hz}, 1 \mathrm{H}\right) .{ }^{31} \mathrm{P} \mathrm{NMR}\left(161 \mathrm{MHz}, \mathrm{C}_{6} \mathrm{D}_{6}, 25{ }^{\circ} \mathrm{C}\right)$ : $\delta_{\mathrm{P}} 29.2\left(\mathrm{~d},{ }^{2} J_{\mathrm{P}, \mathrm{P}}=22.5 \mathrm{~Hz}, 1 \mathrm{P}\right), 27.3\left(\mathrm{~d},{ }^{2} J_{\mathrm{P}, \mathrm{P}}=22.5 \mathrm{~Hz}, 1 \mathrm{P}\right)$. ${ }^{13} \mathrm{C}$ NMR $\left(100 \mathrm{MHz}, \mathrm{C}_{6} \mathrm{D}_{6}, 25{ }^{\circ} \mathrm{C}\right) \delta_{\mathrm{C}} 160.1\left(\mathrm{~d},{ }^{2} J_{\mathrm{C}, \mathrm{P}}=9.1\right.$ $\mathrm{Hz}), 159.8\left(\mathrm{~d},{ }^{2} J_{\mathrm{C}, \mathrm{P}}=11.4 \mathrm{~Hz}\right), 136.6\left(\equiv \mathrm{CPh}, \mathrm{dd},{ }^{2} \mathrm{~J}_{\mathrm{C}, \mathrm{P}}=34.9\right.$ $\left.\mathrm{Hz},{ }^{2} J_{\mathrm{C}, \mathrm{P}}=4.8 \mathrm{~Hz}\right), 136.1,135.5\left(\mathrm{dd}, J_{\mathrm{C}, \mathrm{P}}=34.8 \mathrm{~Hz}, J_{\mathrm{C}, \mathrm{P}}=4.1\right.$ $\mathrm{Hz}), 134.9\left(\mathrm{~d}, J_{\mathrm{C}, \mathrm{P}}=14.5 \mathrm{~Hz}\right), 133.8\left(\mathrm{~d}, J_{\mathrm{C}, \mathrm{P}}=12.7 \mathrm{~Hz}\right), 132.9$ $\left(\mathrm{d}, J_{\mathrm{C}, \mathrm{P}}=1.8 \mathrm{~Hz}\right), 130.7,130.0,129.8\left(\mathrm{~d}, J_{\mathrm{C}, \mathrm{P}}=3.8 \mathrm{~Hz}\right), 129.6$, $129.4\left(\mathrm{~d}, J_{\mathrm{C}, \mathrm{P}}=1.7 \mathrm{~Hz}\right), 129.3,129.0\left(\mathrm{~d}, J_{\mathrm{C}, \mathrm{P}}=3.1 \mathrm{~Hz}\right), 128.8$ $\left(\mathrm{d}, J_{\mathrm{C}, \mathrm{P}}=1.5 \mathrm{~Hz}\right), 125.3,125.7\left(\equiv \mathrm{CH}, \mathrm{dd},{ }^{2} J_{\mathrm{C}, \mathrm{P}}=34.9 \mathrm{~Hz},{ }^{2} J_{\mathrm{C}, \mathrm{P}}\right.$ $=4.8 \mathrm{~Hz}) 124.9\left(\mathrm{~d}, J_{\mathrm{C}, \mathrm{P}}=4.0 \mathrm{~Hz}\right), 124.1\left(\mathrm{~d}, J_{\mathrm{C}, \mathrm{P}}=4.0 \mathrm{~Hz}\right)$, $122.9\left(\mathrm{~d}, J_{\mathrm{C}, \mathrm{P}}=4.9 \mathrm{~Hz}\right), 118.3\left(\mathrm{~d}, J_{\mathrm{C}, \mathrm{P}}=3.4 \mathrm{~Hz}\right)$. ATR-IR: $\nu$ $\left[\mathrm{cm}^{-1}\right]$ 3286, 3171, 3052, 1749, 1588, 1564, 1480, 1461, 1434, $1259,1213,1095,882,834,745,692,554,503$. Due to the high sensitivity of ${ }^{\mathrm{Ph}} \mathbf{6}-\mathbf{P h}$, no elemental analysis data was obtained. The purity and identity of the compound was established by NMR and by its X-ray diffraction structure.

Alternative Synthesis of ${ }^{\mathrm{Ph}} \mathbf{6 - P h}$. Under inert atmosphere, $\mathrm{Ni}(\operatorname{cod})_{2}$ (292 mg, $\left.1.06 \mathrm{mmol}\right),{ }^{\mathrm{Ph}} \mathrm{L} 3$ (567 mg, $\left.1.05 \mathrm{mmol}\right)$, and phenylacetylene $(108 \mathrm{mg}, 1.06 \mathrm{mmol})$ were mixed together and dissolved in dried degassed toluene $(7 \mathrm{~mL})$. The reaction mixture was subsequently stirred at room temperature for $20 \mathrm{~min}$. Precipitation of a yellow solid was observed after adding dried degassed hexane $(10 \mathrm{~mL})$ and leaving the solution to stand overnight. The resulting solid was filtered, washed with hexanes $(5 \times 5 \mathrm{~mL})$, and dried under vacuum to afford ${ }^{\mathrm{Ph}} \mathbf{6}-\mathbf{P h}$ as a yellow powder $(387 \mathrm{mg}, 0.55$ mmol, 53\%).

Synthesis of Deuterated Analogue of ${ }^{\mathrm{Ph}} 6-\mathrm{Ph},\left[\left({ }^{\mathrm{Ph}} \mathrm{L3}\right) \mathrm{Ni}\right.$ $(D C \equiv C P h)]$. The same experimental procedure as for the synthesis of ${ }^{\mathrm{Ph}} \mathbf{6}$ - $\mathbf{P h}$ was followed, using $\mathrm{Ni}(\operatorname{cod})_{2}(50 \mathrm{mg}, 0.18$ mmol), ${ }^{\text {Ph }} \mathbf{L} 3$ (99 mg, $0.18 \mathrm{mmol}$ ), and $d$-phenylacetylene (19 $\mathrm{mg}, 0.18 \mathrm{mmol})$ as starting materials. $\left[\left({ }^{\mathrm{Ph}} \mathbf{L} 3\right) \mathrm{Ni}(\mathrm{DC} \equiv \mathrm{CPh})\right]$ was isolated as a yellow powder $(60 \mathrm{mg}, 0.08 \mathrm{mmol}, 48 \%)$. $\left[\left({ }^{\mathrm{Ph}} \mathrm{L} 3\right) \mathrm{Ni}(\mathrm{DC} \equiv \mathrm{CPh})\right]$ can also be generated from reaction of ${ }^{\mathrm{Ph}} 3$ with $d$-acetylene in a $1: 1$ stoichiometry. ${ }^{1} \mathrm{H}$ NMR (400 $\left.\mathrm{MHz}, \mathrm{C}_{6} \mathrm{D}_{6}, 2{ }^{\circ} \mathrm{C}\right): \delta_{\mathrm{H}} 7.94-7.87(\mathrm{ArH}, \mathrm{m}, 4 \mathrm{H}), 7.46-7.40$ $(\mathrm{ArH}, \mathrm{m}, 4 \mathrm{H}), 7.30\left(\mathrm{ArH}, \mathrm{dd},{ }^{3} J_{\mathrm{H}, \mathrm{H}}=6.8 \mathrm{~Hz},{ }^{4} J_{\mathrm{H}, \mathrm{H}}=1.4 \mathrm{~Hz}\right.$, $2 \mathrm{H}), 7.05-6.80(\mathrm{ArH}, \mathrm{m}, 17 \mathrm{H}), 6.75\left(\mathrm{ArH}, \mathrm{ddd},{ }^{3} \mathrm{~J}_{\mathrm{H}, \mathrm{H}}=7.6\right.$ $\left.\mathrm{Hz},{ }^{4} \mathrm{~J}_{\mathrm{H}, \mathrm{P}}=4.4 \mathrm{~Hz},{ }^{4} \mathrm{~J}_{\mathrm{H}, \mathrm{H}}=1.2 \mathrm{~Hz}, 1 \mathrm{H}\right), 6.66-6.56(\mathrm{ArH}, \mathrm{m}$, $3 \mathrm{H}), 6.39\left(\mathrm{ArH}, \mathrm{ddd},{ }^{3} \mathrm{~J}_{\mathrm{H}, \mathrm{H}}=7.2 \mathrm{~Hz}, \mathrm{~J}_{\mathrm{H}, \mathrm{P}}=4.4 \mathrm{~Hz},{ }^{4} J_{\mathrm{H}, \mathrm{H}}=1.2\right.$ $\mathrm{Hz}, 1 \mathrm{H}), 6.32\left(\mathrm{ArH}, \mathrm{tt},{ }^{3} J_{\mathrm{H}, \mathrm{H}}=7.6 \mathrm{~Hz},{ }^{4} J_{\mathrm{H}, \mathrm{H}}=1.0 \mathrm{~Hz}, 1 \mathrm{H}\right) .{ }^{31} \mathrm{P}$ NMR $\left(161 \mathrm{MHz}, \mathrm{C}_{6} \mathrm{D}_{6}, 25{ }^{\circ} \mathrm{C}\right): \delta_{\mathrm{P}} 29.2\left(\mathrm{~d},{ }^{2} J_{\mathrm{P}, \mathrm{P}}=22.5 \mathrm{~Hz}\right.$, 1P), $27.3\left(\mathrm{~d},{ }^{2} J_{\mathrm{P}, \mathrm{P}}=22.5 \mathrm{~Hz}, 1 \mathrm{P}\right) .{ }^{13} \mathrm{C} \mathrm{NMR}\left(100 \mathrm{MHz}, \mathrm{C}_{6} \mathrm{D}_{6}\right.$, $\left.25^{\circ} \mathrm{C}\right): \delta_{\mathrm{C}} 160.1\left(\mathrm{~d},{ }^{2} J_{\mathrm{C}, \mathrm{P}}=9.1 \mathrm{~Hz}\right), 159.8\left(\mathrm{~d},{ }^{2} J_{\mathrm{C}, \mathrm{P}}=11.4 \mathrm{~Hz}\right)$, $136.4\left(\equiv C \mathrm{Ph}, \mathrm{dd}, J_{\mathrm{C}, \mathrm{P}}=34.9 \mathrm{~Hz}, J_{\mathrm{C}, \mathrm{P}}=4.8 \mathrm{~Hz}\right), 136.1,135.5$ $\left(\mathrm{dd}, J_{\mathrm{C}, \mathrm{P}}=34.8 \mathrm{~Hz}, J_{\mathrm{C}, \mathrm{P}}=4.1 \mathrm{~Hz}\right), 134.9\left(\mathrm{~d}, J_{\mathrm{C}, \mathrm{P}}=14.5 \mathrm{~Hz}\right)$, $133.8\left(\mathrm{~d}, J_{\mathrm{C}, \mathrm{P}}=12.7 \mathrm{~Hz}\right), 132.9\left(\mathrm{~d}, J_{\mathrm{C}, \mathrm{P}}=1.8 \mathrm{~Hz}\right), 130.7,130.0$, $129.8\left(\mathrm{~d}, J_{\mathrm{C}, \mathrm{P}}=3.8 \mathrm{~Hz}\right), 129.6,129.4\left(\mathrm{~d}, J_{\mathrm{C}, \mathrm{P}}=1.7 \mathrm{~Hz}\right), 129.3$, $129.0\left(\mathrm{~d}, J_{\mathrm{C}, \mathrm{P}}=3.1 \mathrm{~Hz}\right), 128.8\left(\mathrm{~d}, J_{\mathrm{C}, \mathrm{P}}=1.5 \mathrm{~Hz}\right), 125.3,124.9$ $\left(\mathrm{d}, J_{\mathrm{C}, \mathrm{P}}=4.0 \mathrm{~Hz}\right), 124.1\left(\mathrm{~d}, J_{\mathrm{C}, \mathrm{P}}=4.0 \mathrm{~Hz}\right), 122.9\left(\mathrm{~d}, J_{\mathrm{C}, \mathrm{P}}=4.9\right.$ $\mathrm{Hz}), 118.3\left(\mathrm{~d}, J_{\mathrm{C}, \mathrm{P}}=3.4 \mathrm{~Hz}\right)$. ATR-IR: $\nu\left[\mathrm{cm}^{-1}\right] 3052,1588$, 1564, 1461, 1434, 1259, 1213, 1095, 882, 745, 692, 503.

In Situ Generation of $\left[\left({ }^{P h} L 3\right) \mathrm{Ni}(\mathrm{PhC} \equiv C \mathrm{CPh})\right]$ for Analytical Comparison with [( $\left.\left.\left.{ }^{\mathrm{Ph}} \mathrm{L} 3\right) \mathrm{Ni}(\mathrm{HC} \equiv \mathrm{CPh})\right]{ }^{\left({ }^{\mathrm{Ph}} 6-\mathrm{Ph}\right)}\right)$. Under inert atmosphere, $\mathrm{Ni}(\operatorname{cod})_{2}(7.6 \mathrm{mg}, 0.028 \mathrm{mmol}),{ }^{\mathrm{Ph}} \mathbf{L} 3(15.6 \mathrm{mg}$, $0.029 \mathrm{mmol})$, and diphenylacetylene $(5.0 \mathrm{mg}, 0.028 \mathrm{mmol})$ were combined together and diluted in $\mathrm{C}_{6} \mathrm{D}_{6}(0.6 \mathrm{~mL})$ at room 
temperature, turning the solution red. The mixture was transferred into a Young-type NMR tube and measured after 30 min of reaction. NMR analysis showed full conversion of the starting reagents and the release of cod, in addition to the single generation of a new species, $\left[\left({ }^{\mathrm{Ph}} \mathbf{L 3}\right) \mathrm{Ni}(\mathrm{PhC} \equiv \mathrm{CPh})\right]$. ${ }^{1} \mathrm{H}$ NMR $\left(400 \mathrm{MHz}, \mathrm{C}_{6} \mathrm{D}_{6}, 25{ }^{\circ} \mathrm{C}\right): \delta_{\mathrm{H}} 7.71-7.61(\mathrm{~m}, 8 \mathrm{H})$, $7.18-7.13(\mathrm{~m}, 4 \mathrm{H}), 6.97-7.88(\mathrm{~m}, 12 \mathrm{H}), 6.86-6.82(\mathrm{~m}, 6 \mathrm{H})$, $6.73-6.66(\mathrm{~m}, 4 \mathrm{H}), 6.55\left(\mathrm{dd},{ }^{3} \mathrm{~J}_{\mathrm{H}, \mathrm{H}}=8.0 \mathrm{~Hz},{ }^{4} \mathrm{~J}_{\mathrm{H}, \mathrm{P}}=2.8 \mathrm{~Hz}\right.$, $2 \mathrm{H}), 6.44\left(\mathrm{t},{ }^{3} \mathrm{~J}_{\mathrm{H}, \mathrm{H}}=7.6 \mathrm{~Hz}, 2 \mathrm{H}\right), 5.58(\mathrm{cod}, \mathrm{s}, 4 \mathrm{H}), 2.21(\mathrm{cod}$, s, $8 \mathrm{H}) .{ }^{31} \mathrm{P}$ NMR $\left(161 \mathrm{MHz}, \mathrm{C}_{6} \mathrm{D}_{6}, 25^{\circ} \mathrm{C}\right): \delta_{\mathrm{P}} 28.1(\mathrm{~s}, 2 \mathrm{P})$. ${ }^{13} \mathrm{C}$ NMR $\left(100 \mathrm{MHz}, \mathrm{C}_{6} \mathrm{D}_{6}, 25{ }^{\circ} \mathrm{C}\right): \delta_{\mathrm{C}} 159.8\left(\mathrm{t},{ }^{2} J_{\mathrm{C}, \mathrm{P}}=5.0\right.$ $\mathrm{Hz}), 136.3\left(\equiv \mathrm{CPh}, \mathrm{t},{ }^{2} J_{\mathrm{C}, \mathrm{P}}=6.8 \mathrm{~Hz}\right), 136.3,136.0,135.8$ $135.3,135.2,135.0\left(\mathrm{~d}, J_{\mathrm{C}, \mathrm{P}}=3.2 \mathrm{~Hz}\right), 134.8,134.7,134.5(\mathrm{t}$, $\left.J_{\mathrm{C}, \mathrm{P}}=7.0 \mathrm{~Hz}\right), 140.0,130.4,129.6,129.5\left(\mathrm{~d}, J_{\mathrm{C}, \mathrm{P}}=3 \mathrm{~Hz}\right)$, $129.3,129.1,128.8,128.7,124.4$ (cod), 123.9, 121.1, 28.4 (cod).

Ligand Exchange Reactions (Scheme 4). In Situ Generation of $\left.\left[{ }^{p \text {-tol }} \mathbf{L} 1\right) N i\left(P P h_{3}\right)\right]\left({ }^{p-t o l} 7-P P h_{3}\right)$. In the glovebox, ${ }^{p \text { tol }} 1$ ( $\left.5 \mathrm{mg}, 5.9 \mu \mathrm{mol}\right)$ and 1 equiv of $\mathrm{PPh}_{3}(1.6 \mathrm{mg}, 5.9$ $\mu \mathrm{mol}$ ) were dissolved in $0.6 \mathrm{~mL}$ of $\mathrm{C}_{6} \mathrm{D}_{6}$. The solution was transferred into a Young-type NMR tube, and an NMR spectrum was recorded approximately $15 \mathrm{~min}$ after the two reactants have been mixed together, showing full conversion of ${ }^{p \text {-tol }} \mathbf{1}$. The analyzed solution contains a mixture of ${ }^{p \text {-tol } 7-\mathbf{P P h}_{3}}$ and BPI in a $1: 1$ ratio. $\left[\left({ }^{p \text {-tol }} \mathbf{L} \mathbf{1}\right) \mathrm{Ni}\left(\mathrm{PPh}_{3}\right)\right]\left({ }^{p \text {-tol }} 7-\mathbf{P P h}_{3}\right)$. $\left[\left({ }^{\mathrm{Ph}} \mathbf{L} \mathbf{1}\right) \mathrm{Ni}\left(\mathrm{PPh}_{3}\right)\right]$, with phenyl substituents on the phosphine ligand, has previously been reported. ${ }^{24}{ }^{1} \mathrm{H}$ NMR $(400 \mathrm{MHz}$, $\left.\mathrm{C}_{6} \mathrm{D}_{6}, 25{ }^{\circ} \mathrm{C}\right): \delta_{\mathrm{H}} 7.86\left(\mathrm{ArH}, \mathrm{d},{ }^{3} J_{\mathrm{H}, \mathrm{H}}=8.0 \mathrm{~Hz}, 2 \mathrm{H}\right), 7.62$ (ArH, t, $\left.{ }^{3} J_{\mathrm{H}, \mathrm{P}}=8.8 \mathrm{~Hz}, 6 \mathrm{H}\right), 7.44-7.39$ (ArH, m, 2H), 7.387.33 (ArH, m, 4H), 7.25-7.19 (ArH, m, 4H), 6.93-7.80 $(\mathrm{ArH}, \mathrm{m}, 9 \mathrm{H}), 6.67\left(p\right.$-tolArH, d, $\left.{ }^{3} \mathrm{~J}_{\mathrm{H}, \mathrm{H}}=7.6 \mathrm{~Hz}, 2 \mathrm{H}\right), 6.61(p$ tolArH, d, $\left.{ }^{3} J_{\mathrm{H}, \mathrm{H}}=7.6 \mathrm{~Hz}, 2 \mathrm{H}\right), 1.97\left(\mathrm{CH}_{3}, \mathrm{~s}, 6 \mathrm{H}\right), 1.96\left(\mathrm{CH}_{3}\right.$, s, 6H). ${ }^{31} \mathrm{P}$ NMR $\left(161 \mathrm{MHz}, \mathrm{C}_{6} \mathrm{D}_{6}, 25{ }^{\circ} \mathrm{C}\right): \delta_{\mathrm{P}} 38.5\left(\mathrm{Ph}_{3} \mathrm{P}, \mathrm{t}\right.$, $\left.{ }^{2} J_{\mathrm{P}, \mathrm{P}}=25.7 \mathrm{~Hz} 1 \mathrm{P}\right), 17.1\left(p-\operatorname{tol}_{2} P, \mathrm{~d},{ }^{2} J_{\mathrm{P}, \mathrm{P}}=25.7 \mathrm{~Hz}, 2 \mathrm{P}\right) .{ }^{13} \mathrm{C}$ NMR $\left(100 \mathrm{MHz}, \mathrm{C}_{6} \mathrm{D}_{6}, 25^{\circ} \mathrm{C}\right): \delta_{\mathrm{C}} 155.1\left(\mathrm{dd}, J_{\mathrm{C}, \mathrm{P}}=19.1 \mathrm{~Hz}\right.$, $\left.J_{\mathrm{C}, \mathrm{P}}=16.0 \mathrm{~Hz}\right), 142.8\left(\mathrm{dt}, J_{\mathrm{C}, \mathrm{P}}=8.4 \mathrm{~Hz}, J_{\mathrm{C}, \mathrm{P}}=16.8 \mathrm{~Hz}\right), 138.4$, $137.6\left(\mathrm{dt}, J_{\mathrm{C}, \mathrm{P}}=29.8 \mathrm{~Hz}, J_{\mathrm{C}, \mathrm{P}}=4.6 \mathrm{~Hz}\right), 136.9,135.2\left(\mathrm{t}, J_{\mathrm{C}, \mathrm{P}}=\right.$ $11.4 \mathrm{~Hz}), 134.3-136.0(\mathrm{~m}), 132.8\left(\mathrm{t}, J_{\mathrm{C}, \mathrm{P}}=7.0 \mathrm{~Hz}\right), 132.2$, 130.6, 128.7-128.5 (m), 126.8, $120.4\left(\mathrm{C}=\mathrm{O}, \mathrm{dt},{ }^{2} \mathrm{~J}_{\mathrm{C}, \mathrm{P}}=13.8\right.$ $\left.\mathrm{Hz},{ }^{2} J_{\mathrm{C}, \mathrm{P}}=4.4 \mathrm{~Hz}\right) 21.2\left(\mathrm{CH}_{3}\right) 21.1\left(\mathrm{CH}_{3}\right)$.

In Situ Generation of [( $\left.\left.{ }^{(-t o l} L 1\right) N i(P h C N)\right]\left({ }^{p-t o l} 7-P h C N\right)$ and $K_{\text {eq }}$ Determination for the Reaction ${ }^{p \text {-tol } 1}+P h C N \Leftrightarrow{ }^{p \text {-tol }} 7$ $P h C N+B P I$. In the glovebox, $\left.{ }^{p \text {-tol } 1 ~} 14.9 \mathrm{mg}, 5.8 \mu \mathrm{mol}\right)$ was dissolved in $0.6 \mathrm{~mL}$ of $\mathrm{C}_{6} \mathrm{D}_{6}$, and 1 equiv of $\mathrm{PhCN}$ was added via a microsyringe $(0.6 \mu \mathrm{L}, 5.8 \mu \mathrm{mol})$. The solution was transferred to a Young-type NMR tube, and an NMR spectrum was recorded approximately $15 \mathrm{~min}$ after the two reactants have been mixed together. ${ }^{31} \mathrm{P}$ NMR was recorded with a relaxation time of $21 \mathrm{~s}$. For ${ }^{1} \mathrm{H} \mathrm{NMR}$, the singlets at $10.01 \mathrm{ppm}$ $(1 \mathrm{H}), 2.10 \mathrm{ppm}(6 \mathrm{H})$, and $1.91 \mathrm{ppm}(6 \mathrm{H})$ for ${ }^{p \text {-tol }} 1$ and the triplet at $6.63(3 \mathrm{H})$ for $\mathrm{PhCN}$ were selected to determine the relative concentration of the reactants. As regards the determination of the concentration of products, the two singlets at $2.04 \mathrm{ppm}(6 \mathrm{H})$ and $2.03 \mathrm{ppm}(6 \mathrm{H})$ for ${ }^{p \text {-tol } 7-P h C N}$ and the singlet at $9.82(1 \mathrm{H})$ for BPI were selected. The same procedure was repeated at different stoichiometry of PhCN (i.e., 50 equiv and 200 equiv compared to ${ }^{p \text {-tol }} \mathbf{1}$ ). ${ }^{1} \mathrm{H}$ NMR $\left(400 \mathrm{MHz}, \mathrm{C}_{6} \mathrm{D}_{6}, 25^{\circ} \mathrm{C}\right): \delta_{\mathrm{H}} 10.01\left({ }^{p \text {-tol }} \mathbf{1}, \mathrm{NH}, \mathrm{s}, 1 \mathrm{H}\right), 9.82$ (BPI, NH, br. s, $1 \mathrm{H}), 8.03\left({ }^{p \text {-tol }} \mathbf{1}, \mathrm{ArH}, \mathrm{d},{ }^{3} J_{\mathrm{H}, \mathrm{H}}=7.4 \mathrm{~Hz}, 2 \mathrm{H}\right)$, $7.92\left({ }^{p \text {-tol }} \mathbf{1}, \mathrm{ArH}, \mathrm{dd},{ }^{3} J_{\mathrm{H}, \mathrm{H}}=7.7,{ }^{4} J_{\mathrm{H}, \mathrm{H}}=1.3,2 \mathrm{H}\right), 7.70\left({ }^{p \text {-tol }} \mathbf{1}\right.$, $\left.\mathrm{ArH}, \mathrm{dt},{ }^{3} J_{\mathrm{H}, \mathrm{H}}=7.9,{ }^{4} J_{\mathrm{H}, \mathrm{P}}=4.6,4 \mathrm{H}\right), 7.35-7.29\left({ }^{p \text {-tol }} \mathbf{1}, \mathrm{ArH}, \mathrm{m}\right.$, $2 \mathrm{H}), 7.10\left({ }^{p \text {-tol }} 1, \mathrm{ArH}, \mathrm{dt},{ }^{3} J_{\mathrm{H}, \mathrm{H}}=7.9 \mathrm{~Hz},{ }^{4} J_{\mathrm{HP}}=4.4 \mathrm{~Hz}\right), 7.02-$ $6.92\left({ }^{p \text {-tol }} 1, \mathrm{ArH}, \mathrm{m}, 6 \mathrm{H}\right), 6.91-6.76\left({ }^{p \text {-tol }} 1, \mathrm{ArH}, \mathrm{m}, 14 \mathrm{H}\right)$, $6.63\left(\mathrm{PhCN}, \mathrm{ArH}, \mathrm{t},{ }^{3} \mathrm{~J}_{\mathrm{H}, \mathrm{H}}=7.6,2 \mathrm{H}\right) 2.10\left({ }^{p \text {-tol }} 1, \mathrm{CH}_{3}, \mathrm{~s}, 6 \mathrm{H}\right)$, $\left.2.04{ }^{p \text {-tol } 7-P h C N}, \mathrm{CH}_{3}, \mathrm{~s}, 6 \mathrm{H}\right), 2.03$ ( ${ }^{p \text {-tol } 7-P h C N}, \mathrm{CH}_{3}, \mathrm{~s}$, $6 \mathrm{H}), 1.91\left({ }^{p \text {-tol }} 1, \mathrm{CH}_{3}, \mathrm{~s}, 6 \mathrm{H}\right) .{ }^{31} \mathrm{P}$ NMR $\left(161 \mathrm{MHz}, \mathrm{C}_{6} \mathrm{D}_{6}, 25\right.$ $\left.{ }^{\circ} \mathrm{C}\right): \delta_{\mathrm{P}} 15.5\left({ }^{p \text {-tol }} 1, \mathrm{~s}, 2 \mathrm{P}\right), 12.7\left(p^{p \text {-tol }} 7\right.$-PhCN, s, 2P).

${ }^{13} \mathrm{C}$ NMR was acquired in order to locate the resonances from the carbonyl and methyl groups of the ligand of ${ }^{p \text {-tol }} 7$ PhCN. ${ }^{13} \mathrm{C}$ NMR $\left(100 \mathrm{MHz}, \mathrm{C}_{6} \mathrm{D}_{6}, 25{ }^{\circ} \mathrm{C}\right): \delta_{\mathrm{c}} 22.8\left(\mathrm{CH}_{3}\right)$. No carbonyl peak around $200 \mathrm{ppm}$ was detected.

In Situ Generation of [( $\left.\left.{ }^{p-t o l} \mathrm{~L} 1\right) \mathrm{Ni}\left(\mathrm{C}_{2} \mathrm{H}_{3} \mathrm{Ph}\right)\right]\left({ }^{p-t o l} 7-\mathrm{C}_{2} \mathrm{H}_{3} \mathrm{Ph}\right)$ and $K_{\text {eq }}$ Determination for the Reaction ${ }^{p \text {-tol } 1}+\mathrm{C}_{2} \mathrm{H}_{3} P h \Leftrightarrow$ p-tol $7-\mathrm{C}_{2} \mathrm{H}_{3} \mathrm{Ph}+\mathrm{BPI}$. In the glovebox, ${ }^{p \text {-tol }} \mathbf{1}(4.4 \mathrm{mg}, 5.2 \mu \mathrm{mol})$ was dissolved in $0.6 \mathrm{~mL}$ of $\mathrm{C}_{6} \mathrm{D}_{6}$ and 1 equiv of styrene was added via a microsyringe $(0.6 \mu \mathrm{L}, 5.2 \mu \mathrm{mol})$. The solution was transferred to a Young-type NMR tube, and an NMR spectrum was recorded approximately $15 \mathrm{~min}$ after the two reactants have reacted. ${ }^{31} \mathrm{P}$ NMR was recorded with a relaxation time of $21 \mathrm{~s}$. For ${ }^{1} \mathrm{H} \mathrm{NMR}$, the singlet at $10.01 \mathrm{ppm}(1 \mathrm{H})$ for ${ }^{p \text {-tol }} \mathbf{1}$ and the four sets of peaks at $7.23 \mathrm{ppm}(2 \mathrm{H}), 6.58 \mathrm{ppm}(1 \mathrm{H}), 5.60$ ppm $(1 \mathrm{H})$, and $5,07 \mathrm{ppm}(1 \mathrm{H})$ for $\mathrm{C}_{2} \mathrm{H}_{3} \mathrm{Ph}$ were selected to determine the relative concentration of the reactants. As regards the determination of the concentration of products, the four sets of peaks at $6.34 \mathrm{ppm}(2 \mathrm{H}), 5.02-4.92 \mathrm{ppm}(1 \mathrm{H})$, $4.53 \mathrm{ppm}(1 \mathrm{H}), 3.78-3.73(1 \mathrm{H})$ for ${ }^{p \text {-tol }} 7-\mathrm{C}_{2} \mathbf{H}_{3} \mathbf{P h}$ and the singlet at $9.82(1 \mathrm{H})$ for BPI were selected. The same procedure was repeated at different stoichiometry of styrene (i.e., 50 equiv and 200 equiv compared to ${ }^{p \text {-tol }} \mathbf{1}$ ). ${ }^{1} \mathrm{H}$ NMR $\left(400 \mathrm{MHz}, \mathrm{C}_{6} \mathrm{D}_{6}, 25^{\circ} \mathrm{C}\right): \delta_{\mathrm{H}} 10.01\left({ }^{p \text {-tol }} 1, \mathrm{NH}, \mathrm{s}, 1 \mathrm{H}\right), 9.82$ (BPI, NH, br. s, $1 \mathrm{H}), 8.03\left({ }^{p \text {-tol } 1, ~ A r H, ~ d, ~}{ }^{3} J_{\mathrm{H}, \mathrm{H}}=7.4 \mathrm{~Hz}, 2 \mathrm{H}\right)$, $7.92\left({ }^{p \text {-tol }} \mathbf{1}, \mathrm{ArH}, \mathrm{dd},{ }^{3} J_{\mathrm{H}, \mathrm{H}}=7.7,{ }^{4} J_{\mathrm{H}, \mathrm{H}}=1.3,2 \mathrm{H}\right), 7.70\left({ }^{p \text {-tol }} \mathbf{1}\right.$, $\left.\mathrm{ArH}, \mathrm{dt},{ }^{3} J_{\mathrm{H}, \mathrm{H}}=7.9,{ }^{4} J_{\mathrm{H}, \mathrm{P}}=4.6,4 \mathrm{H}\right), 7.35-7.29\left({ }^{p \text {-tol }} \mathbf{1}, \mathrm{ArH}, \mathrm{m}\right.$, $2 \mathrm{H}), 7.23\left(\mathrm{C}_{2} \mathrm{H}_{3} \mathrm{Ph}, \mathrm{PhH}, \mathrm{d},{ }^{3} J_{\mathrm{H}, \mathrm{H}}=7.2 \mathrm{~Hz}, 2 \mathrm{H}\right) ; 7.10\left({ }^{p \text {-tol }} \mathbf{1}\right.$, $\left.\mathrm{ArH}, \mathrm{dt},{ }^{3} J_{\mathrm{H}, \mathrm{H}}=7.9 \mathrm{~Hz},{ }^{4} J_{\mathrm{HP}}=4.4 \mathrm{~Hz}\right), 7.02-6.92\left({ }^{p-\text { tol }} \mathbf{1}, \mathrm{ArH}\right.$, m, 6H), 6.91-6.76 ( $\left.{ }^{p \text {-tol } 1, ~} \mathrm{ArH}, \mathrm{m}, 14 \mathrm{H}\right), 6.58\left(\mathrm{C}_{2} \mathrm{H}_{3} \mathrm{Ph},=\right.$ $\left.\mathrm{CH}, \mathrm{dd},{ }^{3} \mathrm{~J}_{\mathrm{H}, \mathrm{H}}=17.6 \mathrm{~Hz},{ }^{3} J_{\mathrm{H}, \mathrm{H}}=10.8 \mathrm{~Hz}, 1 \mathrm{H}\right), 6.34\left(^{p \text {-tol }} 7-\right.$ $\left.\mathrm{C}_{2} \mathrm{H}_{3} \mathbf{P h}, \mathrm{PhH}, \mathrm{d},{ }^{3} \mathrm{~J}_{\mathrm{H}, \mathrm{H}}=7.2 \mathrm{~Hz}, 2 \mathrm{H}\right), 5.60\left(\mathrm{C}_{2} \mathrm{H}_{3} \mathrm{Ph},=\mathrm{CH}_{2}\right.$, d, $\left.{ }^{3} J_{\mathrm{H}, \mathrm{H}}=17.6 \mathrm{~Hz}, 1 \mathrm{H}\right), 5.07\left(\mathrm{C}_{2} \mathrm{H}_{3} \mathrm{Ph},=\mathrm{CH}_{2}, \mathrm{~d},{ }^{3} J_{\mathrm{H}, \mathrm{H}}=10.8\right.$ $\mathrm{Hz}, 1 \mathrm{H}), 5.02-4.92\left({ }^{p \text {-tol }} 7-\mathrm{C}_{2} \mathbf{H}_{3} \mathbf{P h},=\mathrm{CH}, \mathrm{m}, 1 \mathrm{H}\right), 4.53$ $\left({ }^{p \text {-tol }} 7-\mathrm{C}_{2} \mathbf{H}_{3} \mathbf{P h},=\mathrm{CH}_{2}, J=9.6 \mathrm{~Hz}, \mathrm{~d}, 1 \mathrm{H}\right) ; 3.78-3.73{ }^{p \text {-tol }} 7-$ $\left.\mathrm{C}_{2} \mathrm{H}_{3} \mathrm{Ph},=\mathrm{CH}_{2}, \mathrm{~m}, 1 \mathrm{H}\right), 2.10\left({ }^{p \text {-tol }} \mathbf{1}, \mathrm{CH}_{3}, \mathrm{~s}, 6 \mathrm{H}\right) ; 2.05\left({ }^{p \text {-tol }} 7\right.$ $\left.\mathbf{C}_{2} \mathbf{H}_{3} \mathbf{P h}, \mathrm{CH}_{3}, \mathrm{~s}, 6 \mathrm{H}\right), 2.01$ ( $\left.{ }^{\text {-tol }} 7-\mathrm{C}_{2} \mathbf{H}_{3} \mathbf{P h}, \mathrm{CH}_{3}, \mathrm{~s}, 6 \mathrm{H}\right), 1.91$ $\left(p^{\text {-tol }} 1, \mathrm{CH}_{3}, \mathrm{~s}, 6 \mathrm{H}\right) .{ }^{31} \mathrm{P} \mathrm{NMR}\left(161 \mathrm{MHz}, \mathrm{C}_{6} \mathrm{D}_{6}, 25{ }^{\circ} \mathrm{C}\right): \delta_{\mathrm{P}}$ $39.2\left({ }^{p \text {-tol }} 7-\mathbf{C}_{2} \mathbf{H}_{3} \mathbf{P h}, \mathrm{d},{ }^{2} J_{\mathrm{p}, \mathrm{P}}=33.8 \mathrm{~Hz}, 1 \mathrm{P}\right), 15.9\left(^{p \text {-tol }} 7-\right.$ $\left.\mathrm{C}_{2} \mathrm{H}_{3} \mathrm{Ph}, \mathrm{d},{ }^{2} J_{\mathrm{P}, \mathrm{P}}=33.8 \mathrm{~Hz}, 1 \mathrm{P}\right), 15.4\left({ }^{p \text {-tol }} \mathbf{1}, \mathrm{s}, 2 \mathrm{P}\right)$.

${ }^{13} \mathrm{C}$ NMR was acquired in order to locate the resonances from the carbonyl and methyl groups of the ligand of ${ }^{p \text {-tol }} 7$ $\mathrm{C}_{2} \mathrm{H}_{3}$ Ph. ${ }^{13} \mathrm{C}$ NMR $\left(100 \mathrm{MHz}, \mathrm{C}_{6} \mathrm{D}_{6}, 25{ }^{\circ} \mathrm{C}\right): \delta_{\mathrm{C}} 21.9\left(\mathrm{CH}_{3}\right)$, $21.8\left(\mathrm{CH}_{3}\right)$. No carbonyl peak around $200 \mathrm{ppm}$ was detected.

In Situ Generation of $\left[\left({ }^{p-t o l} L 1\right) N i\left(C_{2} P h_{2}\right)\right]\left({ }^{p-t o l} 7-C_{2} P h_{2}\right)$ and $K_{\text {eq }}$ Determination for the Reaction ${ }^{p \text {-tol }} 1+C_{2} P h_{2} \Leftrightarrow{ }^{p \text {-tol }} 7$ $\mathrm{C}_{2} \mathrm{Ph}_{2}+\mathrm{BPI}$. In the glovebox, ${ }^{p \text {-tol }} \mathbf{1}(4.7 \mathrm{mg}, 5.7 \mu \mathrm{mol})$ and 1 equiv of diphenylacetylene $(1.0 \mathrm{mg}, 5.7 \mu \mathrm{mol})$ was dissolved in $0.6 \mathrm{~mL}$ of $\mathrm{C}_{6} \mathrm{D}_{6}$. The solution was transferred to a Young-type NMR tube, and an NMR spectrum was recorded approximately $15 \mathrm{~min}$ after the two reactants have reacted. ${ }^{31} \mathrm{P}$ NMR was recorded with a relaxation time of $21 \mathrm{~s}$. For ${ }^{1} \mathrm{H}$ NMR, the singlets at $10.01 \mathrm{ppm}(1 \mathrm{H}), 2.10 \mathrm{ppm}(6 \mathrm{H})$, and $1.91 \mathrm{ppm}$ $(6 \mathrm{H})$ for ${ }^{p \text {-tol } 1}$ and the doublet of doublets at $7.52(2 \mathrm{H})$ for $\mathrm{C}_{2} \mathrm{Ph}_{2}$ were selected to determine the relative concentration of the reactants. As regards the determination of the concentration of products, the singlets at $1.95 \mathrm{ppm}(12 \mathrm{H})$ for ${ }^{p \text {-tol }}$ $\mathbf{C}_{2} \mathbf{P h}_{2}$ and the singlet at $9.82(1 \mathrm{H})$ for BPI were selected. The same procedure was repeated at different stoichiometry of 
diphenylacetylene (i.e., 50 equiv and 200 equiv compared to $\left.{ }^{p \text {-tol }} \mathbf{1}\right) .{ }^{1} \mathrm{H}$ NMR $\left(400 \mathrm{MHz}, \mathrm{C}_{6} \mathrm{D}_{6}, 25{ }^{\circ} \mathrm{C}\right): \delta_{\mathrm{H}} 10.01{ }^{p \text {-tol }} \mathbf{1}$, $\mathrm{NH}, \mathrm{s}, 1 \mathrm{H}), 9.82$ (BPI, NH, br. s, $1 \mathrm{H}), 8.03$ ( ${ }^{p \text {-tol }} \mathbf{1}, \mathrm{ArH}, \mathrm{d}$, $\left.{ }^{3} J_{\mathrm{H}, \mathrm{H}}=7.4 \mathrm{~Hz}, 2 \mathrm{H}\right), 7.92\left({ }^{p-t o l} \mathbf{1}, \mathrm{ArH}, \mathrm{dd},{ }^{3} J_{\mathrm{H}, \mathrm{H}}=7.7,{ }^{4} \mathrm{~J}_{\mathrm{H}, \mathrm{H}}=\right.$ $1.3,2 \mathrm{H}), 7.70\left({ }^{p \text {-tol }} 1, \mathrm{ArH}, \mathrm{dt},{ }^{3} J_{\mathrm{H}, \mathrm{H}}=7.9,{ }^{4} J_{\mathrm{H}, \mathrm{P}}=4.6,4 \mathrm{H}\right), 7.52$ $\left(\mathrm{C}_{2} \mathrm{Ph}_{2}, \mathrm{PhH}, \mathrm{dd},{ }^{3} J_{\mathrm{H}, \mathrm{H}}=8.0 \mathrm{~Hz},{ }^{4} J_{\mathrm{H}, \mathrm{H}}=2.4 \mathrm{~Hz}, 2 \mathrm{H}\right), 7.35-$ $7.29\left({ }^{p \text {-tol }} 1, \mathrm{ArH}, \mathrm{m}, 2 \mathrm{H}\right), 7.23\left(\mathrm{C}_{2} \mathrm{H}_{3} \mathrm{Ph}, \mathrm{PhH}, \mathrm{d},{ }^{3} J_{\mathrm{H}, \mathrm{H}}=7.2\right.$ $\mathrm{Hz}, 2 \mathrm{H}), 7.10\left({ }^{p \text {-tol }} \mathbf{1}, \mathrm{ArH}, \mathrm{dt},{ }^{3} J_{\mathrm{H}, \mathrm{H}}=7.9 \mathrm{~Hz},{ }^{4} J_{\mathrm{HP}}=4.4 \mathrm{~Hz}\right)$, 7.02-6.92 ( $\left.{ }^{p \text {-tol }} \mathbf{1}, \mathrm{ArH}, \mathrm{m}, 6 \mathrm{H}\right), 6.91-6.76\left({ }^{p \text {-tol }} \mathbf{1}, \mathrm{ArH}, \mathrm{m}\right.$, $14 \mathrm{H}), 6.70\left({ }^{p \text {-tol }} 7-\mathbf{C}_{2} \mathbf{P h}_{2}, \mathrm{ArH}, \mathrm{d},{ }^{3} J_{\mathrm{H}, \mathrm{H}}=8.0 \mathrm{~Hz} 8 \mathrm{H}\right), 2.10$ $\left({ }^{p \text {-tol }} \mathbf{1}, \mathrm{CH}_{3}, \mathrm{~s}, 6 \mathrm{H}\right), 1.95$ ( $\left.^{p \text {-tol }} 7-\mathbf{C}_{2} \mathbf{P h}_{2}, \mathrm{CH}_{3}, \mathrm{~s}, 12 \mathrm{H}\right), 1.91$ $\left({ }^{p \text {-tol }} 1, \mathrm{CH}_{3}, \mathrm{~s}, 6 \mathrm{H}\right) .{ }^{31} \mathrm{P}$ NMR $\left(161 \mathrm{MHz}, \mathrm{C}_{6} \mathrm{D}_{6}, 25{ }^{\circ} \mathrm{C}\right): \delta_{\mathrm{P}}$ $34.0\left({ }^{p \text {-tol }} 7-\mathrm{C}_{2} \mathbf{P h}_{2}, \mathrm{~s}, 2 \mathrm{P}\right), 15.4\left({ }^{p \text {-tol }} \mathbf{1}, \mathrm{s}, 2 \mathrm{P}\right)$.

${ }^{13} \mathrm{C}$ NMR was acquired in order to locate the resonances

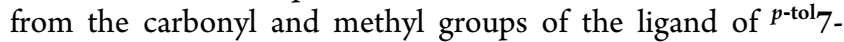
$\mathrm{C}_{2} \mathbf{P h}_{2} \cdot{ }^{13} \mathrm{C}$ NMR $\left(100 \mathrm{MHz}, \mathrm{C}_{6} \mathrm{D}_{6}, 25^{\circ} \mathrm{C}\right): \delta_{\mathrm{C}} 198.3(\mathrm{C}=\mathrm{O}$, $\left.\mathrm{t},{ }^{4} J_{\mathrm{C}, \mathrm{P}}=4.7 \mathrm{~Hz}\right) ; 21.2\left(\mathrm{CH}_{3}\right)$.

Catalysis: General procedure for alkyne cyclotrimerization (Table 3 and Table 4). Method A. In the glovebox, a toluene solution $(3 \mathrm{~mL})$ of alkyne was added slowly, within 1 min, into a toluene solution $(3 \mathrm{~mL})$ containing $0.5 \mathrm{~mol} \%$ of the nickel catalyst (Ni-cat. ${ }^{p \text {-tol }} \mathbf{1}$ to $\mathrm{Ni}$-cat. $\left.{ }^{\mathrm{Ph}} \mathbf{3}\right)$. The solution was stirred at room temperature (substrates 8-11) or $50{ }^{\circ} \mathrm{C}$ (substrates 12 and 13) for $16 \mathrm{~h}$. The solution was then opened to air, and the organic layer was extracted with $\mathrm{HCl} 1 \mathrm{M}(1 \times$ $10 \mathrm{~mL})$ and water $(2 \times 10 \mathrm{~mL})$. The aqueous layer was washed with $\mathrm{Et}_{2} \mathrm{O}(3 \times 10 \mathrm{~mL})$, and the organic portions were combined together, dried over $\mathrm{MgSO}_{4}$, filtered, and concentrated under vacuum. The product was extracted with $\mathrm{Et}_{2} \mathrm{O}$ and filtered through a silica plug. The final product was dried in vacuo and analyzed by GC-MS and NMR. The NMR characterization values of the organic catalytic products were compared with literature. The isomeric ratios were calculated and are reported according to ${ }^{1} \mathrm{H}$ NMR. The reported values (yields and isomeric ratios) presented in Table 3 and Table 4 are the average values over two runs.

Method B. In the glovebox, a toluene solution $(3 \mathrm{~mL})$ of alkyne was added slowly, within $1 \mathrm{~min}$, into a toluene solution (3 mL) containing $0.5 \mathrm{~mol} \%$ of the ligand $\left({ }^{p \text {-tol }} \mathbf{L} \mathbf{1}\right.$ to $\left.{ }^{\mathrm{Ph}} \mathbf{L} 4\right)$ and $0.5 \mathrm{~mol} \%$ of $\mathrm{Ni}(\mathrm{cod})_{2}$. The solution was stirred at room temperature for $16 \mathrm{~h}$. The solution was then opened to air, and the organic layer was extracted with $\mathrm{HCl} 1 \mathrm{M}(1 \times 10 \mathrm{~mL})$ and water $(2 \times 10 \mathrm{~mL})$. The aqueous layer was washed with $\mathrm{Et}_{2} \mathrm{O}$ $(3 \times 10 \mathrm{~mL})$, and the organic portions were combined together, dried over $\mathrm{MgSO}_{4}$, filtered, and concentrated under vacuum. The product was extracted with $\mathrm{Et}_{2} \mathrm{O}$ and filtered through a silica plug. The final product was dried under vacuum and analyzed by GC-MS and NMR. The NMR characterization values of the organic catalytic products were compared with literature. The ratios were calculated and are reported according to ${ }^{1} \mathrm{H} \mathrm{NMR}$.

TON Experiment for the Cyclotrimerization of Ethyl Propiolate Catalyzed by ${ }^{p \text {-tol }} 1$. In the glovebox, a toluene solution $(3 \mathrm{~mL})$ of ethyl propiolate $(11,232 \mathrm{mg}, 2.37 \mathrm{mmol})$ was added slowly, within $1 \mathrm{~min}$, into a toluene solution $(3 \mathrm{~mL})$ containing $0.05 \mathrm{~mol} \%$ of the nickel catalyst ${ }^{p \text {-tol } 1}(1 \mathrm{mg}, 1.2$ $\mu \mathrm{mol}$ ). The solution was stirred at room temperature for $16 \mathrm{~h}$. The solution was then opened to air, and the organic layer was extracted with $\mathrm{HCl} 1 \mathrm{M}(1 \times 10 \mathrm{~mL})$ and water $(2 \times 10 \mathrm{~mL})$. The aqueous layer was washed with $\mathrm{Et}_{2} \mathrm{O}(3 \times 10 \mathrm{~mL})$, and the organic portions were combined together, dried over $\mathrm{MgSO}_{4}$, filtered, and concentrated under vacuum. The product was extracted with $\mathrm{Et}_{2} \mathrm{O}$ and filtered through a silica plug. The ratios between 1,2,4- (11a) and 1,3,5- (11b) regioisomers in addition to a minor amount of tetraethyl-cyclooctatetraenetetracarboxylates (11c) were determined by ${ }^{1} \mathrm{H}$ NMR in a ratio of 91:7:2. Triethylbenzene-1,2,4-tricarboxylate (11a) was obtained in a yield of $87 \%(202 \mathrm{mg}, 0.69 \mathrm{mmol})$.

\section{ASSOCIATED CONTENT}

\section{Supporting Information}

The Supporting Information is available free of charge on the ACS Publications website at DOI: 10.1021/acscatal.8b05025.

Experimental, DFT, and crystallographic details (PDF) Crystal structures (CIF)

\section{AUTHOR INFORMATION}

\section{Corresponding Author}

*E-mail: m.moret@uu.nl.

ORCID $\odot$

Marc-Etienne Moret: 0000-0002-3137-6073

Notes

The authors declare no competing financial interest.

CCDC 1882146-1882149 contain the supplementary crystallographic data for this paper. These data can be obtained free of charge from The Cambridge Crystallographic Data Centre via www.ccdc.cam.ac.uk/data_request/cif.

\section{ACKNOWLEDGMENTS}

The X-ray diffractometer has been financed by The Netherlands Organization for Scientific Research (NWO). We acknowledge funding from NWO council under grant agreement ECHO-STIP, project no. 717.014.009. This work was sponsored by NWO Exacte en Natuurwetenschappen (Physical Sciences) for the use of supercomputer facilities, with financial support from the Nederlandse Organisatie voor Wetenschappelijk Onderzoek (Netherlands Organization for Scientific Research, NWO). The DFT work was carried out on the Dutch national e-infrastructure with the support of the SURF Foundation. The authors thank Dr. J. T. B. H. Jastrzebski for assistance with NMR spectroscopic analysis.

\section{REFERENCES}

(1) van der Vlugt, J. I. Cooperative Catalysis with First-Row Late Transition Metals. Eur. J. Inorg. Chem. 2012, 2012, 363-375.

(2) Verhoeven, D. G. A.; Moret, M.-E. Metal-Ligand Cooperation at Tethered $\pi$-Ligands. Dalt. Trans. 2016, 45, 15762-15778.

(3) Grützmacher, H. Cooperating Ligands in Catalysis. Angew. Chem., Int. Ed. 2008, 47, 1814-1818.

(4) The Organometallic Chemistry of Transition Metals, 6th ed.; Crabtree, R. H., Ed.; John Wiley and Sons: Hoboken, USA, 2014.

(5) Catalysis Without Precious Metals; Bullock, R. M., Ed.; WileyVCH: Weinheim, Germany, 2010.

(6) Slone, C. S.; Weinberger, D. A.; Mirkin, C. A. The Transition Metal Coordination Chemistry of Hemilabile Ligands. Prog. Inorg. Chem. 2007, 48, 233-350.

(7) Jeffrey, J. C.; Rauchfuss, T. B. Metal Complexes of Hemilabile Ligands. Reactivity and Structure of Dichlorobis(o(diphenylphosphino)anisole)ruthenium(II). Inorg. Chem. 1979, 18, $2658-2666$

(8) (a) Adams, G. M.; Weller, A. S. POP-type ligands: Variable Coordination and Hemilabile Behaviour. Coord. Chem. Rev. 2018, 355, 150-172. (b) Oliveri, C. G.; Ulmann, P. A.; Wiester, M. J.; Mirkin, C. A. Heteroligated Supramolecular Coordination Complexes Formed via the Halide-Induced Ligand Rearrangement Reaction. Acc. Chem. Res. 2008, 41, 1618-1629. (c) Bader, A.; Lindner, E. Coordination Chemistry and Catalysis with Hemilabile Oxygen- 
Phosphorus Ligands. Coord. Chem. Rev. 1991, 108, 27-110. (d) Moxham, G. L.; Randell-Sly, H. E.; Brayshaw, S. K.; Woodward, R. L.; Weller, A. S.; Willis, M. C. A Second-Generation Catalyst for Intermolecular Hydroacylation of Alkenes and Alkynes Using $\beta$-S-Substituted Aldehydes: The Role of a Hemilabile P-O-P Ligand. Angew. Chem., Int. Ed. 2006, 45, 7618-7622.

(9) (a) Lindner, R.; van den Bosch, B.; Lutz, M.; Reek, J. N. H.; van der Vlugt, J. I. Tunable Hemilabile Ligands for Adaptive Transition Metal Complexes. Organometallics 2011, 30, 499-510. (b) Choualeb, A.; Lough, A. J.; Gusev, D. G. Hemilabile Pincer-Type Hydride Complexes of Iridium. Organometallics 2007, 26, 5224-5229. (c) Müller, C.; Lachicotte, R. J.; Jones, W. D. Catalytic C-C Bond Activation in Biphenylene and Cyclotrimerization of Alkynes: Increased Reactivity of P,N- versus P,P-Substituted Nickel Complexes. Organometallics 2002, 21, 1975-1981. (d) Fryzuk, M. D.; MacNeil, P. A.; Rettig, S. J.; Secco, A. S.; Trotter, J. Tridentate Amido Phosphine Derivatives of the Nickel Triad: Synthesis, Characterization, and Reactivity of Nickel(II), Palladium(II), and Platinum(II) Amide Complexes. Organometallics 1982, 1, 918-930.

(10) (a) Braunstein, P.; Naud, F. Hemilability of Hybrid Ligands and the Coordination Chemistry of Oxazoline-Based Systems. Angew. Chem., Int. Ed. 2001, 40, 680-699. (b) van der Vlugt, J. I.; Pidko, E. A.; Vogt, D.; Lutz, M.; Spek, A. L.; Meetsma, A. T-Shaped Cationic $\mathrm{Cu}^{\mathrm{I}}$ Complexes with Hemilabile PNP-Type Ligands. Inorg. Chem. 2008, 47, 4442-4444. (c) van der Vlugt, J. I.; Pidko, E. A.; Vogt, D.; Lutz, M.; Spek, A. L. Cu ${ }^{\mathrm{I}}$ Complexes with a Noninnocent PNP Ligand: Selective Dearomatization and Electrophilic Addition Reactivity. Inorg. Chem. 2009, 48, 7513-7515.

(11) Deckers, P. J. W.; Hessen, B.; Teuben, J. H. Switching a Catalyst System from Ethene Polymerization to Ethene Trimerization with a Hemilabile Ancillary Ligand. Angew. Chem., Int. Ed. 2001, 40, 2516-2519.

(12) Lindner, E.; Sickinger, A.; Wegner, P. Neuartige Basische Liganden für die Homogenkatalytische Methanolcarbonylierung: XVII. Dioxanylmethyldiorganylphosphane als Steuerliganden bei der Methanol(hydro) Carbonylierung zu Acetaldehyd und Essigsäure. J. Organomet. Chem. 1988, 349, 75-94.

(13) Zhang, J.; Leitus, G.; Ben-david, Y.; Milstein, D. Efficient Homogeneous Catalytic Hydrogenation of Esters to Alcohols. Angew. Chem. 2006, 118, 1131-1133.

(14) Spasyuk, D.; Vicent, C.; Gusev, D. G. Chemoselective Hydrogenation of Carbonyl Compounds and Acceptorless Dehydrogenative Coupling of Alcohols. J. Am. Chem. Soc. 2015, 137, 37433746.

(15) Pawley, R. J.; Huertos, M. A.; Lloyd-Jones, G. C.; Weller, A. S.; Willis, M. C. Intermolecular Alkyne Hydroacylation. Mechanistic Insight from the Isolation of the Vinyl Intermediate that Precedes Reductive Elimination. Organometallics 2012, 31, 5650-5659.

(16) Weng, Z.; Teo, S.; Hor, T. S. A. Metal Unsaturation and Ligand Hemilability in Suzuki Coupling. Acc. Chem. Res. 2007, 40, 676-684.

(17) van der Vlugt, J. I.; Siegler, M. A.; Janssen, M.; Vogt, D.; Spek, A. L. A Cationic $\mathrm{Ag}^{\mathrm{I}}\left(\mathrm{PNP}^{\mathrm{tBu}}\right)$ Species Acting as PNP Transfer Agent: Facile Synthesis of $\mathrm{Pd}\left(\mathrm{PNP}^{\mathrm{tBu}}\right)($ alkyl) Complexes and Their Reactivity Compared to $\mathrm{PCP}^{\mathrm{tBu}}$ Analogues. Organometallics 2009, $28,7025-7032$

(18) Gunanathan, C.; Ben-David, Y.; Milstein, D. Direct Synthesis of Amides from Alcohols and Amines with Liberation of $\mathrm{H}_{2}$. Science 2007, 317, 790-792.

(19) Gunanathan, C.; Milstein, D. Selective Synthesis of Primary Amines Directly from Alcohols and Ammonia. Angew. Chem. 2008, 120, 8789-8792.

(20) For reviews on $\sigma$-acceptor ligands, see (a) Braunschweig, H.; Dewhurst, R. D.; Schneider, A. Electron-Precise Coordination Modes of Boron-Centered Ligands. Chem. Rev. 2010, 110, 3924-3957. (b) Amgoune, A.; Bourissou, D. $\sigma$-Acceptor, Z-Type Ligands for Transition Metals. Chem. Commun. 2011, 47, 859-871.

(21) For examples of triarylborane-supported metal complexes, see ref 20a and (a) Fontaine, F.-G.; Boudreau, J.; Thibault, M. H. Coordination Chemistry of Neutral $\left(\mathrm{L}_{\mathrm{n}}\right)-\mathrm{Z}$ Amphoteric and
Ambiphilic Ligands. Eur. J. Inorg. Chem. 2008, 2008, 5439-5454. (b) Moret, M.-E.; Peters, J. C. Terminal Iron Dinitrogen and Iron Imide Complexes Supported by a Tris(phosphino)borane Ligand. Angew. Chem., Int. Ed. 2011, 50, 2063-2067.

(22) For examples of $\mathrm{C}=\mathrm{C} \pi$-ligands, see (a) Bennett, M. A.; Clark, P. W. Tridentate Chelate $\pi$-Bonded Complexes of Rhodium(I), Iridium(I), and Iridium(III) Chelate $\sigma$-Bonded Complexes of Nickel(II), Palladium(II), and Platinum (II) Formed by Intramolecular Hydrogen Abstarction Reactions. J. Organomet. Chem. 1976, 110, 367-381. (b) Bennett, M. A.; Johnson, R. N.; Tomkins, I. B. Additions to Metal Atom and to Coordinated Ligand in Complexes of Rhodium(I) and Iridium(I) Formed by a Tridentate Olefinic Ditertiary Phosphine: Chelate Olefin Complexes and $\sigma$-Alkyls of Rhodium(III) and Iridium(III). J. Organomet. Chem. 1976, 118, 205232. (c) Linden, A.; Llovera, L.; Herrera, J.; Dorta, R.; Agrifoglio, G.; Dorta, R. Chiral-at-Metal" Hemilabile Nickel Complexes with a Latent $\mathrm{d}^{10}-\mathrm{ML}_{2}$ Configuration: Receiving Substrates with Open Arms. Organometallics 2012, 31, 6162-6171. (d) Barrett, B. J.; Iluc, V. M. Coordination of a Hemilabile Pincer Ligand with an Olefinic Backbone to Mid-to-Late Transition Metals. Inorg. Chem. 2014, 53, 7248-7259. (e) Barrett, B. J.; Iluc, V. M. Group 10 Metal Complexes Supported by Pincer Ligands with an Olefinic Backbone. Organometallics 2014, 33, 2565-2574. (f) Comanescu, C. C.; Vyushkova, M.; Iluc, V. M. Palladium Carbene Complexes as Persistent Radicals. Chem. Sci. 2015, 6, 4570-4579. (g) Campos, J.; Ortega-Moreno, L.; Conejero, S.; Peloso, R.; Lõpez-Serrano, J.; Maya, C.; Carmona, E. Reactivity of Cationic Agostic and Carbene Structures Derived from Platinum(II) Metallacycles. Chem. - Eur. J. 2015, 21, 8883-8896.

(23) For the first synthetic report of ${ }^{\mathrm{Ph}} \mathbf{L} 1$, see Jing, Q.; Sandoval, C. A.; Wang, Z.; Ding, K. Complete Chiral Induction from Enantiopure 1,2-Diamines to Benzophenone-Based Achiral Bisphosphane Ligands in Noyori-Type $\mathrm{Ru}^{\mathrm{II}}$ Catalysts. Eur. J. Org. Chem. 2006, 2006, 36063616.

(24) Saes, B. W. H; Verhoeven, D. G. A.; Lutz, M.; Klein Gebbink, R. J. M.; Moret, M.-E. Coordination of a Diphosphine-Ketone Ligand to $\mathrm{Ni}(0), \mathrm{Ni}(\mathrm{I})$, and $\mathrm{Ni}(\mathrm{II})$ : Reduction-Induced Coordination. Organometallics 2015, 34, 2710-2713.

(25) Verhoeven, D. G. A.; van Wiggen, M. A. C.; Kwakernaak, J.; Lutz, M.; Klein Gebbink, R. J. M.; Moret. Periodic Trends in the Binding of a Phosphine-Tethered Ketone Ligand to $\mathrm{Fe}, \mathrm{Co}, \mathrm{Ni}$, and Cu. Chem. - Eur. J. 2018, 24, 5163-5172.

(26) Mikami, K.; Wakabayashi, K.; Aikawa, K. Achiral” Benzophenone Ligand for Highly Enantioselective Ru Catalysts in Ketone Hydrogenation. Org. Lett. 2006, 8, 1517-1519.

(27) Mikami, K.; Wakabayashi, K.; Yusa, Y.; Aikawa, K. Achiral Benzophenone Ligand-Rhodium Complex with Chiral Diamine Activator for High Enantiocontrol in Asymmetric Transfer Hydrogenation. Chem. Commun. 2006, 22, 2365-2367.

(28) Sung, S.; Boon, J. K.; Lee, J. J. C.; Rajabi, N. A.; Macgregor, S. A.; Krämer, T.; Young, R. D. Convergent (De)hydrogenative Pathways via a Rhodium $\alpha$-Hydroxylalkyl Complex. Organometallics 2017, 36, 1609-1617.

(29) Sung, S.; Joachim, T.; Krämer, T.; Young, R. D. Protonolysis of an $\alpha$-Hydroxyl Ligand for the Generation of a PCcarbeneP Pincer Complex and Subsequent Reactivity Studies. Organometallics 2017, 36, 3117-3124.

(30) Barbato, C.; Baldino, S.; Ballico, M.; Figliolia, R.; Magnolia, S.; Siega, K.; Herdtweck, E.; Strazzolini, P.; Chelucci, G.; Baratta, W. OsXCl(phosphine) ${ }_{2}$ (diamine) and $\mathrm{OsXCl}$ (diphosphine)(diamine) $(\mathrm{X}=\mathrm{Cl}, \mathrm{H})$ Complexes for Ketone Hydrogenation. Organometallics 2018, 37, 65-77.

(31) Sung, S.; Young, R. D. Facile Generation of Iridium PCcarbeneP Pincer Complexes: Via Water Elimination from an Alcohol Proligand. Dalton Trans. 2017, 46, 15407-15414.

(32) Reppe, W.; Schlichting, O.; Klager, K.; Toepel, T. Cyclisierende Polymerisation von Acetylen. I. Über Cyclooctatetraen. Justus Liebigs Ann. Chem. 1948, 560, 1-92.

(33) For reviews on metal-catalyzed alkyne cyclotrimerization reactions, see (a) Broere, D.; Ruijter, E. Recent Advances in 
Transition-Metal-Catalyzed $[2+2+2]$-Cyclo(co)trimerization Reactions. Synthesis 2012, 44, 2639-2672. (b) Domínguez, G.; Pérez-Castells, J. Recent Advances in $[2+2+2]$ Cycloaddition Reactions. Chem. Soc. Rev. 2011, 40, 3430-44. (c) Saito, S.; Yamamoto, Y. Recent Advances in the Transition-Metal-Catalyzed Regioselective Approaches to Polysubstituted Benzene Derivatives. Chem. Rev. 2000, 100, 2901-2915. (d) Chopade, P. R.; Louie, J. [2 + 2+2] Cycloaddition Reactions Catalyzed by Transition Metal Complexes. Adv. Synth. Catal. 2006, 348, 2307-2327. (e) Shibata, T.; Tsuchikama, K. Recent Advances in Enantioselective [2+2+2] Cycloaddition. Org. Biomol. Chem. 2008, 6, 1317-1323. (f) Galan, B. R.; Rovis, T. Beyond Reppe: Building Substituted Arenes by [2+ 2+2] Cycloadditions of Alkynes. Angew. Chem., Int. Ed. 2009, 48, $2830-2834$.

(34) For examples of titanium-catalyzed cyclotrimerization of alkynes, see (a) Johnson, E. S.; Balaich, G. J.; Fanwick, P. E.; Rothwell, I. P. Trimerization of tert-Butylacetylene to 1,3,6-Tri(tertbutyl)fulvene Catalyzed by Titanium Aryloxide Compounds. J. Am. Chem. Soc. 1997, 119, 11086-11087. (b) Ozerov, O. V.; Patrick, B. O.; Ladipo, F. T. Highly Regioselective $[2+2+2]$ Cycloaddition of Terminal Alkynes Catalyzed by $\eta^{6}$-Arene Complexes of Titanium Supported by Dimethylsilyl-Bridged p-tert-Butyl Calix[4]arene Ligand. J. Am. Chem. Soc. 2000, 122, 6423-6431. (c) Ladipo, F. T.; Sarveswaran, V.; Kingston, J. V.; Huyck, R. A.; Bylikin, S. Y. S. Y.; Carr, S. D.; Watts, R.; Parkin, S. Synthesis, Characterization, and Alkyne Cyclotrimerization Chemistry of Titanium Complexes Supported by Calixarene-Derived Bis(aryloxide) Ligation. J. Organomet. Chem. 2004, 689, 502-514. (d) Morohashi, N.; Yokomakura, K.; Hattori, T.; Miyano, S. Highly Regioselective $[2+2+2]$ Cycloaddition of Terminal Alkynes Catalyzed by Titanium Complexes of $\mathrm{p}$ tert-Butylthiacalix[4] arene. Tetrahedron Lett. 2006, 47, 1157-1161. (e) See, X. Y.; Beaumier, E. P.; Davis-Gilbert, Z. W.; Dunn, P. L.; Larsen, J. A.; Pearce, A. J.; Wheeler, T. A.; Tonks, I. A. Generation of $\mathrm{Ti}^{\mathrm{II}}$ Alkyne Trimerization Catalysts in the Absence of Strong Metal Reductants. Organometallics 2017, 36, 1383-1390.

(35) For examples of iron-catalyzed cyclotrimerization of alkynes, see (a) Breschi, C.; Piparo, L.; Pertici, P.; Caporusso, A. M.; Vitulli, G. $\left(\eta^{6}\right.$-Cyclohepta-1,3,5-triene) $\left(\eta^{4}\right.$-cycloocta-1,5-diene)iron(0) Complex as Attractive Precursor in Catalysis. J. Organomet. Chem. 2000, 607, 57-63. (b) Liu, Y.; Yan, X.; Yang, N.; Xi, C. Highly Regioselective Cyclotrimerization of Terminal Alkynes Catalyzed by $\mathrm{Fe}(\mathrm{II})$ Complexes Bearing 2-(Benzimidazolyl)-6-(1-(arylimino)ethyl)pyridines. Catal. Commun. 2011, 12, 489-492. (c) Minakawa, M.; Ishikawa, T.; Namioka, J.; Hirooka, S.; Zhou, B.; Kawatsura, M. IronCatalyzed $[2+2+2]$ Cycloaddition of Trifluoromethyl Group Substituted Unsymmetrical Internal Alkynes. RSC Adv. 2014, 4, 41353-41356. (d) Lipschutz, M. I.; Chantarojsiri, T.; Dong, Y.; Tilley, T. D. Synthesis, Characterization, and Alkyne Trimerization Catalysis of a Heteroleptic Two-Coordinate FeI Complex. J. Am. Chem. Soc. 2015, 137, 6366-6372. (e) Bhatt, D.; Chowdhury, H.; Goswami, A. Atom-Economic Route to Cyanoarenes and 2,2'. Dicyanobiarenes via Iron-Catalyzed Chemoselective $[2+2+2]$ Cycloaddition Reactions of Diynes and Tetraynes with Alkynylnitriles. Org. Lett. 2017, 19, 3350-3353. (f) Brenna, D.; Villa, M.; Gieshoff, T. N.; Fischer, F.; Hapke, M.; Jacobi von Wangelin, A. Iron-Catalyzed Cyclotrimerization of Terminal Alkynes by Dual Catalyst Activation in the Absence of Reductants. Angew. Chem., Int. Ed. 2017, 56, 84518454.

(36) For examples of cobalt-catalyzed cyclotrimerization of alkynes, see (a) Chini, P.; Santambrogio, A.; Palladino, N. Cyclisation of 2Methylbut-3-yn-2-ol. Part I. Cyclisation to Aromatic Compounds. J. Chem. Soc. C 1967, 830-835. (b) Sigman, M. S.; Fatland, A. W.; Eaton, B. E. Cobalt-Catalyzed Cyclotrimerization of Alkynes in Aqueous Solution. J. Am. Chem. Soc. 1998, 120, 5130-5131. (c) Teplý, F.; Stará, I. G.; Starý, I.; Kollárovič, A.; Šaman, D.; Rulísek, L.; Fiedler, P. Synthesis of [5]-, [6]-, and [7]Helicene via $\mathrm{Ni}(0)$ - or $\mathrm{Co}(\mathrm{I})$-Catalyzed Isomerization of Aromatic cis,cisDienetriynes. J. Am. Chem. Soc. 2002, 124, 9175-9180. (d) Dosa, P. I.; Whitener, G. D.; Vollhardt, K. P. C.; Bond, A. D.; Teat, S. J.
Cobalt-Mediated Synthesis of Angular [4] Phenylene: Structural Characterization of a Metallacyclopentadiene(Alkyne) Intermediate and Its Thermal and Photochemical Conversion. Org. Lett. 2002, 4, 2075-2078. (e) Yong, L.; Butenschön, H. The First Cobalt Catalyzed $[2+2+2]$ Alkyne Cyclotrimerization in Aqueous Medium at Room Temperature. Chem. Commun. 2002, 2, 2852-2853. (f) Hilt, G.; Vogler, T.; Hess, W.; Galbiati, F. A Simple Cobalt Catalyst System for the Efficient and Regioselective Cyclotrimerisation of Alkynes. Chem. Commun. 2005, 100, 1474-1475. (g) Hilt, G.; Hess, W.; Vogler, T.; Hengst, C. Ligand and Solvent Effects on Cobalt(I)-Catalysed Reactions: Alkyne Dimerisation versus $[2+2+2]$-Cyclotrimerisation versus Diels-Alder Reaction versus $[4+2+2]$-Cycloaddition. J. Organomet. Chem. 2005, 690, 5170-5181. (h) Chang, H. T.; Jeganmohan, M.; Cheng, C. H. One-Pot Synthesis of Benzolactones and Lactams Via a Cobalt-Catalyzed Regioselective $[2+2+2]$ Cocyclotrimerization of Alkynyl Alcohols and Amines with Propiolates. Chem. Commun. 2005, 39, 4955-4957. (i) Lombardo, M.; Pasi, F.; Trombini, C.; Seddon, K. R.; Pitner, W. R. Task-Specific Ionic Liquids as Reaction Media for the Cobalt-Catalysed Cyclotrimerisation Reaction of Arylethynes. Green Chem. 2007, 9, 321-322. (j) Hilt, G.; Hengst, C.; Hess, W. Solvent-Dependent Regiochemical Cyclotrimerisation of Phenylacetylene with Cobalt Catalysts Containing Disulfide Ligands: A Case Study. Eur. J. Org. Chem. 2008, 2008, 2293-2297. (k) Geny, A.; Agenet, N.; Iannazzo, L.; Malacria, M.; Aubert, C.; Gandon, V. Air-Stable $\left\{\left(\mathrm{C}_{5} \mathrm{H}_{5}\right) \mathrm{Co}\right\}$ Catalysts for $[2+$ 2+2] Cycloadditions. Angew. Chem., Int. Ed. 2009, 48, 1810-1813. (1) Eichman, C. C.; Bragdon, J. P.; Stambuli, J. P. Exploiting Guanidine as a Ligand in Cobalt-Catalyzed Alkyne Cyclotrimerizations. Synlett 2011, 2011, 1109-1112. (m) Xu, L.; Yu, R.; Wang, Y.; Chen, J.; Yang, Z. Highly Regioselective Syntheses of Substituted Triphenylenes from 1,2,4-trisubstituted Arenes via a Co-Catalyzed Intermolecular Alkyne Cyclotrimerization. J. Org. Chem. 2013, 78, 5744-5750. (n) Jungk, P.; Fischer, F.; Hapke, M. In Situ-Generated Chiral Co(I)-Catalyst for Asymmetric [2+2+2] Cycloadditions of Triynes. ACS Catal. 2016, 6, 3025-3029. (o) Wang, Y. I.; Hsu, W. L.; Ho, F. C.; Li, C. P.; Wang, C. F.; Chen, H. H. Efficient Regioselective Approach for Polysubstituted Benzene Derivatives by Intermolecular [2 + 2+2] Cyclotrimerization of Alkynes. Tetrahedron 2017, 73, 7210-7216. (p) Kumon, T.; Yamada, S.; Agou, T.; Kubota, T.; Konno, T. Highly Regioselective Cobalt-Catalyzed $[2+2+2]$ Cycloaddition of Fluorine-Containing Internal Alkynes to Construct Various Fluoroalkylated Benzene Derivatives. J. Fluorine Chem. 2018, 213, 11-17. (q) Xu, F.; Si, X. J.; Wang, X. N.; Kou, H. D.; Chen, D. M.; Liu, C.-S.; Du, M. A High-Activity Cobalt-Based MOF Catalyst for $[2+2+2]$ Cycloaddition of Diynes and Alkynes: Insights Into Alkyne Affinity and Selectivity Control. RSC Adv. 2018, 8, 48954899.

(37) For examples of nickel-catalyzed cyclotrimerization of alkynes, see refs 9c, 36a, and c and (a) Meriwether, L. S.; Leto, M. F.; Colthup, E. C.; Kennerly, G. W. The Polymerization of Acetylenes by NickelCarbonyl-Phosphine Complexes. IV. Kinetics and Polymerization Mechanisms. J. Org. Chem. 1962, 27, 3930-3941. (b) Simons, L. H.; Lagowski, J. J. Novel Oligomers of Propyne: Tetramethylcyclooctatetraenes and (Z)-2,4-Dimethyl-1,3-heptadien-5-yne. J. Org. Chem. 1978, 43, 3247-3248. (c) Diercks, R.; Stamp, L.; Kopf, J.; tom Dieck, H. Elementary Steps in Catalytic 1-alkyne Coupling to Substituted Cyclooctatetraenes. Angew. Chem., Int. Ed. Engl. 1984, 23, 893-894. (d) Dieck, H. T.; Dietrich, J. Diazadienes as Controlling Ligands in Catalysis. Synthesis of Chiral Diazadienes $R^{*}-\mathrm{N}=\mathrm{CR}^{\prime}-$ $\mathrm{CR}^{\prime}=\mathrm{N}-\mathrm{R}^{*}$. Chem. Ber. 1984, 117, 694-701. (e) Diercks, R.; Dieck tom, H. Diazadiene als Steuerliganden in der Homogenen Katalyse. Katalytische Cyclotetramerisierung von Propiolsäureestern. Chem. Ber. 1985, 118, 428-435. (f) Lawrie, C. J.; Gable, K. P.; Carpenter, B. K. Catalytic and Stoichiometric Formation of Cyclooctatetraenes from Soluble Nickel Complexes. Organometallics 1989, 8, 2274-2276. (g) Bhatarah, P.; Smith, E. H. Oxygen Ligation in the Nickel-Mediated $[2+2+2]$ Co-cyclisation of a Hepta-1,6diyne and Alkynol Derivatives. J. Chem. Soc., Perkin Trans. 1 1990, 26, 2603-2606. (h) Bhatarah, P.; Smith, E. H. A Singular Substituent 
Effect in the Nickel(0) Mediated Cocyclisation of Octa-1,7-diynes with Alkynols. One-Step Synthesis of Tetralin Lactones from Acyclic Precursors. J. Chem. Soc., Chem. Commun. 1991, 5, 277-278. (i) Bhatarah, P.; Smith, E. H. Nickel(0)-Promoted Synthesis of Tetralin Lactones from the Co-cyclisation of Monoynes and Octa-1,7diynes Terminally Substituted with Ester or Amide Groups. J. Chem. Soc., Perkin Trans. 1 1992, 14, 2163-2168. (j) Sato, Y.; Nishimata, T.; Mori, M. Asymmetric Synthesis of Isoindoline and Isoquinoline Derivatives Using Nickel(0)-Catalyzed $[2+2+2]$ Cocyclization. J. Org. Chem. 1994, 59, 6133-6135. (k) Duckworth, D. M.; Lee-Wong, S.; Slawin, A. M. Z.; Smith, E. H.; Williams, D. J. Co-cyclizations of Nitrogen-Containing Acetylenes Induced by a Nickel Triphenylphosphine Complex to Give Aminoindane, Isoindoline and Isoindolinone Derivatives. J. Chem. Soc., Perkin Trans. 1 1996, 1, 815-821. (1) Sato, Y.; Ohashi, K.; Mori, M. Synthesis of Biaryls using Nickel-Catalyzed [2+2+2] Cocyclization. Tetrahedron Lett. 1999, 40, 5231-5234. (m) Mori, N.; Ikeda, S. I.; Odashima, K. Chemo- and Regioselective Cyclotrimerization of Monoynes Catalyzed by a $\operatorname{Nickel}(0)$ and Zinc(II) Phenoxide System. Chem. Commun. 2001, 54, 181-182. (n) Hocek, M.; Stará, I. G.; Starý, I.; Dvořáková, H. Cyclotrimerization of 6-Ethynylpurines. Synthesis of 1,2,4- and 1,3,5Tris(purin-6-yl)benzenes as Novel Hoogsteen-Triplet Analogues. Tetrahedron Lett. 2001, 42, 519-521. (o) Saito, S.; Kawasaki, T.; Tsuboya, N.; Yamamoto, Y. Highly Regioselective Cyclotrimerization of 1-Perfluoroalkylenynes Catalyzed by Nickel. J. Org. Chem. 2001, 66, 796-802. (p) Jeevanandam, A.; Korivi, R. P.; Huang, I.; Cheng, C.-H. Ni-Catalyzed Highly Regio- and Chemoselective Cocycloaddition of Nonconjugated Diynes with 1,3-Diynes: A Novel Method for Polysubstituted Arylalkynes. Org. Lett. 2002, 4, 807-810. (q) Rosenthal, U.; Schulz, W. Zusammenhånge Zwischen Alkinkomplexierung und Aktivierung in Komplexen des Types (ligand) ${ }_{2} \mathrm{Ni}$ (alkin). J. Organomet. Chem. 1987, 321, 103-117. (r) Deaton, K. R; Gin, M. S. Regioselective $[2+2+2]$ Cycloaddition of a Nickel-Benzyne Complex with 1,3-Diynes. Org. Lett. 2003, 5, 2477-2480. (s) Turek, P.; Kotora, M.; Tislerová, I.; Hocek, M.; Votruba, I.; Císarová, I. Cocyclotrimerization of 6-Alkynylpurines with $\alpha, \omega$-Diynes as a Novel Approach to Biologically Active 6-Arylpurines. J. Org. Chem. 2004, 69, 9224-33. (t) Teske, J. A.; Deiters, A. Microwave-Mediated NickelCatalyzed Cyclotrimerization Reactions: Total Synthesis of Illudinine. J. Org. Chem. 2008, 73, 342-345. (u) Xi, C.; Sun, Z.; Liu, Y. Cyclotrimerization of Terminal Alkynes Catalyzed by the System of $\mathrm{NiCl}_{2} / \mathrm{Zn}$ and (Benzimidazolyl)-6-(1-(arylimino)ethyl)pyridines. Dalton Trans. 2013, 42, 13327-13330. (v) Rodrigo, S. K.; Powell, I. V.; Coleman, M. G.; Krause, J. A.; Guan, H. Efficient and Regioselective Nickel-Catalyzed [2+2+2] Cyclotrimerization of Ynoates and Related Alkynes. Org. Biomol. Chem. 2013, 11, 7653-7657. (w) Pal, S.; Uyeda, C. Evaluating the Effect of Catalyst Nuclearity in NiCatalyzed Alkyne Cyclotrimerizations. J. Am. Chem. Soc. 2015, 137, 8042-8045. (x) Xue, F.; Loh, Y. K.; Song, X.; Teo, W. J.; Chua, J. Y. D.; Zhao, J.; Hor, T. S. A. Nickel-Catalyzed Facile $[2+2+2]$ Cyclotrimerization of Unactivated Internal Alkynes to Polysubstituted Benzenes. Chem. - Asian J. 2017, 12, 168-173. (y) Hollingsworth, R. L.; Bheemaraju, A.; Lenca, N.; Lord, R. L.; Groysman, S. Divergent Reactivity of a New dinuclear Xanthene-Bridged Bis(iminopyridine) Di-Nickel Complex with Alkynes. Dalton Trans. 2017, 46, 5605. (z) Beesam, R.; Nareddula, D. R. Pd and Ni Complexes of a Novel Vinylidene $\beta$-diketimine Ligand: Their Application as Catalysts in Heck Coupling and Alkyne Trimerization. Appl. Organomet. Chem. 2017, 31, e3696.

(38) For examples of molybdenum-catalyzed cyclotrimerization of alkynes, see (a) Kaneta, N.; Hirai, T.; Mori, M. Reaction of Alkyne Having Hydroxyphenyl Group with $\mathrm{Mo}(\mathrm{CO})_{6}$. Chem. Lett. 1995, 24, 627-628. (b) Matusiak, R.; Keller, A. Cyclotrimerization of Phenylacetylene and Living Polymerization of tert-Butylacetylene by $\mathrm{Mo}_{2}\left(\mathrm{O}_{2} \mathrm{CCH}_{3}\right)_{4}$-Lewis Acid Systems. J. Mol. Catal. A: Chem. 2003, 195, 29-35. (c) Kotha, S.; Sreevani, G. Molybdenum Hexacarbonyl: Air Stable Catalyst for Microwave Assisted Intermolecular [2+2+2] Co-Trimerization Involving Propargyl Halides. Tetrahedron Lett. 2015, 56, 5903-5908.
(39) For examples of ruthenium-catalyzed cyclotrimerization of alkynes, see (a) Rüba, E.; Schmid, R.; Kirchner, K.; Calhorda, M. J. Ruthenium-Mediated Cyclotrimerization of Alkynes Utilizing the Cationic Complex $\left[\mathrm{RuCp}\left(\mathrm{CH}_{3} \mathrm{CN}\right)_{3}\right] \mathrm{PF}_{6}$. J. Organomet. Chem. 2003, 682, 204-211. (b) Ura, Y.; Sato, Y.; Shiotsuki, M.; Kondo, T.; Mitsudo, T. A. Ruthenium-Catalysed Synthesis of o-Phthalates by Highly Chemoselective Intermolecular $[2+2+2]$ Cycloaddition of Terminal Alkynes and Dimethyl Acetylenedicarboxylate. J. Mol. Catal. A: Chem. 2004, 209, 35-39. (c) Yamamoto, Y.; Ishii, J. I.; Nishiyama, H.; Itoh, K. Cp*RuCl-Catalyzed Formal Intermolecular Cyclotrimerization of Three Unsymmetrical Alkynes through a Boron Temporary Tether: Regioselective Four-Component Coupling Synthesis of Phthalides. J. Am. Chem. Soc. 2005, 127, 9625-9631. (d) Cadierno, V.; García-Garrido, S. E.; Gimeno, J. Efficient Intermolecular $[2+2+2]$ Alkyne Cyclotrimerization in Aqueous Medium Using a Puthenium(IV) Precatalyst. J. Am. Chem. Soc. 2006, 128, 15094-15095. (e) Dutta, B.; Curchod, B. F. E.; Campomanes, P.; Solari, E.; Scopelliti, R.; Rothlisberger, U.; Severin, K. Reactions of Alkynes with $[\mathrm{RuCl}($ cyclopentadienyl)] Complexes: The important First Steps. Chem. - Eur. J. 2010, 16, 8400-8409. (f) Öztürk, B. Ö.; Karabulut, S.; Imamoğlu, Y. Activity of Homobimetallic Ruthenium Alkylidene Complexes on Intermolecular $[2+2+2]$ Cyclotrimerisation Reactions of Terminal Alkynes. Inorg. Chim. Acta 2011, 378, 257-263. (g) Kawatsura, M.; Yamamoto, M.; Namioka, J.; Kajita, K.; Hirakawa, T.; Itoh, T. Ruthenium-Catalyzed Regioselective $[2+2+$ 2] Cyclotrimerization of Trifluoromethyl Group Substituted Internal Alkynes. Org. Lett. 2011, 13, 1001-1003. (h) Geetharani, K.; Tussupbayev, S.; Borowka, J.; Holthausen, M. C.; Ghosh, S. A Mechanistic Study of the Utilization of Arachno-Diruthenaborane $\left[(\mathrm{Cp} * \mathrm{RuCO})_{2} \mathrm{~B}_{2} \mathrm{H}_{6}\right]$ as an Active Alkyne-Cyclotrimerization Catalyst. Chem. - Eur. J. 2012, 18, 8482-9. (i) Chen, C. R.; Lin, Y. C. Syntheses of Arylphosphonium Salts from Cyclotrimerization of Terminal Aryl Alknyes by a Ruthenium Pentadienyl Complex and Revisiting the Catalytic Dimerization. Organometallics 2014, 33, 6408-6412.

(40) For examples of rhodium-catalyzed cyclotrimerization of alkynes, see (a) Amer, I.; Bernstein, T.; Eisen, M.; Blum, J.; Vollhardt, K. P. C. Oligomerization of Alkynes by the $\mathrm{RhCl}_{3}$-Aliquat 336 Catalyst System. Part 1. Formation of Benzene Derivatives. J. Mol. Catal. 1990, 60, 313-321. (b) Tanaka, K.; Shirasaka, K. Highly Chemo- and Regioselective Intermolecular Cyclotrimerization of Alkynes Catalyzed by Cationic Rhodium(I)/Modified BINAP Complexes. Org. Lett. 2003, 5, 4697-4699. (c) Tanaka, K.; Toyoda, K.; Wada, A.; Shirasaka, K.; Hirano, M. Chemo- and Regioselective Intermolecular Cyclotrimerization of Terminal Alkynes Catalyzed by Cationic Rhodium(I)/Modified BINAP Complexes: Application to One-Step Synthesis of Paracyclophanes. Chem. - Eur. J. 2005, 11, 1145-1156. (d) Yoshida, K.; Morimoto, I.; Mitsudo, K.; Tanaka, $\mathrm{H}$. $\mathrm{RhCl}_{3} /$ Amine-Catalyzed $[2+2+2]$ Cyclization of Alkynes. Tetrahedron 2008, 64, 5800-5807. (e) Dachs, A.; Torrent, A.; Pla-Quintana, A.; Roglans, A.; Jutand, A. Rates and Mechanism of Rhodium-Catalyzed $[2+2+2]$ Cycloaddition of Bisalkynes and a Monoalkyne. Organometallics 2009, 28, 6036-6043. (f) Shibata, Y.; Tanaka, K. Rhodium-Catalyzed [2+2+2] Cycloaddition of Alkynes for the Synthesis of Substituted Benzenes: Catalysts, Reaction Scope, and Synthetic Applications. Synthesis 2012, 44, 323-350. (g) Heya, A.; Namba, T.; Hara, J.; Shibata, Y.; Tanaka, K. Cationic Rhodium(I)/BIPHEP Complex-Catalyzed Cross-Cyclotrimerization of Silylacetylenes and Unsymmetrical Electron-Deficient Internal Alkynes. Tetrahedron Lett. 2015, 56, 4938-4942. (h) Hayase, N.; Miyauchi, Y.; Aida, Y.; Sugiyama, H.; Uekusa, H.; Shibata, Y.; Tanaka, $\mathrm{K}$. Synthesis of [8]Cycloparaphenylene-Octacarboxylates via RhCatalyzed Stepwise Cross-Alkyne Cyclotrimerization. Org. Lett. 2017, 19, 2993-2996. (i) Nishigaki, S.; Shibata, Y.; Tanaka, K. RhodiumCatalyzed Chemo- and Regioselective Intermolecular Cross-Cyclotrimerization of Nonactivated Terminal and Internal Alkynes. J. Org. Chem. 2017, 82, 11117-11125.

(41) For examples of palladium-catalyzed cyclotrimerization of alkynes, see (a) Jhingan, A. K.; Maier, W. F. Homogeneous Catalysis 
with a Heterogeneous Palladium Catalyst. An Effective Method for the Cyclotrimerization of Alkynes. J. Org. Chem. 1987, 52, 11611165. (b) Gevorgyan, V.; Radhakrishnan, U.; Takeda, A.; Rubina, M.; Rubin, M.; Yamamoto, Y. Palladium-Catalyzed Highly Chemo- and Regioselective Formal $[2+2+2]$ Sequential Cycloaddition of Alkynes: A Renaissance of the Well Known Trimerization Reaction? J. Org. Chem. 2001, 66, 2835-2841. (c) Li, J.; Jiang, H.; Chen, M. $\mathrm{CuCl}_{2}$-Induced Regiospecifical Synthesis of Benzene Derivatives in the Palladium-Catalyzed Cyclotrimerization of Alkynes. J. Org. Chem. 2001, 66, 3627-3629. (d) Carvalho, M. F. N. N.; Almeida, F. M. T.; Galvão, A. M.; Pombeiro, A. J. L. Benzene Ring Assembly Promoted by a Camphor Derived Palladium Complex. J. Organomet. Chem. 2003, 679, 143-147. (e) Cheng, J. S.; Jiang, H. F. PalladiumCatalyzed Regioselective Cyclotrimerization of Acetylenes in Supercritical Carbon Dioxide. Eur. J. Org. Chem. 2004, 2004, 643-646. (f) Li, J. H.; Xie, Y. X. Carbon Dioxide Promoted PalladiumCatalyzed Cyclotrimerization of Alkynes in Water. Synth. Commun. 2004, 34, 1737-1743. (g) Cheng, J.-S.; Wei, G.-F.; Huang, S.-W.; JinZhao; Jiang, H.-F. Solvent-Controlled Chemoselective PalladiumCatalyzed Oligomerization of tert-Butyl Acetylene. J. Mol. Catal. A: Chem. 2007, 263, 169-174. (h) Chinchilla, R.; Nájera, C. Chemicals from Alkynes with Palladium Catalysts. Chem. Rev. 2014, 114, 17831826.

(42) For examples of iridium-catalyzed cyclotrimerization of alkynes, see (a) Takeuchi, R.; Tanaka, S.; Nakaya, Y. Iridium ComplexCatalyzed $[2+2+2]$ Cycloaddition of $\alpha, \omega$-Diynes with Monoalkynes: A New and Efficient Catalyst for Cyclotrimerization of Alkynes. Tetrahedron Lett. 2001, 42, 2991-2994. (b) Takeuchi, R.; Nakaya, Y. Iridium Complex-Catalyzed Highly Selective Cross $[2+2+2]$ Cycloaddition of Two Different Monoynes: 2:1 Coupling versus 1:2 Coupling. Org. Lett. 2003, 5, 3659-3662. (c) Farnetti, E.; Marsich, N. Regioselective Cyclotrimerization of Phenylacetylenes to 1,2,4Triarylbenzenes Catalyzed by Iridium-Diphosphine Complexes. J. Organomet. Chem. 2004, 689, 14-17. (d) Hashimoto, T.; Okabe, A.; Mizuno, T.; Izawa, M.; Takeuchi, R. Iridium-Catalyzed $[2+2+2]$ Cycloaddition of $\alpha, \omega$-Diynes with Alkynyl Ketones and Alkynyl Esters. Tetrahedron 2014, 70, 8681-8689.

(43) Modern Alkyne Chemistry: Catalytic and Atom-Economic Transformations; Trost, B. M., Li, C. J., Eds.; Wiley-VCH Verlag GmbH \& Co. KGaA: Weinheim, Germany, 2015.

(44) Kwon, D.-H.; Proctor, M.; Mendoza, S.; Uyeda, C.; Ess, D. H. Catalytic Dinuclear Nickel Spin Crossover Mechanism and Selectivity for Alkyne Cyclotrimerization. ACS Catal. 2017, 7, 4796-4804.

(45) For the first synthetic report of the phenyl-substituted analogue

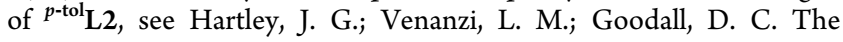
Preparation and Complex-Forming Properties of One Tritertiary and One Tetratertiary Phosphine. J. Chem. Soc. 1963, 3930-3936.

(46) Chakkaradhari, G.; Chen, Y.-T.; Karttunen, A. J.; Dau, M. T.; Jänis, J.; Tunik, S. P.; Chou, P.-T.; Ho, M.-L.; Koshevoy, I. O. Luminescent Triphosphine Cyanide $\mathrm{d}^{10}$ Metal Complexes. Inorg. Chem. 2016, 55, 2174-2184.

(47) Zhang, F.; Wang, L.; Chang, S.-H.; Huang, K.-L.; Chi, Y.; Hung, W.-Y.; Chen, C.-M.; Lee, G.-H.; Chou, P.-T. Phosphorescent Ir(III) Complexes with Both Cyclometalate Chromophores and Phosphine-Silanolate Ancillary: Concurrent Conversion of Organosilane to Silanolate. Dalt. Trans. 2013, 42, 7111-7119.

(48) Basic One- and Two-Dimensional NMR Spectroscopy, 5th ed.; Friebolin, H., Ed.; Wiley-VCH: Weinheim, Germany, 2011.

(49) For the first synthetic report of ${ }^{\mathrm{Ph}}$ L3, see: Kranenburg, M.; van der Burgt, Y. E. M.; Kamer, P. C. J.; van Leeuwen, P. W. N. M.; Goubitz, K.; Fraanje, J. New Diphosphine Ligands Based on Heterocyclic Aromatics Inducing Very High Regioselectivity in Rhodium-Catalyzed Hydroformylation: Effect of the Bite Angle. Organometallics 1995, 14, 3081-3089.

(50) Chemical Bonds and Bond Energy; Sanderson, R. T., Ed.; Academic Press Inc.: New York, USA, 1976.

(51) For examples of $\eta^{2}(\mathrm{C}, \mathrm{N})$-bound imine to $\mathrm{Ni}(0)$, see (a) Manan, R. S.; Kilaru, P.; Zhao, P. Nickel-Catalyzed Hydroimination of Alkynes. J. Am. Chem. Soc. 2015, 137, 6136-6139. (b) Hoberg, H.; Krüger, C.; Tsay, Y.-H. Darstellung, Eigenschaften und Bintiungsverh- \& ltnisse von Benzophenoneimino-Nickel(0)Komplexen. J. Organomet. Chem. 1979, 169, 209-217. (c) Weng, Z.; Teo, S.; Koh, L. L.; Hor, T. S. A. Ethylene Oligomerization at Coordinatively and Electronically Unsaturated Low-Valent Nickel. Angew. Chem., Int. Ed. 2005, 44, 7560-7564. (d) Cámpora, J.; Matas, I.; Palma, P.; Álvarez, E.; Graiff, C.; Tiripicchio, A. Monomeric Alkoxo and Amido Methylnickel(II) Complexes. Synthesis and Heterocumulene Insertion Chemistry. Organometallics 2007, 26, 3840-3849. (e) Iglesias, A. L.; Muñoz-Hernández, M.; García, J. J. Fluoro Aromatic Imine Nickel(0) Complexes: Synthesis and Structural Studies. J. Organomet. Chem. 2007, 692, 3498-3507. (f) Hoshimoto, Y.; Ohata, T.; Ohashi, M.; Ogoshi, S. Nickel-Catalyzed Synthesis of N-Aryl-1,2-dihydropyridines by $[2+2+2]$ Cycloaddition of Imines with Alkynes Through T-Shaped 14-Electron Aza-Nickelacycle Key Intermediates. Chem. - Eur. J. 2014, 20, 4105-4110. (g) Reed, B. R.; Yousif, M.; Lord, R. L.; McKinnon, M.; Rochford, J.; Groysman, S. Coordination Chemistry and Reactivity of Bis(aldimino)pyridine Nickel Complexes in Four Different Oxidation States. Organometallics 2017, 36, 582-593. (h) Verhoeven, D. G. A.; Negenman, H. A.; Orsino, A. F.; Lutz, M.; Moret, M.-E. Versatile Coordination and C-C Coupling of Diphosphine-Tethered Imine Ligands with $\mathrm{Ni}(\mathrm{II})$ and $\mathrm{Ni}(0)$. Inorg. Chem. 2018, 57, 10846-10856.

(52) For examples of ${ }^{\mathrm{Ph}} \mathrm{L} 3$-substituted $\mathrm{Ni}(0)$ complexes, see (a) Wilting, J.; Müller, C.; Hewat, A. C.; Ellis, D. D.; Tooke, D. M.; Spek, A. L.; Vogt, D. Nickel-Catalyzed Isomerization of 2-Methyl3-butenenitrile. Organometallics 2005, 24, 13-15. (b) Minami, Y.; Yoshiyasu, H.; Nakao, Y.; Hiyama, T. Highly Chemoselective CarbonCarbon $\sigma$-Bond Activation: Nickel/Lewis Acid Catalyzed Polyfluoroarylcyanation of Alkynes. Angew. Chem., Int. Ed. 2013, 52, 883-887.

(53) For examples of structurally characterized monomeric $\mathrm{Ni}(0)$ complexes of internal alkynes, see refs $9 \mathrm{c}$ and $52 \mathrm{~b}$ and (a) Diercks, R.; Kopf, J.; tom Dieck, H. (2-3- $\eta$-2-Butyne-1,4-diol)[N,N'ethanediylidenebis (2,6-diisopropylaniline)]nickel(0), [Ni$\left(\mathrm{C}_{26} \mathrm{H}_{36} \mathrm{~N}_{2}\right)\left(\mathrm{C}_{4} \mathrm{H}_{6} \mathrm{O}_{2}\right)$ ]. Acta Crystallogr., Sect. C: Cryst. Struct. Commun. 1984, 40, 363-365. (b) Diercks, R.; Dieck tom, H. Diazadiene als Steuerliganden in der Homogenen Katalyse. IX. Katalytische Cyclotetramerisierung von Propiols. Chem. Ber. 1985, 118, 428-435. (c) Dickson, R. S.; Ibers, J. A. The Structure of $\mathrm{Bis}$ (tert-butyl isocyanide)(diphenylacetylene)nickel(0), Ni$\left(\mathrm{C}_{6} \mathrm{H}_{5} \mathrm{C} \equiv \mathrm{CC}_{6} \mathrm{H}_{5}\right)\left[\left(\mathrm{CH}_{3}\right)_{3} \mathrm{C}-\mathrm{N} \equiv \mathrm{C}\right]_{2}$. J. Organomet. Chem. 1972, 36, 191-207. (d) Rosenthal, U.; Oehme, G.; et al. Crystal and Molecular Structure of $2-3-\eta^{2}-\left(\mathrm{iPr}_{3} \mathrm{P}\right)_{2} \mathrm{Ni}\left(\mathrm{HOCH}_{2} \mathrm{C} \equiv \mathrm{CCH}_{2} \mathrm{OH}\right)$ - Some Peculiarities of the Complexation of 2-Butyne-1,4-diol with $\operatorname{Nickel}(0)$ Complexes. J. Organomet. Chem. 1991, 409, 299-306. (e) Bartik, T.; Happ, B.; Iglewsky, M.; Bandmann, H.; Boese, R.; Heimbach, P.; Hoffmann, T.; Wenschuh, E. Synthesis and Characterization of Bis(phosphine)nickel(0) Complexes Containing Nonsymmetrically Substituted Acetylenes. Organometallics 1992, 11, 1235-1241. (f) Walther, D.; Schmidt, A.; Klettke, T.; Imhof, W.; Gorls, H. Bis(tetramethylbutynediol)nickel(0), the First Pure Monoalkyne Complex of Nickel and Its Chemistry. Angew. Chem., Int. Ed. Engl. 1994, 33, 1373-1376. (g) Walther, D.; Klettke, T.; Görls, H.; Imhof, W. Homoleptische Alkin-Nickel(0) Komplexe: Kombination von $\operatorname{Nickel}(0)$ Zentren mit Alkinylsilanen $\mathrm{R}_{\mathrm{n}}^{1} \mathrm{Si}\left(-\mathrm{C} \equiv \mathrm{C}-\mathrm{R}^{2}\right)_{4-\mathrm{n}}$ zu Nickelorganschen Analoga von Siloxanen. J. Organomet. Chem. 1997, 534, 129-137. (h) Edelbach, B. L.; Lachicotte, R. J.; Jones, W. D. Catalytic Carbon-Carbon and Carbon-Silicon Bond Activation and Functionalization by Nickel Complexes. Organometallics 1999, 18, 4660-4668. (i) Eisch, J. J.; Ma, X.; Han, K. I.; Gitua, J. N.; Krüger, C. Mechanistic Comparison of the Nickel(0)-Catalyzed Homo-Oligomerization and Co-Oligomerization of Alkynes and Nitriles. Eur. J. Inorg. Chem. 2001, 2001, 77-88. (j) Waterman, R.; Hillhouse, G. L. Formation of Phosphirenes by Phosphinidene Group-Transfer Reactions from $(\mathrm{dtbpe}) \mathrm{Ni}=(\mathrm{dmp})$ to Alkynes. Organometallics 2003, 22, 51825184. (k) Schaub, T.; Backes, M.; Radius, U. Nickel(0) Complexes of N-Alkyl-Substituted N-Heterocyclic Carbenes and Their Use in the Catalytic Carbon-Carbon Bond Activation of Biphenylene. Organometallics 2006, 25, 4196-4206. (1) Weng, Z.; Teo, S.; Hor, T. S. A. 
Stabilization of Nickel(0) by Hemilabile P,N-Ferrocene Ligands and Their Ethylene Oligomerization Activities. Organometallics 2006, 25, 4878-4882. (m) Ruhland, K.; Obenhuber, A.; Hoffmann, S. D. Cleavage of Unstrained $\mathrm{C}\left(\mathrm{sp}^{2}\right)-\mathrm{C}\left(\mathrm{sp}^{2}\right)$ Single Bonds with $\mathrm{Ni}(0)$ Complexes using Chelating Assistance. Organometallics 2008, 27, 3482-3495. (n) Sgro, M. J.; Stephan, D. W. Synthesis and Exchange Reactions of Ni-Dimine-COD, Acetylene and Olefin Complexes. Dalton Trans. 2010, 39, 5786-5794. (o) Hatnean, J. A.; Beck, R.; Borrelli, J. D.; Johnson, S. A. Carbon-Hydrogen Bond Oxidative Addition of Partially Fluorinated Aromatics to a $\mathrm{Ni}\left(\mathrm{PiPr}_{3}\right)_{2}$ Synthon: The Influence of Steric Bulk on the Thermodynamics and Kinetics of C-H Bond Activation. Organometallics 2010, 29, 6077-6091. (p) Barrios-Francisco, R.; Benítez-Páez, T.; Flores-Alamo, M.; Arévalo, A.; García, J. J. Nickel(0) Complexes with Fluorinated Alkyne Ligands and Their Reactivity Towards Semihydrogenation and Hydrodefluorination with Water. Chem. - Asian J. 2011, 6, 842849. (q) Staudaher, N. D.; Stolley, R. M.; Louie, J. Synthesis, Mechanism of Formation, and Catalytic Activity of Xantphos Nickel $\pi$-Complexes. Chem. Commun. 2014, 50, 15577-15580. (r) Reed, B. R.; Yousif, M.; Lord, R. L.; McKinnon, M.; Rochford, J.; Groysman, S. Coordination Chemistry and Reactivity of Bis(aldimino)pyridine Nickel Complexes in Four Different Oxidation States. Organometallics 2017, 36, 582-593.

(54) For examples of structurally characterized monomeric $\mathrm{Ni}(0)$ complexes of terminal alkynes, see ref $22 \mathrm{c}$ and (a) Pörschke, K.-R. Coupling of Two Ethyne Molecules at a Nickel Center to Form a Nickelacyclopentadiene Complex. Angew. Chem., Int. Ed. Engl. 1987, 26, 1288-1290. (b) Bonrath, B. W.; Porschke, K. R.; Wilke, C.; Angermund, K.; Kruger, C. Mono- and Dinuclear Nickel(0) Complexes of Butadiyne. Angew. Chem., Int. Ed. Engl. 1988, 27, 833-835.

(55) For examples of crystal structure determinations of a range of disordered molecules of phenylacteylene, see Thakur, T. S.; Sathishkumar, R.; Dikundwar, A. G.; Guru Row, T. N.; Desiraju, G. R. Third Polymorph of Phenylacetylene. Cryst. Growth Des. 2010, 10, 4246-4249.

(56) Kim, Y. E.; Kim, J.; Lee, Y. Formation of a Nickel Carbon Dioxide Adduct and Its Transformation Mediated by a Lewis Acid. Chem. Commun. 2014, 50, 11458-11461.

(57) Anderson, J. S.; Iluc, V. M.; Hillhouse, G. L. Reactions of $\mathrm{CO}_{2}$ and $\mathrm{CS}_{2}$ with 1,2-Bis(di-tert-butylphosphino)ethane Complexes of Nickel(0) and Nickel(I). Inorg. Chem. 2010, 49, 10203-10207.

(58) Ge, S.; Hartwig, J. F. Nickel-Catalyzed Asymmetric $\alpha$-Arylation and Heteroarylation of Ketones with Chloroarenes: Effect of Halide on Selectivity, Oxidation State, and Room-Temperature Reactions. J. Am. Chem. Soc. 2011, 133, 16330-16333.

(59) Wang, C.; Xi, Z. Metal Mediated Synthesis of Substituted Cyclooctatetraenes. Chem. Commun. 2007, 5119-5133.

(60) For mechanistic studies on cobalt-catalyzed cyclotrimerzation reactions, see (a) Hardesty, J. H.; Koerner, J. B.; Albright, T. A.; Lee, G. Y. Theoretical Study of the Acetylene Trimerization with CpCo. J. Am. Chem. Soc. 1999, 121, 6055-6067. (b) Dahy, A. R. A.; Koga, N. Theoretical Study on the Transformation of Bis(acetylene)cobalt to Cobaltacyclopentadiene and the Regioselectivity in this Transformation. Bull. Chem. Soc. Jpn. 2005, 78, 781-791. (c) McAlister, D. R.; Bercaw, J. E.; Bergman, R. G. Parallel Reaction Pathways in the Cobalt-Catalyzed Cyclotrimerization of Acetylenes. J. Am. Chem. Soc. 1977, 99, 1666-1668. (d) Varela, J. A.; Saá, C. CpRuCl- and CpCoCatalyzed or Mediated Cyclotrimerizations of Alkynes and [2+2+2] Cycloadditions of Alkynes to Alkenes: A Comparative DFT Study. J. Organomet. Chem. 2009, 694, 143-149. (e) Agenet, N.; Gandon, V.; Vollhardt, K. P. C.; Malacria, M.; Aubert, C. Cobalt-Catalyzed Cyclotrimerization of Alkynes: The Answer to the Puzzle of Parallel Reaction Pathways. J. Am. Chem. Soc. 2007, 129, 8860-8871.

(61) For studies on metallacyclopentadiene-forming transition states (TS1 from Scheme 5) that concertedly form a $\mathrm{C}-\mathrm{C} \sigma$ bond and two metal-vinyl carbon bonds, see refs 44,60d, and e and (a) Kirchner, K.; Calhorda, M. J.; Schmid, R.; Veiros, L. F. Mechanism for the Cyclotrimerization of Alkynes and Related Reactions Catalyzed by
CpRuCl. J. Am. Chem. Soc. 2003, 125, 11721-11729. (b) Orian, L.; Swart, M.; Bickelhaupt, F. M. Indenyl Effect due to Metal Slippage? Computational Exploration of Rhodium-Catalyzed Acetylene [2 + 2+2] Cyclotrimerization. ChemPhysChem 2014, 15, 219-228. (c) Liu, Z.; Cheng, R.; He, X.; Liu, B. Reactivity and Regioselectivity of Methylacetylene Cyclotrimerization Over the Phillips Cr/Silica Catalyst: A DFT Study. ACS Catal. 2013, 3, 1172-1183. (d) Guo, C. H.; Wu, H. S.; Hapke, M.; Jiao, H. Theoretical Studies on Acetylene Cyclotrimerization into Benzene Catalyzed by CpIr Fragment. J. Organomet. Chem. 2013, 748, 29-35. (e) Calhorda, M. J.; Costa, P. J.; Kirchner, K. A. Benzene and Heterocyclic Rings Formation in Cycloaddition Reactions Catalyzed by RuCp Derivatives: DFT studies. Inorg. Chim. Acta 2011, 374, 24-35. (f) Dachs, A.; Osuna, S.; Roglans, A.; Solà, M. Density Functional Study of the [2+ $2+2]$ Cyclotrimerization of Acetylene Catalyzed by Wilkinson's Catalyst, $\mathrm{RhCl}\left(\mathrm{PPh}_{3}\right)_{3}$. Organometallics 2010, 29, 562-569. (g) Orian, L.; Van Stralen, J. N. P.; Bickelhaupt, F. M. Cyclotrimerization Reactions Catalyzed by Rhodium(I) Half-Sandwich Complexes: A Mechanistic Density Functional Study. Organometallics 2007, 26, 3816-3830. (h) Rüba, E.; Schmid, R.; Kirchner, K.; Calhorda, M. J. Ruthenium-Mediated Cyclotrimerization of Alkynes Utilizing the Cationic Complex $\left[\mathrm{RuCp}\left(\mathrm{CH}_{3} \mathrm{CN}\right)_{3}\right] \mathrm{PF}_{6}$. J. Organomet. Chem. 2003, 682, 204-211. (i) Becker, E.; Mereiter, K.; Puchberger, M.; Schmid, R.; Kirchner, K.; Doppiu, A.; Salzer, A. Novel [2+2+1] Cyclotrimerization of Alkynes Mediated by Bidentate Cyclopentadienyl-Phosphine Ruthenium Complexes. Organometallics 2003, 22, 3164-3170. (j) Ma, W.; Yu, C.; Chen, T.; Xu, L.; Zhang, W.-X.; Xi, Z. Metallacyclopentadienes: Synthesis, Structure and Reactivity. Chem. Soc. Rev. 2017, 46, 1160-1192. (k) Fang, B.; Hou, G.; Zi, G.; Fang, D.-C.; Walter, M. D. A Thorium Metallacyclopentadiene Complex: a Combined Experimental and Computational Study. Dalton Trans. 2015, 44, 7927-7934. (1) Fang, B.; Hou, G.; Zi, G.; Ding, W.; Walter, M. D. Steric and Electronic Influences of Internal Alkynes on the Formation of Thorium Metallacycles: A Combined Experimental and Computational Study. Organometallics 2016, 35, 1384-1391. (m) Baldridge, K. K.; Siegel, J. S.; O’Connor, J. M. Structure and Dynamics in Unsymmetrically Substituted FiveCoordinate Iridacyclopentadiene Complexes. J. Phys. Org. Chem. 2015, 28, 199-202.

(62) For studies on the general mechanisms proposed for the insertion of the third alkyne involving mononuclear metallacyclopentadiene intermediates, see refs $60 \mathrm{c}-\mathrm{e}$ and $61 \mathrm{a}-\mathrm{i}$ and (a) Calderazzo, F.; Pampaloni, G.; Pallavicini, P.; Strähle, J.; Wurst, K. Reactions of Zirconium $\left(\eta^{6}\right.$-benzene $)\left(\mathrm{AlCl}_{4}\right)_{2}$ with Alkynes: Cyclooligomerization Reactions and Crystal and Molecular Structure of the SevenMembered Metallacycle $\left[\mathrm{ZrCPh}(\mathrm{CPh})_{4} \mathrm{CPh}\right]\left[(\mu-\mathrm{Cl})_{2} \mathrm{AlCl}_{2}\right]_{2}$. Organometallics 1991, 10, 896-901. (b) Takahashi, T.; Xi, Z.; Yamazaki, A.; Liu, Y.; Nakajima, K.; Kotora, M. Cycloaddition Reaction of Zirconacyclopentadienes to Alkynes: Highly Selective Formation of Benzene Derivatives from Three Different Alkynes. J. Am. Chem. Soc. 1998, 120, 1672-1680. (c) Álvarez, E.; Gómez, M.; Paneque, M.; Posadas, C. M.; Poveda, M. L.; Rendón, N.; Santos, L. L.; Rojas-Lima, S.; Salazar, V.; Mereiter, K.; Ruiz, C. Coupling of Internal Alkynes in $\mathrm{TpMe}_{2} \mathrm{Ir}$ Derivatives: Selective Oxidation of a Noncoordinated Double Bond of the Resulting Iridacycloheptatrienes. J. Am. Chem. Soc. 2003, 125, 1478-1479. (d) Paneque, M.; Poveda, M. L.; Rendón, N.; Mereiter, K. Isolation of a Stable 1-Iridabicyclo [3.2.0] Hepta1,3,6-triene and Its Reversible Transformation into an Iridacycloheptatriene. J. Am. Chem. Soc. 2004, 126, 1610-1611. (e) Hill, J. E.; Balaich, G.; Fanwick, P. E.; Rothwell, I. P. The Chemistry of Titanacyclopentadiene Rings Supported by 2,6-Diphenylphenoxide Ligation: Stoichiometric and Catalytic Reactivity. Organometallics 1993, 12, 2911-2924. (f) Collman, J. P.; Kang, J. W.; Little, W. F.; Sullivan, M. F. Metallocyclopentadiene Complexes of Iridium and Rhodium and Their Role in the Catalytic Cyclotrimerization of Disubstituted Acetylenes. Inorg. Chem. 1968, 7, 1298-1303. (g) Yamamoto, K.; Nagae, H.; Tsurugi, H.; Mashima, K. Mechanistic Understanding of Alkyne Cyclotrimerization on Mononuclear and Dinuclear Scaffolds: [4 + 2] Cycloaddition of the Third Alkyne Onto 
Metallacyclopentadienes and Dimetallacyclopentadienes. Dalton Trans. 2016, 45, 17072-17081.

(63) Schore, N. E. Transition Metal-Mediated Cycloaddition Reactions of Alkynes in Organic Synthesis. Chem. Rev. 1988, 88, 1081-1119.

(64) For examples of ${ }^{\mathrm{Ph}} \mathrm{L} 3$-substituted complexes in which the cental oxygen atom binds to the metal center, see ref $8 \mathrm{~d}$ and (a) Stevens, T. E.; Smoll, K. A.; Goldberg, K. I. Direct Formation of Carbon $\left(\mathrm{sp}^{3}\right)-$ Heteroatom Bonds from $\mathrm{Rh}(\mathrm{III})$ to Produce Methyl Iodide, Thioethers, and Alkylamines. J. Am. Chem. Soc. 2017, 139, 77257728. (b) Hooper, J. F.; Chaplin, A. B.; González-Rodríguez, C.; Thompson, A. L.; Weller, A. S.; Willis, M. C. Aryl Methyl Sulfides as Substrates for Rhodium-Catalyzed Alkyne Carbothiolation: Arene Functionalization with Activating Group Recycling. J. Am. Chem. Soc. 2012, 134, 2906-2909. (c) Dallanegra, R.; Chaplin, A. B.; Weller, A. S. Rhodium Cyclopentyl Phosphine Complexes of Wide-Bite-Angle Ligands DPEphos and Xantphos. Organometallics 2012, 31, 27202728. (d) Kuang, S. M.; Fanwick, P. E.; Walton, R. A. Unsymmetrical Dirhenium Complexes that Contain $\left[\mathrm{Re}_{2}\right]^{6+}$ and $\left[\mathrm{Re}_{2}\right]^{5+}$ Cores Complexed by Tridentate Ligands with $\mathrm{P}_{2} \mathrm{O}$ and $\mathrm{P}_{2} \mathrm{~N}$ Donor Sets. Inorg. Chem. 2002, 41, 405-412. (e) Van Leeuwen, P. W. N. M.; Zuideveld, M. A.; Swennenhuis, B. H. G.; Freixa, Z.; Kamer, P. C. J.; Goubitz, K.; Fraanje, J.; Lutz, M.; Spek, A. L. Alcoholysis of Acylpalladium(II) Complexes Relevant to the Alternating Copolymerization of Ethene and Carbon Monoxide and the Alkoxycarbonylation of Alkenes: The Importance of Cis-Coordinating Phosphines. J. Am. Chem. Soc. 2003, 125, 5523-5539.

(65) Purification of Laboratory Chemicals; Armarego, W. L. F., Chai, C. L. L., Eds.; Elsevier Science: Oxford, UK, 2003.

(66) Fulmer, G. R.; Miller, A. J. M.; Sherden, N. H.; Gottlieb, H. E.; Nudelman, A.; Stoltz, B. M.; Bercaw, J. E.; Goldberg, K. I. NMR Chemical Shifts of Trace Impurities: Common Laboratory Solvents, Organics, and Gases in Deuterated Solvents Relevant to the Organometallic Chemist. Organometallics 2010, 29, 2176-2179.

(67) All calculations were performed with Frish, M. J.; Trucks, G. W.; Schlegel, H. B.; Scuseria, G. E.; Robb, M. A.; Cheeseman, J. R.; Scalmani, G.; Barone, V.; Mennucci, B.; Petersson, G. A.; Nakatsuji, H.; Caricato, M.; Li, X.; Hratchian, H. P.; Izmaylov, A. F.; Bloino, J.; Zheng, G.; Sonnenberg, J. L.; Hada, M.; Ehara, M.; Toyota, K.; Fukuda, R.; Hasegawa, J.; Ishida, M.; Nakajima, T.; Honda, Y.; Kitao, O.; Nakai, H.; Vreven, T.; Montgomery, J. A.; Peralta, J. E.; Ogliaro, F.; Bearpark, M.; Heyd, J. J.; Brothers, E.; Kudin, K. N.; Staroverov, V. N.; Kobayashi, R.; Normand, J.; Raghavachari, K.; Rendell, A.; Burant, J. C.; Iyengar, S. S.; Tomasi, J.; Cossi, M.; Rega, N.; Millam, J. M.; Klene, M.; Knox, J. E.; Cross, J. B.; Bakken, V.; Amado, C.; Jaramillo, J.; Gomperts, R.; Stratmann, R. E.; Yazyev, O.; Austin, A. J.; Cammi, R.; Pomelli, C.; Ochterski, J. W.; Martin, R. L.; Morokuma, K.; Zakrzewski, V. G.; Voth, G. A.; Salvador, P.; Dannenberg, J. J.; Dapprich, S.; Daniels, A. D.; Farkas, Ö.; Foresman, J. B.; Ortiz, V.; Cioslowski, J.; Fox, D. J. Gaussian 09, revision D.01; Gaussian, Inc.: Wallingford, CT, 2013.

(68) All NBO analyses are performed with Glendening, E. D.; Badenhoop, J. K.; Reed, A. E.; Carpenter, J. E.; Bohmann, J. A.; Morales, C. M.; Landis, C. R.; Weinhold, F. NBO 6.0; Theoretical Chemistry Institute, University of Wisconsin: Madison, WI, 2013.

(69) Sperger, T.; Sanhueza, I. A.; Kalvet, I.; Schoenebeck, F. Computational Studies of Synthetically Relevant Homogeneous Organometallic Catalysis Involving $\mathrm{Ni}$, Pd, Ir, and $\mathrm{Rh}$ : An Overview of Commonly Employed DFT Methods and Mechanistic Insights. Chem. Rev. 2015, 115, 9532-9586. 